MARITZA CHIRINOS MARROQUÍN

\title{
ADEQUAÇÃO ÀS CONDIÇÕES BRASILEIRAS DE MODELO DE CARACTERIZAÇÃO PARA A CATEGORIA DE IMPACTO USO DO SOLO
}


MARITZA CHIRINOS MARROQUÍN

\title{
ADEQUAÇÃO ÀS CONDIÇÕES BRASILEIRAS DE MODELO DE CARACTERIZAÇÃO PARA A CATEGORIA DE IMPACTO USO DO SOLO
}

\author{
Dissertação apresentada à Escola \\ Politécnica da Universidade de São \\ Paulo para a obtenção do Título de \\ Mestre em Engenharia
}

Áreas de Concentração:

Engenharia Química

Orientador: Prof. Dr. Gil Anderi da Silva.

São Paulo 


\section{Chirinos Marroquín, Maritza}

Adequação às condições brasileiras de modelo de caracterização para a categoria de impacto do uso do solo / M. Chirinos Marroquín. -- São Paulo, 2013.

$147 \mathrm{p}$.

Dissertação (Mestrado) - Escola Politécnica da Universidade de São Paulo. Departamento de Engenharia Química.

1. Uso do solo - Brasil 2. Impactos ambientais - Brasil I. Universidade de São Paulo. Escola Politécnica. Departamento de Engenharia Química II. t. 



\section{DEDICATÓRIA}

Dedico este trabalho a meus amados pais, meus irmãos e a meus pequenos sobrinhos pelas suas existencias. 


\section{AGRADECIMENTOS}

Agradeço a Deus pela oportunidade na realização deste trabalho.

Agradeço aos meus queridos pais (Roberto e Maria) e a meus Irmãos (Edwin, Jenny, Roxana e Richard), pessoas que representam o berço da minha vida. Obrigada pelo seu amor doado, proporcionando assim os recursos indispensáveis para a realização do trabalho.

Ao meu orientador Prof. Dr. Gil Anderi da Silva pela confiança, incentivo e atenção manifestadas no transcorrer da preparação do trabalho.

Ao Conselho Nacional de Desenvolvimento Científico e Tecnológico (CNPQ) pelo apoio financeiro.

Ao meu amigo Prof. Dr. Luiz Kulay e a sua esposa Gisele pelo apoio, confiança e palavras de incentivo nos momentos nos quais mais precisei.

Aos amigos do Grupo de Prevenção da Poluição (GP2): Alex e a sua família, Eduardo, Laurinha, Laércio, Letícia, Luis, Maíra, Nayara, Rafael, Regina, Ricardo e Vivian pela amizade e companheirismo.

Agradeço à Professora Patrícia Matai e à Professora Rita pela confiança no meu trabalho, obrigada por tudo.

Aos meus amigos do grupo Melgarcito e Trupicada Carlos Herrera, Dany Andrade, Dennis Roldan, Erick Portugal, Erick Renato, Gerby Rondan, Jelis Arenas, Ligia Cateriano, Luciane; à família Alves dos Santos, Mozart Camargo, Ivan Ferreira; à família Cavalgante pela grande amizade, pelos momentos de alegria e tristezas que temos passado e por tudo o que tenho aprendido de cada um deles.

Aos meus amigos Erika Guetti, Veronica Carranza, Victoria, Zaira, Marvin Chambi, Rosa Chambi, Jesus Falcón e Victor Perez pelo seu carinho e reuniões onde foram compartilhados momentos agradáveis.

Ao meu bom amigo Milward Soto.

Aos muitos amigos e familiares que, de uma forma ou outra, apoiaram-me durante todo o desenrolar deste trabalho.

A meus amigos funcionários do departamento: Alexandre, Elisete, Graça e Fátima da EPUSP, pelo auxilio prestado desde meu ingresso na Pós - graduação. 
"Primeiro, foi preciso civilizar ao homem na sua relação com o homem. Agora, é necessário civilizar ao homem na sua relação com a natureza e os animais" (Victor Hugo). 



\section{RESUMO}

O uso intensivo de áreas do solo provoca alterações na sua qualidade, tornando-se necessária a criação de métodos de avaliação e monitoramento. A técnica de Avaliação do Ciclo de Vida (ACV) é uma importante ferramenta para o cálculo de impactos ambientais, relativos a um sistema de produto com fronteiras delimitadas, sendo o Uso do Solo uma das categorias de impacto avaliada. Na ACV este impacto é avaliado, a partir de fatores de caracterização, os quais utilizam indicadores que quantificam as consequências de modificações na estrutura do solo, levando em consideração a realidade e as características morfológicas de cada país ou região. Este estudo tem como objetivo apresentar adequações relacionadas às condições brasileiras do modelo para a caracterização de impactos provocados pelo uso do solo, a partir da adaptação de fatores de caracterização. De acordo com a pesquisa bibliográfica acerca dos métodos de avaliação do uso do solo na ACV, dois grupos são avaliados a Biodiversidade e as Funções de Suporte de Vida (FSV). Neste estudo foram identificados diferentes métodos que avaliam os impactos nas FSV e a partir de alguns critérios adotados foram posteriormente submetidos a uma análise, a fim de se determinar o método de maior relevância para as condições brasileiras. O método escolhido utiliza como indicador a Matéria Orgânica do Solo (MOS), porém devido à ausência de dados em algumas regiões, podem ser utilizados valores de Carbono Orgânico do Solo (COS), componente essencial da MOS. Os valores para o COS no estado natural foram atribuídos segundo dados de literatura para o bioma Amazônia, os quais foram posteriormente adaptados para se obter o COS para os tipos de uso de solo considerados neste estudo, segundo a realidade brasileira.

Palavras chaves: Avaliação do Ciclo de Vida (ACV), Avaliação do Impacto do Ciclo de Vida (AICV), Impacto do Uso do Solo, Biodiversidade, Funções de Suporte de Vida (FSV), Fatores de Caracterização. 


\begin{abstract}
The intensive use of land areas cause changes in its quality, making it necessary to create methods for assessing and monitoring. The technique of Life Cycle Assessment (LCA) is an important tool for the calculation of environmental impacts related to a product system with defined borders, and the Land Use category of impact assessed. In this LCA impacts are assessed from factors characterization using indicators that quantify the effects of changes in soil structure, taking into account the reality and the morphological characteristics of each country or region. This study aims to present adjustments related to the Brazilian model for characterizing impacts caused by land use, based on the calculation of characterization factors. In accordance with the literature of the LCA methods, two groups contribute to this category Biodiversity and Life Support Functions (FSV). In this study were discussed and evaluated different methods to calculate (FSV), from some criteria adopted, these were subjected to a comparative analysis, to the method of greatest relevance to Brazilian conditions. The method chosen to use as an indicator of Soil Organic Matter (SOM), but due to lack of data in some regions, can be used values of Soil Organic Carbon (COS) essential component of SOM. The values for COS in the natural state were assigned according to the literature data of the Amazon biome, which were adapted to obtain the COS for the types of land use considered in this study according to the Brazilian reality.
\end{abstract}

Keywords: Life Cycle Assessment (LCA) Impact Assessment Life Cycle (LCIA), Impact of Land Use, Biodiversity, Life Support Functions (LSF), Characterization Factors. 


\section{GLOSSÁRIO}

Área de Proteção: Classe de pontos finais de categorias (GOEDKOOP; SPRIENSMA, 2001).

Aspecto ambiental: É o elemento das atividades, produtos ou serviços de uma organização que pode interagir com o meio ambiente (ABNT, 2009a).

Ciclo de Vida: Estágios sucessivos e encadeados de um sistema de produto, desde a aquisição da matéria-prima ou geração de recursos naturais à disposição final (ABNT, 2009a).

Fatores de caracterização: São fatores derivados de um modelo de caracterização que é aplicado para converter o resultado da análise do inventario do ciclo de Vida na unidade comum do indicador (ABNT, 2009b).

Fluxo elementar: É o material ou energia retirado do meio ambiente que entra no sistema em estudo sem sofrer transformação prévia por interferência humana, ou material ou energia que é liberado no meio ambiente pelo sistema em estudo sem sofrer alterações subsequentes por interferência humana (ABNT, 2009b).

Impactos ambientais: Qualquer modificação adversa ou benéfica no meio ambiente (ABNT, 2004).

Indicadores de categoria: É uma representação quantificável de uma categoria de impacto (ABNT, 2009a).

Processo elementar: É o menor elemento considerado na análise do inventário do ciclo de vida para o qual os dados de entrada e saída são quantificados (ABNT, 2009a).

Sistema de produto: É o conjunto de processos elementares, fluxos elementares e de produtos desempenhando uma ou mais funções definidas e que modela o ciclo de vida do produto (ABNT, 2009a). 


\section{LISTA DE FIGURAS}

FIGURA 2. 1 - ESTÁGIOS DO CICLO DE VIDA DE UM PRODUTO (SILVA; KULAY, 2006).7

FIGURA 2. 2 - FASES DA ACV (ABNT, 2009A)...

FIGURA 2. 3 - ELEMENTOS DA AVALIAÇÃO DO IMPACTO DO CICLO DE VIDA (ABNT, 2009B).

FIGURA 2. 4 - ESTRUTURA DAS CATEGORIAS DE IMPACTO PARA CARACTERIZAÇÃO DE MODELOS NOS NÍVEIS INTERMEDIÁRIOS E FINAIS (ADAPTADO GOEDKOOP; SPRIENSMA, 2001) 18

FIGURA 2. 5 - OS PASSOS DA CARACTERIZAÇÃO (COLIN, 2010) ............................... 20 FIGURA 2. 6 OS IMPACTOS DO USO DO SOLO (ADAPTADO LINDEIJER, 2002B).........25 FIGURA 2. 7 - MECANISMO AMBIENTAL GENERAL DA CATEGORIA DE IMPACTO DE

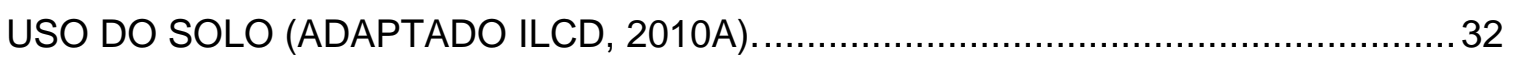

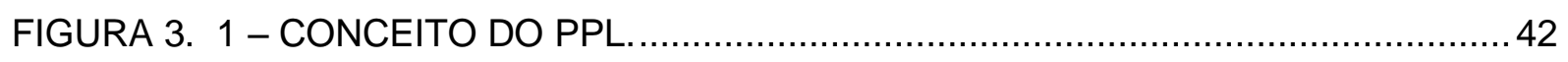
FIGURA 3. 2 - PASSOS PARA O CÁLCULO NA RESISTÊNCIA NA EROSÃO …............... 46 FIGURA 3. 3 - PASSOS PARA O CÁLCULO PARA A FILTRAÇÃO MECÂNICA …............ 47 FIGURA 3. 4 - PASSOS PARA O CÁLCULO PARA A FILTRAÇÃO FÍSICO-QUÍMICA . .... 48 FIGURA 3. 5 - PASSOS PARA O CÁLCULO PARA A PRODUÇÃO DA BIOTA.................48 FIGURA 3. 6 - PASSOS PARA O CÁLCULO PARA REPOSIÇÃO DE ÁGUAS

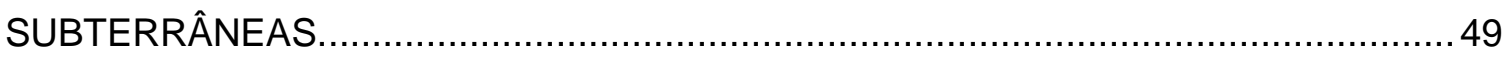

FIGURA 3. 7 - CICLO DO CARBONO (ADAPTADO MILÀ I CANALS, 2003) ......................52

FIGURA 3. 8 - ESTRUTURA GERAL DO MODELO ……….........................................

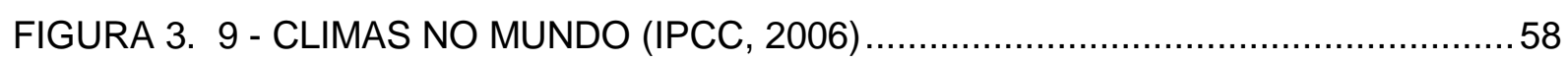

FIGURA 4. 1 - LOCALIZAÇÃO DOS BIOMAS BRASILEIROS (IBGE, 2012) …....................67 FIGURA 4. 2 - MECANISMO AMBIENTAL DA MOS NAS FSV (ADAPTADO MILÀ I CANALS, 2003). 


\section{LISTA DE TABELAS}

TABELA 2. 1 - FUNÇÕES ECOLÓGICAS E SOCIOECONÔMICAS DO SOLO (MILÀ I

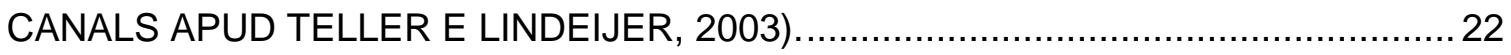
TABELA 3. 1 - A PPL PARA O CASO DA TRANSFORMAÇÃO (T. HA ${ }^{-1}$.ANO $\left.{ }^{-1}\right)$ (LINDEIJER, 2000A). 44

TABELA 3. 2 - A PPL PARA O CASO DA OCUPAÇÃO (T. HA ${ }^{-1}$.ANO $\left.{ }^{-1}\right)$ (LINDEIJER, 2000A).

TABELA 3. 3 - ESCOLHA DOS FATORES DE CARACTERIZAÇÃO (LANCA, 2008). 50

TABELA 3. 4 - SOFTWARES QUE MODELAM O COMPORTAMENTO DA MOS (MILA I

CANALS, 2003) 54

TABELA 3. 5 - CRITÉRIOS PARA ANÁLISE DOS MÉTODOS. 55

TABELA 3. 6 - TIPOS DE BIOMAS NO BRASIL (MMA,2010) 57

TABELA 3. 7 - TIPOS DE SOLOS NO BRASIL (EMBRAPA, 2009) ... 57

TABELA 4. 1 - COMPARAÇÃO DOS MÉTODOS QUE AVALIAM O USO DO SOLO NAS FSV

TABELA 4. 2 - BIOMAS NO BRASIL SEGUNDO A ÁREA OCUPADA (IBGE; MMA, 2012) 66 TABELA 4. 3 - EXTENSÃO E DISTRIBUIÇÃO DOS TIPOS DE SOLOS NAS REGIÕES DO BRASIL (IBGE; EMBRAPA, 2012) 68

TABELA 4. 4 CLASSES DE COBERTURA DE SOLO NO BRASIL (IBGE, 2006)........ 69

TABELA 4. 5 - CARBONO ORGÂNICO DO SOLO (COS) NO ESTADO NATURAL PARA O

BIOMA DA AMAZÔNIA (LANGE, 2012) .... 69

TABELA 4. 6 - TEMPOS DE REGENERAÇÃO PARA O CASO DO BRASIL EM ANOS (ADAPTADO DE SOUZA, 2011)... 70

TABELA 4. 7 - TEMPOS DE REGENERAÇÃO MÉTODO DE KÖLLNER EM ANOS (ADAPTADO DE KÖLLNER, 1999).

TABELA 4. 8 - TEMPOS DE REGENERAÇÃO PARA O CASO DO BRASIL EM ANOS (ADAPTADO DE SOUZA, 2011; KÖLLNER

TABELA A. 1 - TIPOS DE USO DO SOLO NO BRASIL (IBGE, 2006) .............................. 87

TABELA B. 1 - TIPOS DE SOLO NO BRASIL (EMBRAPA, 2009) …................................ 90

TABELA C. 1 - FATORES PARA LAVOURAS (EC, 2010) ............................................. 92

TABELA C. 2 - FATORES PARA SAFRAS PERENES, OU SEJA, CULTURAS PLURIANUAIS CUJO CAULE NÃO É GERALMENTE COLHIDO ANUALMENTE TAL COMO A TALHADA DE ROTAÇÃO CURTA E CULTIVO DE ÓLEO DE PALMA (EC, 2010) 
TABELA C. 3 - FATORES NA PRADARIA E NAS SAVANAS (EC, 2010) 97

TABELA C. 4 - FATORES PARA FLORESTAS TENDO MENOS DE 10\% DE COBERTURA DOSSEL (EC, 2010). 98

TABELA D. 1 - CARBONO ORGÂNICO DO SOLO ANTES DA TRANSFORMAÇÃO COS ${ }_{1}$

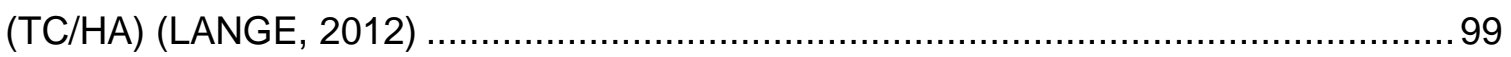

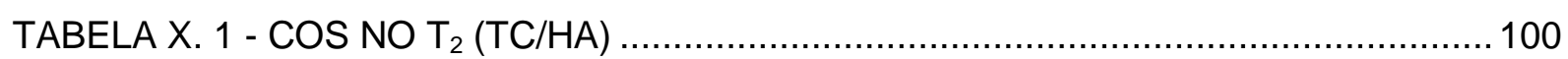

TABELA Y. 1 - FATORES DE CARACTERIZAÇÃO PARA A TRANSFORMAÇÃO (TCHA

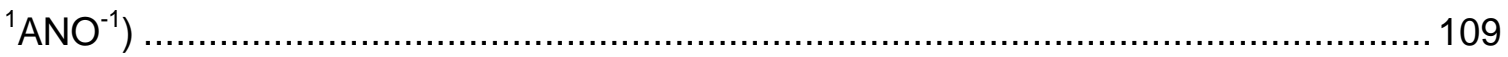

TABELA W. 1 - FATORES DE CARACTERIZAÇÃO PARA A OCUPAÇÃO (TC HA ${ }^{-1}$ ANO- ${ }^{1}$ ANO) 


\section{LISTA DE ABREVIATURAS E SIGLAS}
ABNT Associacao Brasileira de Normas Técnicas
ACV Avaliação do Ciclo de vida
AICV Avaliação dos Impactos Ambientais do Ciclo de Vida
CETEA Centro de Tecnologia de Embalagem
cos Carbono Orgânico do solo
EMBRAPA Empresa Brasileira de Pesquisa Agropecuária
FAO Food and Agriculture Organization of the United Nations
FSV Funções de Suporte de Vida
IBGE Instituição Brasileira de Geografia e Estatística
ICV Inventario do Ciclo de Vida
ILCD International Reference Life Cycle Data System
IPCC Intergovernmental Panel on Climate Change
ISO International Organization for Standardization
LCI Life Cycle Assessment
MMA Ministério do Meio Ambiente do Brasil
MOS Matéria Orgânica do Solo
MRI Midwest Research Institute
PDF Fração de Espécies Potencialmente Desaparecidas
PPB Produção Primaria Bruta
PPL Produção Primaria Liquida
REPA Resource and Environmental Profile Analysis
SETAC Society of Environmental Toxicology and Chemistry
SIG Sistema de Informação Geográfica
UNEP United Nations Environment Programme 


\section{SUMÁRIO}

RESUMO.

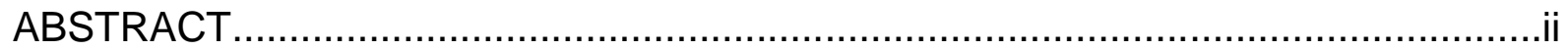

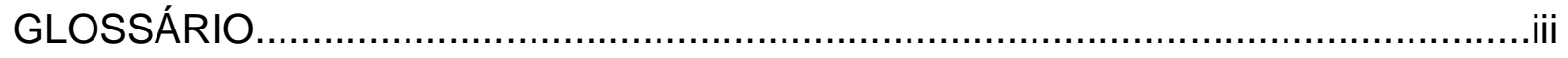

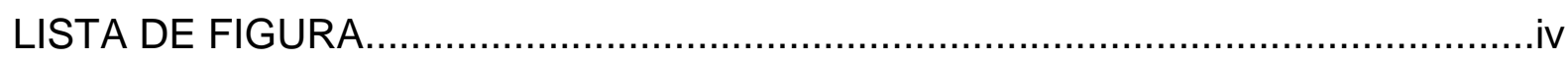

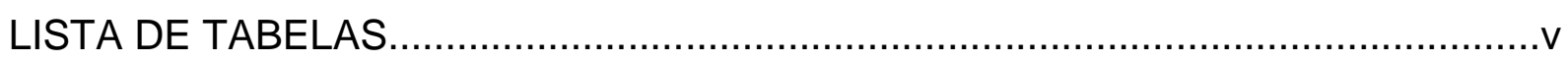

LISTA DE ABREVIATURAS E SIGLAS................................................................ii

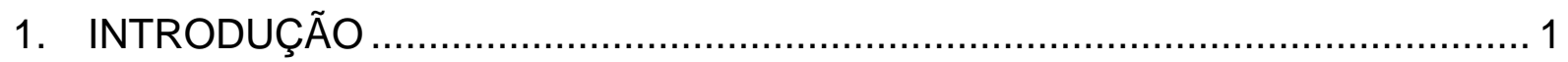

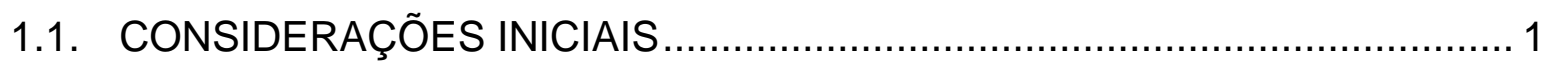

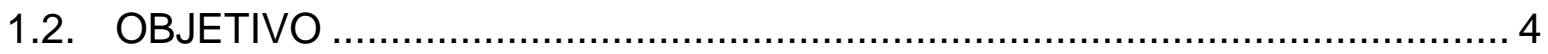

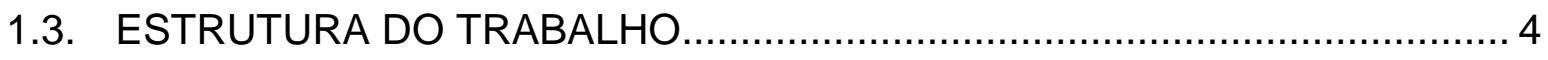

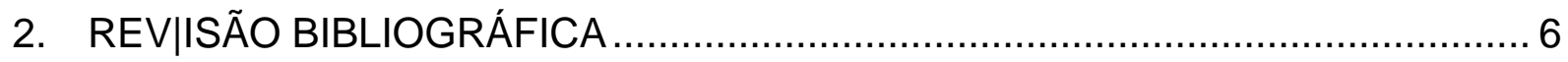

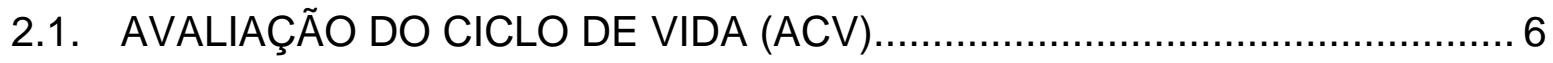

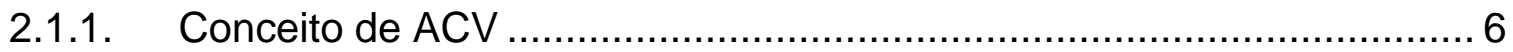

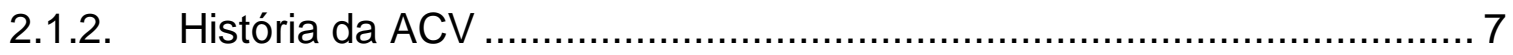

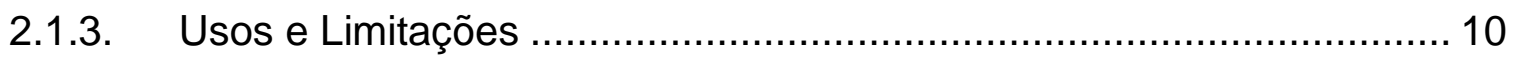

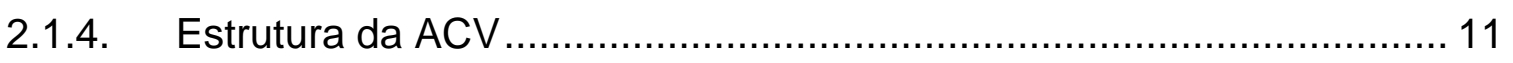

2.2. AVALIAÇÃO DOS IMPACTOS DO CICLO DE VIDA (AICV) ...................... 14

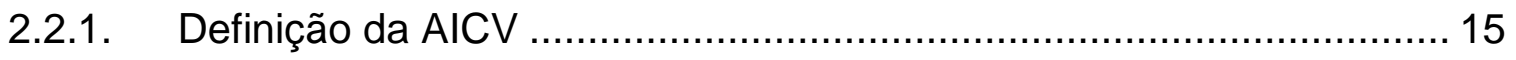

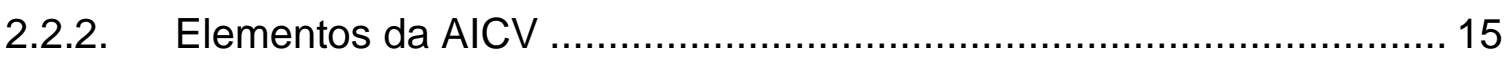

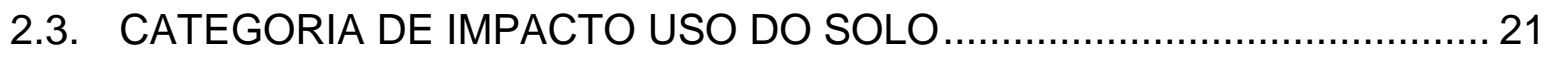

2.3.1. Definição do Impacto do Uso do Solo............................................... 21

2.3.2. Impactos de Transformação e Ocupação do Solo ............................... 23

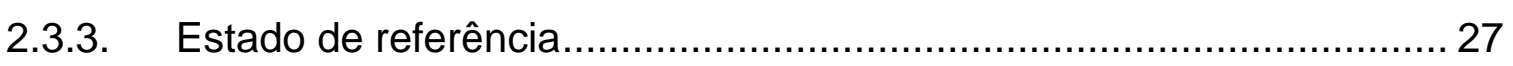

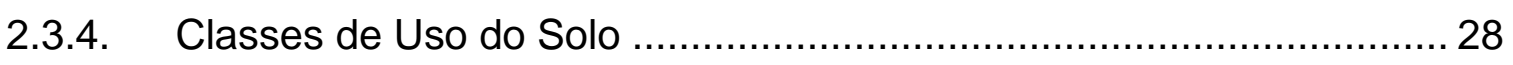

2.3.5. Tempo de Recuperação do Solo .................................................... 30

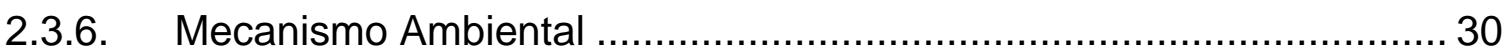

2.3.7. As Áreas Afetadas pelo Uso do Solo .................................................. 33

2.3.8. Métodos de avaliação de Impacto do Uso do Solo ................................. 36 
3. METODOLOGIA .40

3.1. SELEÇÃO DAS REFERÊNCIAS .40

3.2. ESTUDO DOS MÉTODOS. 41

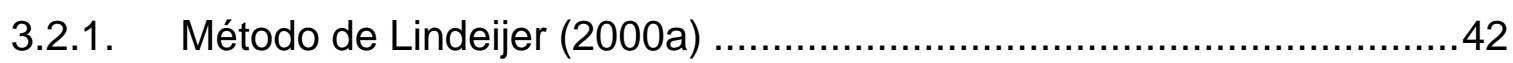

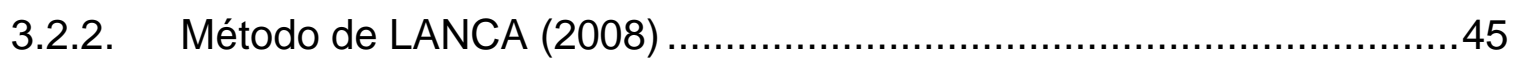

3.2.3. Método de Brandão e Milà i Canals (2012) .........................................51

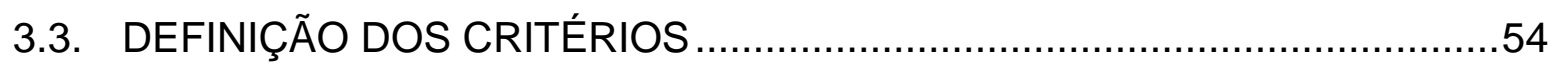

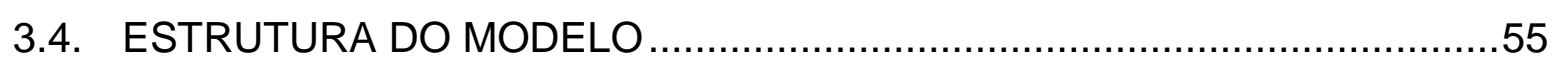

3.4.1. Desenvolvimento das premissas do modelo .....................................56

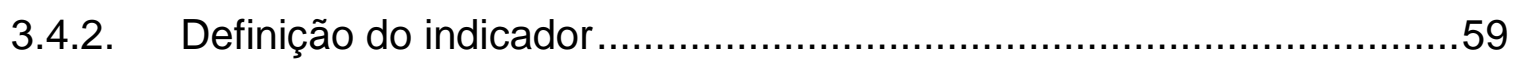

3.4.3. Cálculo dos fatores de caracterização para as condições Brasileiras.. 59

4. RESULTADOS E DISCUSSÃO .60

4.1. COMPARAÇÃO E ANÁLISE DOS MÉTODOS .......................................60

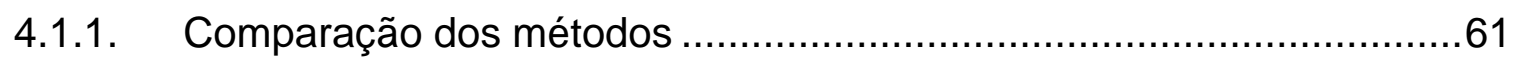

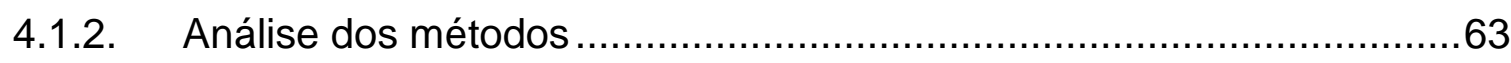

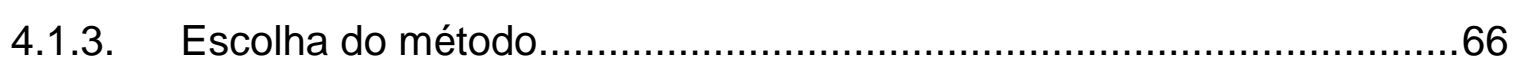

4.2. DESENVOLVIMENTO DAS PREMISSAS DO MODELO ...........................66

4.2.1. Definição da escala espacial ..........................................................66

4.2.2. Tipos de Uso de Solos para o Brasil ................................................68

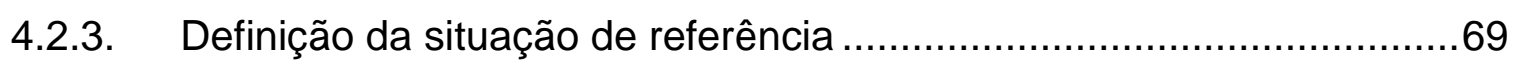

4.2.4. Definição do tempo de recuperação..................................................70

4.3. DEFINIÇÃO DO INDICADOR UTILIZADO …........................................72

4.3.1. Definição do mecanismo ambiental do COS .....................................72

4.3.2. Cálculo dos valores do COS .............................................................74

4.4. CÁlCULO DOS FATORES DE CARACTERIZAÇÃO PARA AS CONDIÇÕES BRASILEIRAS ......................................................................75

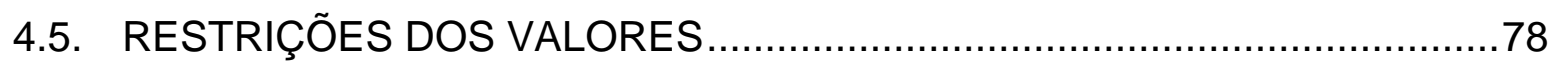

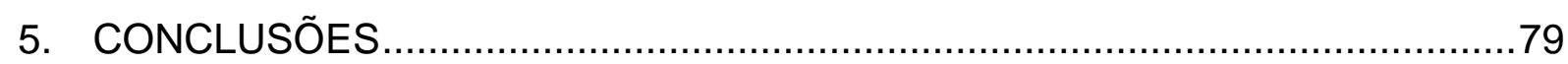

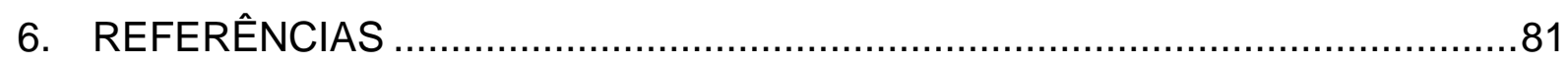

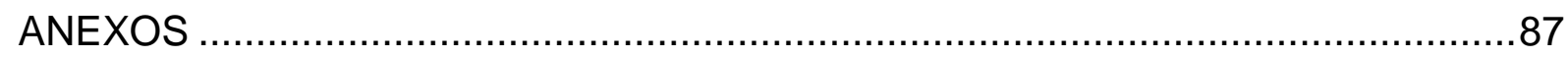


ANEXO A - Tipos de uso do solo no Brasil ................................................ 87

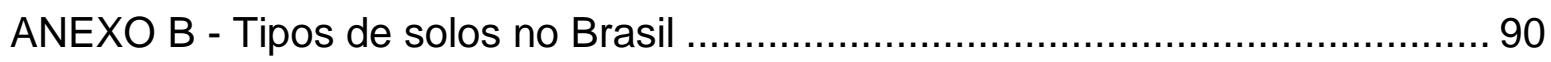

ANEXO C - Fatores de Ajuste para o COS segundo Clima, Uso e Gestão do Solo. 92

ANEXO D: Carbono orgânico do solo antes da transformação solo $\left(\mathrm{COS}_{1}\right) \ldots . . . . .99$

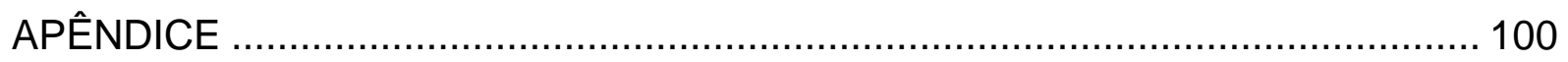

APÊNDICE X - Carbono Orgânico do Solo após a transformação $\left(\mathrm{COS}_{2}\right)$......... 100

APÊNDICE Y - Fator de caracterização para a transformação do solo............... 109

APÊNDICE W - Fator de caracterização para a ocupação do solo .................... 121 


\section{INTRODUÇÃO}

\subsection{CONSIDERAÇÕES INICIAIS}

Com o avanço tecnológico e a crescente industrialização vem ocorrendo aumento no descarte de rejeitos e efluentes no meio ambiente, causando desta forma alterações e possível impacto ambiental no mesmo. Além disso, considera-se a natureza como fornecedora de recursos e energia, entretanto esta também atua como depósito de descarte de produtos e rejeitos - de produtores e consumidores. A velocidade com que isso vem acontecendo é mais rápida do que a assimilação e a recuperação da natureza, causando desta forma danos ao Planeta (CHEHEBE, 1997).

Debates sobre o meio ambiente vêm alcançando grande público, o que incentivou os governos a criarem leis mais restritivas, mediante regulamentos públicos e legislações, responsabilizando assim aos fabricantes pelo gerenciamento dos seus resíduos.

Dessa forma, as empresas estão buscando melhorias nos seus processos, a fim de cumprir com sua responsabilidade social, que, entre outras coisas, implica na preservação do meio ambiente, evitando qualquer tipo de contaminação (BORGER, 2006).

No intuito de solucionar estes problemas, as empresas buscam técnicas de gestão ambiental capazes de avaliar os impactos dos seus processos. Entre essas técnicas podemos citar: Auditorias ambientais, Avaliação de Impactos Ambientais, Produção mais Limpa e Avaliação do Ciclo de vida (ACV), todas elas se prestando ao estudo do comportamento ambiental do produto ou serviço (SILVA; KULAY, 2006).

A International Organization for Standardization (ISO) dedicou uma serie de normas - família 14040 - que tratam sobre a ACV. Estas normas, entre outros assuntos, abordam as etapas operativas da ACV. Uma das etapas é a Avaliação dos Impactos Ambientais do Ciclo de Vida (AICV), na qual aspectos ambientais são avaliados de acordo com a sua capacidade de gerar impactos ao meio ambiente. No caso, por exemplo, de emissões atmosféricas, uma vez liberadas estas poderiam agir diretamente no meio ambiente ou sofrer transformações podendo causar 
estragos à saúde humana, à disponibilidade de recursos naturais ou à qualidade do ecossistema (SETAC, 2002).

A não inclusão de alguns impactos ambientais na ACV pode tornar questionáveis os resultados. Por esta razão, The Society of Environmental Toxicology and Chemistry (SETAC) e a United Nations Environment Programme (UNEP), uniram-se a fim de diminuir este problema criando o programa The Life Cycle Initiative que trabalha na expansão da capacidade mundial para aplicar e melhorar as abordagens do ciclo de vida ( $\mathrm{LCl}, 2011)$.

Este programa conta com várias áreas de trabalho, dentre elas uma com o objetivo de padronizar métodos de avaliação de impactos ambientais (toxicidade, biodiversidade, uso do solo, recursos naturais, entre outros). A falta de uma base de dados em certos países faz com que os impactos locais sejam dificilmente avaliados, este é o caso do Impacto Uso do Solo, que, apesar de sua importância, não é muito trabalhada na realização da AICV, em consequência das limitações na obtenção de dados sobre as características biogeográficas, clima e vegetação da região.

O solo é utilizado em diferentes atividades humanas que inicialmente tinham baixa interferência na biodiversidade e nas paisagens, não apresentando desta forma grandes modificações nas suas propriedades. Entretanto, isso mudou em consequência da alta intensidade com que se desenvolvem estas atividades. Tais modificações têm reflexo na perda da biodiversidade e em alterações na qualidade do solo nas Funções de Suporte de Vida (FSV) causando assim o impacto do uso do solo (MILÀ I CANALS; ROMANYA; COWELL, 2007).

Os primeiros estudos que consideraram o impacto do uso do solo levavam nos seus cálculos apenas a questão da área ocupada (SETAC, 2002). Trabalhos recentes (GOEDKOOP; SPRIENSMA, 2001; LINDEIJER, 2000b; MICHELSEN, 1998; MILA I CANALS, 2003; SCHMIDT, 2008; VOGTLÄNDER, 2004) ressaltam a importância da definição de indicadores adicionalmente as alterações nas propriedades do solo causadas pelo tipo de ocupação e transformação que este sofre, assim como o tempo no qual acontecem estas atividades.

Portanto, necessita-se a adoção de indicadores que possam converter os aspectos ambientais a uma mesma base, sendo que, isso é feito mediante uso de fatores de caracterização. O estabelecimento dos mesmos, sempre que possível, deve ocorrer com base em modelos científicos que demonstrem os mecanismos de 
como cada aspecto ambiental contribui para o impacto. Nos modelos, para cada categoria de impacto é definida uma substância padrão em relação a qual são convertidas as quantidades equivalentes dos outros aspectos ambientais, contribuintes para o mesmo impacto (SILVA; KULAY, 2006).

No Impacto de Uso do Solo a correlação é difícil de estabelecer, pela quantidade de propriedades que o solo possui, provocando divergência de opiniões na comunidade científica (SETAC, 2002). No entanto, chegou-se ao consenso de que este impacto deveria ser dividido, para efeito de modelagem, em duas partes: 0 impacto de transformação e o impacto de ocupação (ILCD, 2010b).

O Brasil é um país de grandes proporções continentais, onde: seus 8,5 milhões $\mathrm{km}^{2}$ ocupam quase a metade da América do Sul e possui várias zonas climáticas - como o trópico úmido no Norte, o semi-árido no Nordeste e áreas temperadas no Sul. Estas diferenças climáticas levam a variações ecológicas, formando zonas biogeográficas distintas ou biomas: a Floresta Amazônica; o Pantanal; o Cerrado de savanas e bosques; a Caatinga de florestas semi-áridas; os campos dos Pampas; e a floresta tropical pluvial da Mata Atlântica (MMA, 2010).

Estas características contribuem significativamente para a riqueza da flora, da fauna e na boa produtividade dos solos do país, fatores que contribuem positivamente para atividades econômicas ligadas a agricultura. Particularmente em razão do crescimento da importância dos biomateriais e biocombustíveis. Isso devido à produção em escala de biocombustíveis que foi acentuada pelo fato que o governo brasileiro estabeleceu porcentuais mínimos de adição de biodiesel ao diesel como consta na Lei n 11.097, 2005 (BRASIL, 2005). Diante este cenário, é possível inferir que a necessidade da produtividade agronômica (especificamente de plantas oleaginosas como mamona, dendê, babaçu, amendoim, pinhão manso, girassol, algodão e soja) demandará mais extensões de terras a serem cultivas incrementando assim as modificações nas propriedades do solo. Por essa razão, se vê a necessidade da avaliação da categoria de impacto do uso do solo segundo condições biogeográficas (tipo de solo, tipo e clima, entre outros) do Brasil.

Finalmente, este trabalho visa à obtenção de fatores de caracterização para a categoria de impacto do uso do solo mediante a adequação de um método que seja de acordo a realidade brasileira contribuindo desta forma a sua inclusão em trabalhos de ACV. 


\subsection{OBJETIVO}

Determinar Fatores de Caracterização do Impacto do Uso do Solo na Avaliação do Ciclo de Vida (ACV) de acordo as condições brasileiras mediante a adaptação de um método que avalie o Impacto do Uso do Solo nas Funções de Suporte de Vida (FSV).

\subsection{ESTRUTURA DO TRABALHO}

Para uma melhor compreensão da estrutura deste trabalho, é necessário apresentar uma breve descrição dos seus capítulos.

O presente capítulo refere-se a uma introdução que expõe a justificativa do desenvolvimento ou adaptação de métodos existentes para avaliar o impacto do uso do solo, de acordo com as características do país e a necessidade de se obter fatores de caracterização que avaliem não só os impactos globais, mas também os locais. Apresenta ainda a estrutura e os objetivos do trabalho.

No Capítulo 2, serão abordados conceitos da ACV, bem como as quatro etapas operativas desta técnica. A terceira etapa, conhecida como AICV, é descrita com mais detalhes, uma vez que ela se presta a avaliar os impactos ambientais, dentre os quais o uso do solo pode ser considerado um dos de grande relevância. Finalmente, é feita uma apresentação acerca dos conceitos relacionados a esta categoria de impacto.

O Capítulo 3 apresentará a metodologia empregada na aquisição do conhecimento dos métodos do impacto do uso do solo, utilizando os conceitos adquiridos dos capítulos anteriores, visando cumprir os objetivos estabelecidos no primeiro capítulo.

O Capítulo 4, apresenta os resultados e as discussões do trabalho.

O Capítulo 5, apresenta as conclusões desta dissertação.

No Capítulo 6, serão citadas as referências bibliográficas utilizadas para a realização deste trabalho de pesquisa.

Nos Anexos, são apresentados os tipos de usos de solo para o Brasil, os tipos de solos no Brasil, os fatores de ajuste para o carbono orgânico do solo (COS) para diferentes tipos de gestão do solo e o teor do COS antes da transformação e ocupação do solo. 
Finalmente, nos apêndices são apresentados o teor do COS durante a ocupação do solo, os fatores de caracterização na transformação e ocupação do solo para o Brasil. 


\section{REV|ISÃO BIBLIOGRÁFICA}

$\mathrm{Na}$ presente pesquisa bibliográfica realizou-se um levantamento de informação com foco em três vertentes, as quais são apresentadas de forma sintetizada: a técnica de ACV, a etapa de AICV e, finalmente, a categoria de Impacto do Uso do Solo.

Em relação à $A C V$ foram investigadas as normas nas quais se rege a técnica e suas etapas, dentre as quais se destaca a AICV, para evidenciar a compreensão do processo de avaliação de impactos ambientais.

$\mathrm{Na}$ AICV foram apresentados cada um de seus elementos, dentre as quais se destacou a caracterização, que busca correlacionar como são realizados os cálculos dos fatores de caracterização das categorias de impactos.

$\mathrm{Na}$ Avaliação do Impacto do Uso do Solo, buscou-se a aquisição de conceitos considerados necessários e relevantes para a compreensão do impacto. Nesse sentido, também foram avaliadas áreas que são afetadas, assim como os métodos desenvolvidos para o estudo desta categoria de impacto.

\subsection{AVALIAÇÃO DO CICLO DE VIDA (ACV)}

Os produtos e serviços visam ao atendimento das necessidades dos seres humanos e nas suas produções acontecem fluxos de entradas e saídas de matérias e energia. Tendo que ser analisados a fim de avaliar os impactos ambientais potenciais.

\subsubsection{Conceito de ACV}

Segundo a norma ABNT NBR ISO 14040 (ABNT, 2009a), a ACV pode ser entendida como: a compilação e avaliação das entradas, saídas e dos impactos ambientais potenciais de um sistema de produto ao longo do seu ciclo de vida. Nesse sentido, a ACV se presta a avaliar produtos e serviços desde a extração dos recursos naturais até o uso e disposição final, além de considerar o transporte associado às suas atividades. Assim, todas as entradas e saídas de matéria e energia podem ser associadas a uma unidade funcional, isto é, ao objeto em estudo será atribuída uma parcela dos aspectos ambientais decorrentes de todo os 
processos envolvidos em seu ciclo de vida (SILVA; KULAY, 2006). A Figura 2.1 a seguir representa os estágios do ciclo de vida de um produto:

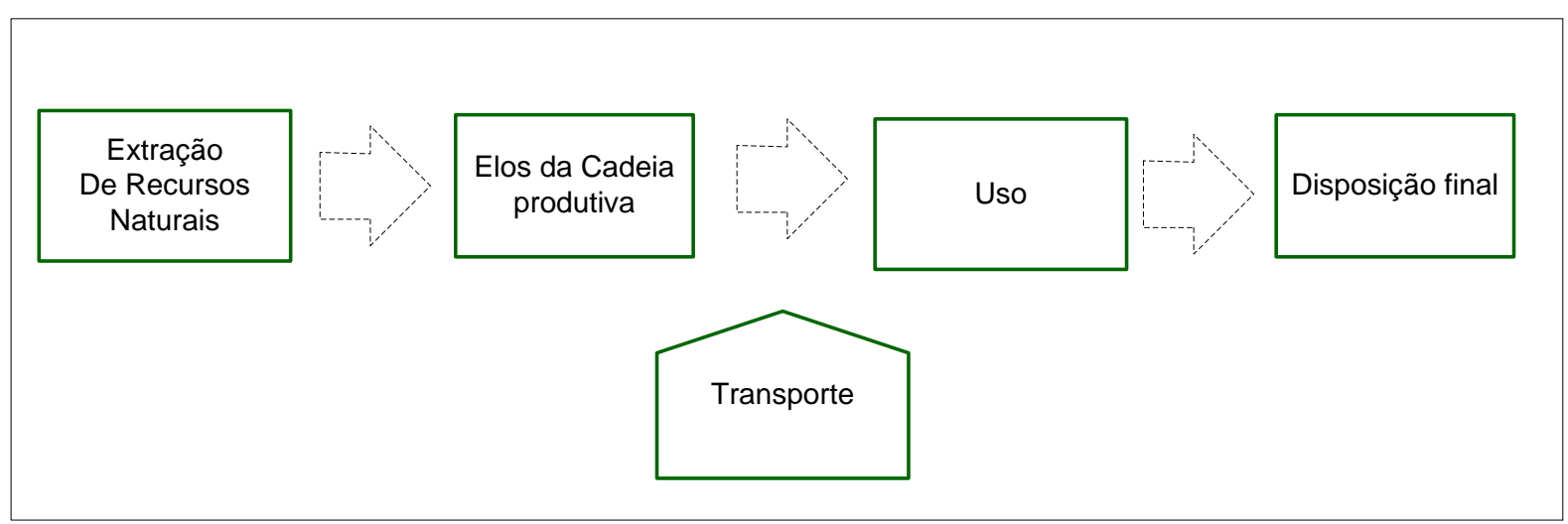

Figura 2. 1 - Estágios do ciclo de vida de um produto (SILVA; KULAY, 2006).

\subsubsection{História da ACV}

Segundo Baumann e Tillman (2004), o primeiro estudo de ACV foi realizado pela companhia Coca-Cola, na metade da década de 1960, que delegou ao "The Midwest Research Institute - MRl" a sua execução. O produto final do estudo consistiu um relatório que ficou conhecido como "Resource and Environmental Profile Analysis - REPA", o qual que trazia as primeiras ideias do conceito de ACV. No trabalho foram desenvolvidos estudos comparativos sobre diferentes tipos de embalagens de refrigerantes (plástico e vidro), com a finalidade de estimar algumas emissões para o meio ambiente e verificar qual delas possuía o melhor desempenho em relação ao consumo de recursos naturais associadas a seus respectivos ciclos de vida (BAUMANN; TILLMAN, 2004).

Os resultados do trabalho não foram divulgados ao público. Entretanto, uma das modificações feitas pela companhia após o estudo foi trocar suas embalagens de vidro pelas de plástico, decisão essa questionada porque na época o plástico não tinha uma boa reputação, pelo menos no que diz respeito a termos ambientais.

No Reino Unido em 1972. No departamento de ciências materiais da universidade Aberta do Reino Unido o professor Boustead desenvolveu um trabalho sobre a produção de garrafas para o acondicionamento de leite, que focou-se no estudo da energia associada à produção de garrafas retornáveis e não retornáveis. Outro estudo de ACV foi desenvolvido na Alemanha, em 1972, quando o governo encomendou um estudo de caráter ambiental para encontrar a embalagem com 
menor consumo de materiais e energia, julgando assim que o mesmo acarretaria em menores consequências ambientais. Já na Suíça (1973), a companhia Tetra Pack lançou um novo produto (uma garrafa de PVC), após a realização de um estudo sobre as emissões no incinerador.

Desde então o interesse pela ACV foi aumentando com a realização de diversos estudos, porém ao mesmo passo foram observadas discrepâncias entre os resultados, por conta do estabelecimento de premissas arbitrárias e a falta de banco de dados. Tais ações acabaram por expor as limitações da técnica, causando desconfiança na comunidade científica e o seu abandono temporário.

Diante deste cenário desfavorável, algumas instituições começaram a se preocupar no sentido de buscar uma uniformização conceitual da técnica. Dentre estes esforços, cabe destacar o papel desempenhado pela SETAC e UNEP, que acabaram por oferecer contribuições valiosas para a consolidação da técnica, diminuindo assim as subjetividades dos estudos desta natureza (GARRAín, 2009).

Quanto à padronização da ACV, a International Organization for standardization (ISO), estabeleceu a estrutura conceitual que compõe a metodologia. No final da década de 1990, a ISO desenvolveu e publicou as primeiras normas da serie (SILVA; KULAY, 2006):

- ISO 14040: Environmental Management - Life Cycle Assessment - Principles and Framework (1997);

- ISO 14041: Environmental Management - Life Cycle Assessment - Goal and scope definition and inventory analysis (1998);

- ISO 14042: Environmental Management - Life Cycle Assessment - Life cycle impact assessment (2000);

- ISO 14043: Environmental Management - Life Cycle Assessment - Life cycle impact assessment (2000).

Além destas normas, a ISO publicou dois relatórios técnicos (RT) e uma especificação técnica (ET);

- ISO/TR 14047: Environmental Management - Life Cycle Impact Assessment examples of application of ISO 14042 (ISO, 2003);

- ISO/TR 14048: Environmental Management - Life Cycle Impact Assessment data documentation format (ISO, 2002); 
- ISO/TR 14049: Environmental Management - Life Cycle Impact Assessment Examples of Application of ISO 14041 to goal and scope definition and inventory analysis (ISO, 2000).

Porém no ano de 2006 a ISO decidiu substituir o conjunto ISO 14040 a 14043 em dois documentos:

- ISO 14040: Environmental Management - Life Cycle Assessment - principles and framework (2006). Apresenta a definição do objetivo e escopo, análise do inventário, avaliação de impactos e interpretação;

- ISSO 14044: Environmental Management - Life Cycle Assessment requirements and guidelines (2006). Apresenta os requisitos e diretrizes para os estudos de ACV, as quatro etapas do método ACV, bem como as limitações do método e a relação entra as etapas da ACV.

No início de 1996 foi lançada a primeira publicação do periódico bimestral "The international journal of life cycle assessment", que a partir daí passou a se constituir em uma importante referência para os pesquisadores e interessados no tema da ACV (BAUMANN; TILLMAN, 2004).

Em abril de 2002 foi inaugurado o programa "The Life Cycle Iniciative", em cooperação da SETAC e a da UNEP. O principal impulso desta iniciativa foi disseminar o conceito do ciclo de vida ao redor do mundo e fornecendo base de dados que facilitando a utilização dos métodos baseados na técnica de ACV (LCl, 2011).

No Brasil, a Associação Brasileira de Normas Técnicas (ABNT) traduziu as normas ISO para as normas brasileiras: ABNT NBR ISO 14040:2009 (ABNT, 2009a) e a ABNT NBR ISO 14044:2009 (ABNT, 2009b).

Em 1994 foi criado o Grupo de Apoio à Normalização (GANA), para a elaboração de normas ambientais. Já o primeiro estudo usando ACV foi realizado pelo Centro de Tecnologia de Embalagem (CETEA) que avaliou materiais usados nas embalagens de alimentos. Em 1998, junto ao Departamento da Engenharia Química da escola Politécnica da USP, foi criado o Grupo de Prevenção da Poluição (GP2) que trabalha no sentido de contribuir na consolidação do uso da ACV no Brasil (SILVA; KULAY, 2006). 
Como consequência do crescimento rápido da ACV, foi criada em 29 de novembro de 2002, na cidade de Rio de Janeiro, a Associação Brasileira de Ciclo de Vida $(A B C V)$ para divulgar e desenvolver o uso da técnica da ACV no país. Nesse contexto, dois aspectos são prioridades para associação (SILVA; KULAY, 2006):

- Promover a consolidação de uma metodologia para a ACV, compatível com a realidade brasileira;

- Executar a construção de um banco de dados brasileiro para apoiar estudos da técnica.

\subsubsection{Usos e Limitações}

A ACV é uma técnica focada no ciclo de vida do produto, e que busca encontrar informações das interações significativas entre o sistema do produto e o meio ambiente para, em seguida, avaliar os impactos associados ao cumprimento da função do produto, podendo assim auxiliar o processo de tomada de decisões (ILCD, 2010b).

Ela tem como usuários as empresas comerciais; governos nacionais ou locais; órgãos reguladores nacionais e intergovernamentais; organizações não governamentais; grupos ambientais; sindicatos e consumidores (ABNT, 2009a).

Alguns dos principais usos da ACV são indicados a seguir (ABNT, 2009a):

- comunicação através do Marketing;

- ecodesign (incorporação de critérios ambientais no projeto dos produtos);

- rotulagem Ambiental;

- determinação de indicadores de sustentabilidade (pegada ecológica, pegada de carbono, pegada hídrica).

Quanto às limitações da $A C V$, podem ser destacadas ( $A B N T, 2009 a)$ :

- os estudos quase sempre acarretam em grande consumo de tempo;

- grande consumo de recursos financeiros e humanos;

- dependendo da profundidade do estudo que se pretende conduzir, a coleta de dados pode ainda ser dificultada.

- a não disponibilidade de dados importantes pode afetar o resultado final do estudo e, por conseqüência, a sua confiabilidade.

- necessidade de um enorme conjunto de dados a serem coletados 
Torna-se importante, portanto, uma avaliação criteriosa da relação custobenefício para se atingir a qualidade desejada para o estudo, levando-se em consideração que tipo de dado deverá ser coletado, o custo e o tempo para sua coleta, bem como os recursos disponíveis para a condução da ACV.

\subsubsection{Estrutura da ACV}

Segundo a ABNT NBR ISO 14040 (2009a), a metodologia da ACV é dividida em quatro fases. A forma como cada uma interage entre si é ilustrada na Figura 2.2.

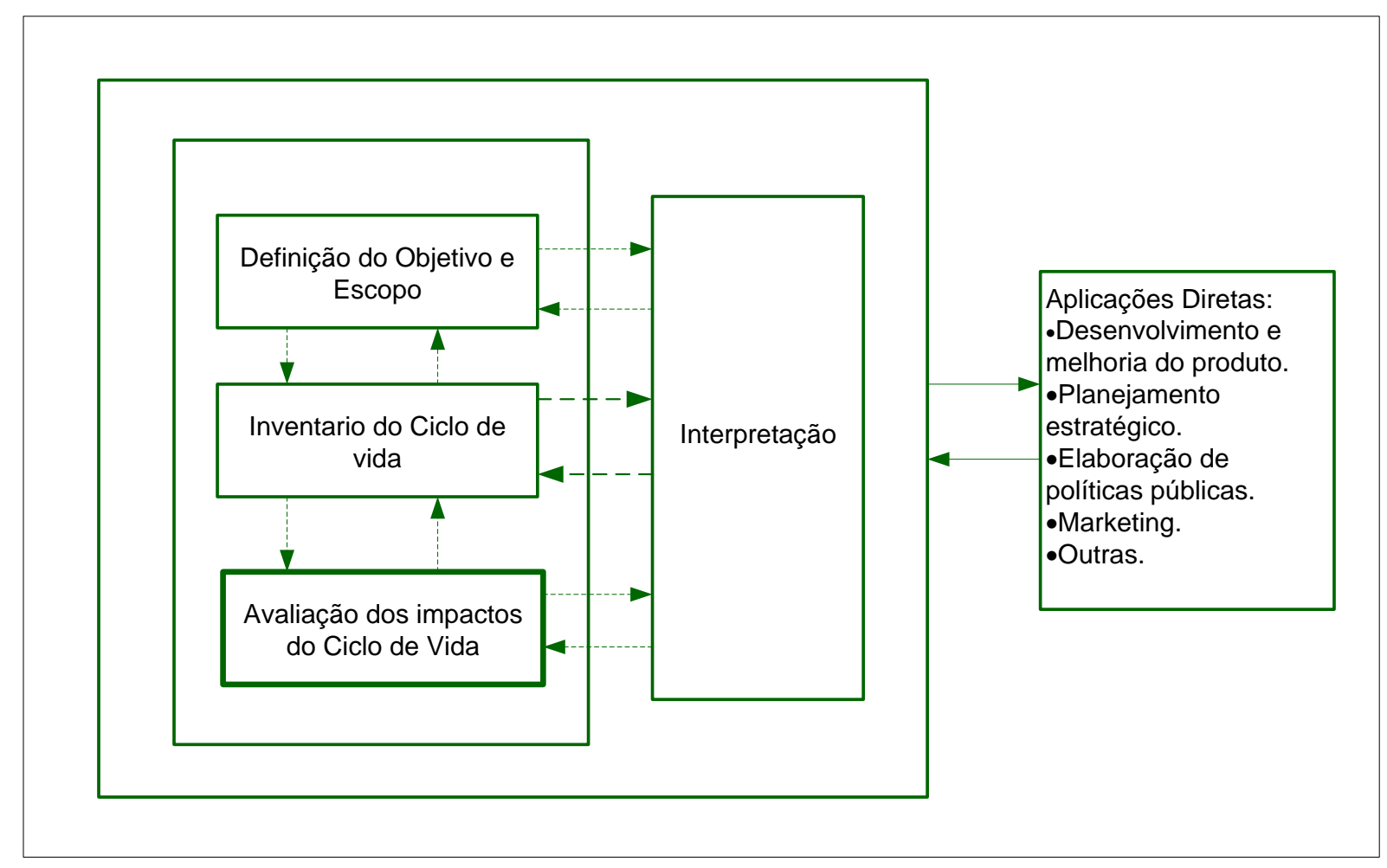

Figura 2. 2 - Fases da ACV (ABNT, 2009a).

Conforme é apresentado na Figura 2.2, cada uma das fases é correlacionada por duplas setas, que indicam a natureza iterativa da ACV. Ou seja, conforme se vai avançando no estudo, é possível voltar em algum ponto anterior para verificar se as metas estão sendo atingidas e se os dados que estão sendo coletados são adequados. Dessa forma, havendo a necessidade, as fases podem ser revisadas e modificadas conforme informações adicionais são coletadas ao longo do estudo (ILCD, 2010b). 
Na sequencia serão abordadas com um maior nível de detalhe cada uma das quatro etapas da $\mathrm{ACV}$, com o intuito de fornecer maior clareza sobre estes conceitos ao leitor.

\section{a. Definição do Objetivo e Escopo}

Esta é a primeira fase da metodologia de ACV. Trata-se de uma etapa de fundamental importância, uma vez que as definições estabelecidas nortearam a execução das etapas subsequentes.

No objetivo, deve-se estabelecer de forma clara (ABNT, 2009a):

- a aplicação pretendida;

- as razões para a realização do estudo;

- o público alvo, ou seja, aquele a quem se pretende comunicar os resultados do estudo;

- se existe a intenção de utilizar os resultados em afirmações comparativas a serem divulgadas publicamente.

Já no escopo do estudo, devem ser considerados e claramente descritos os seguintes itens (ABNT, 2009a):

- o sistema de produto a ser estudado;

- as funções do sistema de produto ou, no caso de estudos comparativos, dos sistemas;

- a unidade funcional;

- a fronteira do sistema;

- procedimentos de alocação;

- metodologia de AICV e tipos de impacto;

- interpretação a ser utilizada;

- requisitos de dados;

- pressupostos;

- escolha de valores e elementos opcionais;

- limitações;

- requisitos de qualidade de dados;

- tipo de revisão crítica, se aplicável; 
- tipo e formato de relatório requerido para o estudo.

\section{b. Inventário do Ciclo de Vida (ICV)}

A segunda fase da ACV é a etapa mais trabalhosa, devido à coleta e o tratamento de grande quantidade de dados que representam as correntes de entrada e saída que circulam pelas fronteiras de cada processo elementar. Estes dados são relativos ao sistema do produto e devem ser correlacionados à unidade funcional definida na primeira fase. Considera-se que a qualidade dos dados coletados exerce influencia na confiabilidade dos resultados do estudo (ILCD, 2010b).

Segundo Baumann e Tillman (2004), as atividades incluídas nesta fase são as seguintes:

- construção de fluxogramas de acordo com as fronteiras do sistema que foram já previamente definidas no objetivo e escopo;

- coleta de dados para todos os processos elementares, seguido pela documentação dos dados coletados;

- cálculo das cargas ambientais (uso de recursos e emissões de poluentes) do sistema em relação à unidade funcional.

\section{c. Avaliação dos Impactos do Ciclo de Vida (AICV)}

Corresponde à terceira etapa de um estudo de ACV. Nela, os aspectos ambientais coletados e tratados ao longo da elaboração do ICV são correlacionados com suas respectivas categorias de impacto.

Atualmente, instituições de pesquisa internacionais trabalham em busca de uma melhor padronização da quantificação das emissões, dos recursos consumidos, dos impactos ao meio ambiente e à saúde humana, relacionando todas estas alterações no meio com os produtos ou serviços desenvolvidos pelo homem (ILCD, 2010a). Esta fase será abordada com maiores detalhes no item 2.2.

\section{d. Interpretação}

Última fase da ACV, em que se devem ser interpretadas as escolhas e premissas, bem como os resultados gerados nas fases anteriores (ICV, AICV), 
ações estas executadas tendo como base as definições de objetivo e escopo da primeira fase da ACV.

Segundo a ABNT NBR ISO 14040 (ABNT, 2009a), a fase de interpretação tem o objetivo de prover informações e recomendações que possam ser úteis para a tomada de decisões.

De acordo com a ABNT NBR ISO 14044 (ABNT, 2009b), existem três elementos básicos na interpretação.

- Identificação dos temas de relevância: pontos importantes como aspectos do inventário ou suas categorias; categorias de impacto e processos unitários ou atividades;

- Avaliações: com o objetivo de determinar a confiabilidade nos resultados e temas de relevância;

- Conclusões, limitações e recomendações: devem ser estabelecidas de modo interativo com outros elementos da etapa de interpretação. Quanto às recomendações, estas devem ser apropriadas a meta e aos objetivos estabelecidos.

Finalmente, o relatório do estudo deve fornecer uma descrição completa de forma transparente e bem detalhada no que se refere às escolhas e suposições.

\subsection{AVALIAÇÃO DOS IMPACTOS DO CICLO DE VIDA (AICV)}

Os impactos considerados na AICV incluem, entre outros: mudanças climáticas, depleção da camada de ozônio, eutrofização, acidificação, toxicidade humana, ecotoxicidade, uso do solo, depleção de recursos. Cada um dos impactos deve ser avaliado por meio de indicadores usando modelos específicos.

Os procedimentos devem ser transparentes e prover flexibilidade para sua aplicação, além de ser bem planejados para atender ao objetivo e escopo do estudo da ACV (BAUMANN; TILLMAN, 2004).

A estrutura metodológica e científica desta fase ainda está em desenvolvimento dentro da comunidade de ACV, e nenhuma metodologia é aceita de forma geral e absoluta (ABNT, 2009a).

No intuito de compreender os modelos de avaliação de impacto, torna-se importante conhecer os elementos da AICV, de forma a compreender com clareza a 
nomenclatura utilizada em estudos desta natureza. Esses são apresentados a seguir.

\subsubsection{Definição da AICV}

Segundo a norma ABNT NBR ISO 14044 (ABNT, 2009b), esta fase visa ao entendimento e avaliação da magnitude e significância dos impactos ambientais potenciais de um sistema de produto ao longo do seu ciclo de vida.

Os impactos ambientais potenciais são relacionados à unidade funcional, quantificando-os mediante indicadores que descrevam estes impactos ambientais. (BAUMANN; TILLMAN. 2004).

\subsubsection{Elementos da AICV}

A AICV é composta por elementos obrigatórios e opcionais como apresentado na Figura 2.3:

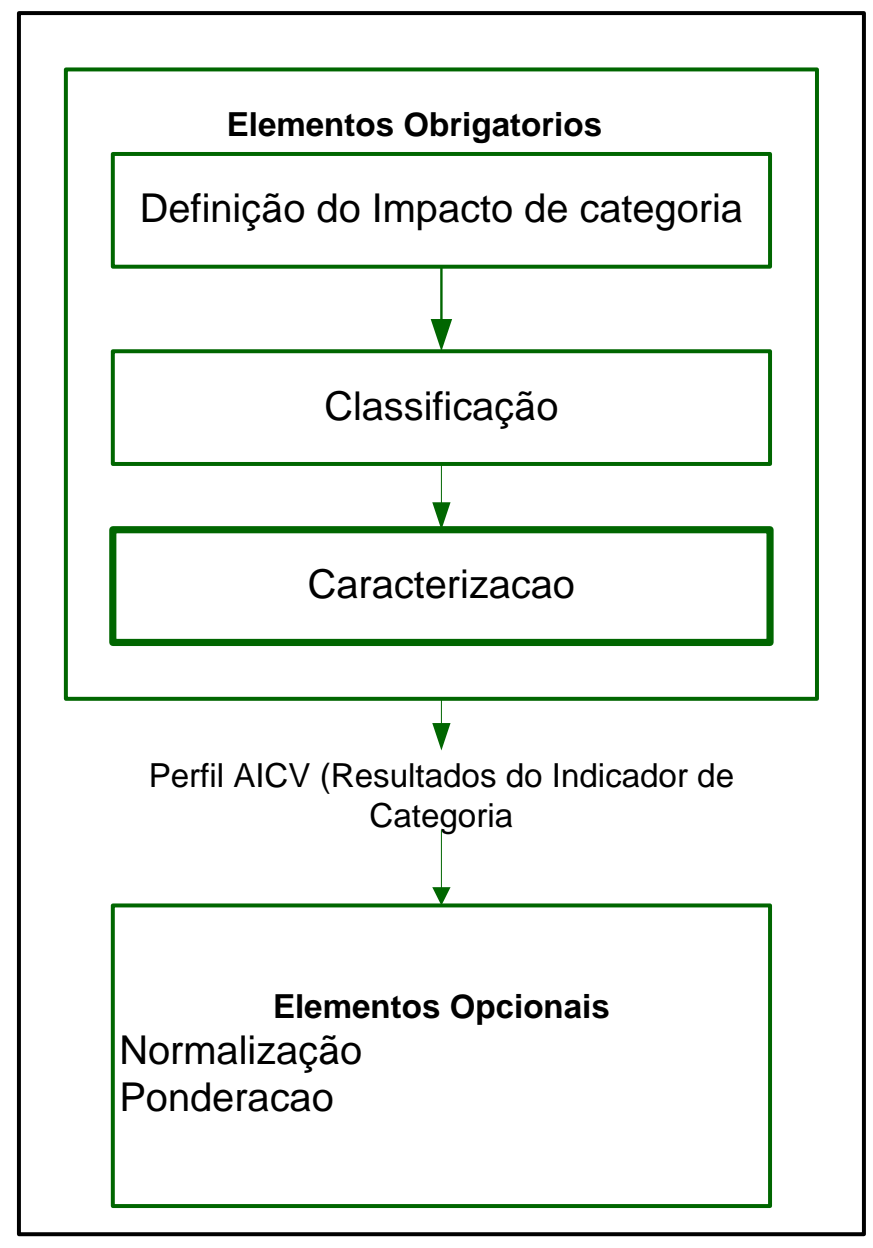

Figura 2. 3 - Elementos da Avaliação do Impacto do Ciclo de Vida (ABNT, 2009b). 
Como observado na Figura 2.3, dentre os elementos obrigatórios da AICV consiste a caracterização, na qual cada impacto é quantificado por meio dos modelos de caracterização.

Os elementos obrigatórios, como o próprio nome indica, devem ser realizados em todos os estudos da ACV; quanto aos opcionais, a sua adoção fica a cargo da consideração do executante da ACV. A seguir se realizará uma breve descrição de cada um destes elementos.

\section{a. Definição do impacto de categoria}

Esta fase consiste na escolha das categorias de impacto, dos indicadores e dos modelos de caracterização.

Nos casos em que não haja informações suficientes para satisfazer o objetivo e espoco definidos na ACV, novas categorias de impacto, indicadores e modelos de caracterização terão que ser definidos, sempre e quando se apliquem as recomendações (ILCD, 2010a).

São muitas as variáveis a serem consideradas no momento de decidir quais categorias de impacto incluir em um estudo. Entre as quais temos (BAUMANN; TILLLMAN, 2004):

- Plenitude - a lista de categorias de impacto deve considerar todos os problemas ambientais de relevância.

- Praticidade - a lista deve conter muitas categorias.

- Independência - as categorias devem ser mutuamente excludentes a fim de evitar dupla contagem.

- Possibilidade de ser integrada nos cálculos de ACV - deve ser possível relacionar, parâmetros indicados no inventário do ciclo de vida para escolher impactos de categoria e métodos de caracterização.

- Relevância Ambiental - os indicadores dos fatores de caracterização devem ser ambientalmente relevantes para as categorias de impacto e as áreas de proteção.

- Método científico - os métodos de caracterização devem ter validade cientifica. 
Alguns dos impactos ambientais comumente considerados em estudos de ACV são listados a seguir (ILCD, 2010a):

- consumo de recursos naturais: inclui recursos materiais e energéticos, tanto renováveis quanto não-renováveis;

- mudanças climáticas: são provocadas pelo acúmulo, na atmosfera, de determinados gases (por exemplo, gás carbônico e metano) que retêm parte da radiação infravermelha emitida pela Terra, provocando o aumento das temperaturas médias globais.

- depleção da Camada de Ozônio: consiste na redução da quantidade de ozônio (O3) presente na estratosfera, por reação com alguns gases (como halocarbonos: CFC11, CFC12, etc.), provocando a diminuição da capacidade que essa camada tem de filtração da radiação ultravioleta proveniente do Sol;

- toxicidade Humana: resultante da disposição de rejeitos tóxicos no meio ambiente; em geral, é considerada em separado a toxicidade humana e a assim chamada ecotoxicidade, que pode ser aquática e terrestre;

- ozônio Fotoquímico: consiste na formação de ozônio nas camadas baixas da atmosfera por reações químicas entre óxidos de nitrogênio e alguns hidrocarbonetos leves (resultantes de emissões), em presença da radiação ultravioleta solar;

- acidificação: consiste no aumento do teor de acidez da atmosfera provocado pela emissão de gases ácidos, tais como óxidos de enxofre e óxidos de nitrogênio, que são dissolvidos pela umidade atmosférica e retornam à crosta terrestre na forma de ácidos;

- uso do Solo: o uso do solo para a agricultura, silvicultura, mineração, construções de casas ou indústrias pode ocasionar impactos significativos, particularmente para a biodiversidade e para a qualidade do solo como um fornecedor do suporte das funções da vida.

De acordo com a norma ABNT NBR ISO 14044 (ABNT, 2009b), os componentes necessários da AICV incluem para cada categoria de impacto:

- identificação do(s) ponto(s) final (is) de categoria;

- definição do indicador de categoria, dado(s), ponto(s) final (is) de categoria; 
- identificação dos resultados apropriados do ICV que podem ser correlacionados à categoria de impacto, levando em conta o indicador de categoria escolhido e o(s) ponto(s) final (is) identificado(s) para a categoria;

- e identificação do modelo de caracterização e dos fatores de caracterização.

\section{b. Classificação}

Segundo os mecanismos ambientais, atribuem-se as entradas e saídas do ICV às categorias de impacto escolhidas, segundo a capacidade de uma determinada substância em contribuir para diferentes problemas ambientais (ILCD, 2010a).

Cabe destacar que cada impacto ambiental pode estar relacionado a uma ou mais áreas de proteção, como é o caso do uso do solo que afetará a duas áreas de proteção (recursos naturais e o ecossistema). Isto é mostrado na Figura 2.4 a seguir:

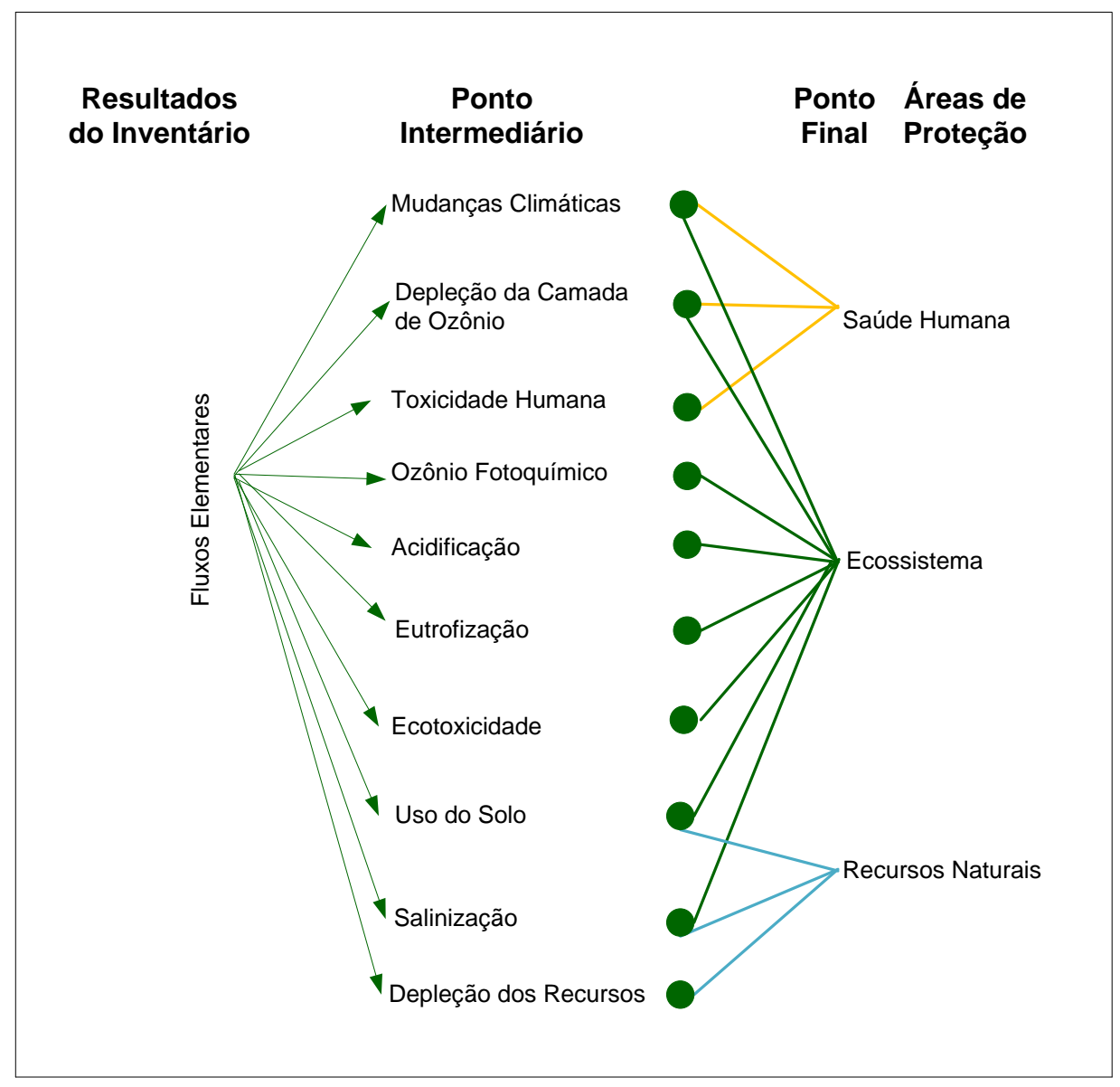

Figura 2. 4 - Estrutura das Categorias de Impacto para Caracterização de Modelos nos níveis Intermediários e Finais (Adaptado GOEDKOOP; SPRIENSMA, 2001). 
A classificação é qualitativa e baseada em análises científicas. Portanto, são necessários conhecimentos de qual categoria de impacto será afetada por cada aspecto ambiental inventariado antes no ICV. Afortunadamente, existem listas em que várias substâncias são relacionadas a cada categoria de impacto, as quais são úteis durante a execução de estudos (BAUMMAN; TILMANN, 2004).

Alguns aspectos ambientais podem contribuir com diferentes impactos ambientais e, por essa razão, têm que ser associados mais de uma vez em cada categoria de impacto identificada. Não há problema quanto a isso, desde que os efeitos produzidos sejam diferentes e que estes efeitos independam um do outro. Por outro lado, a dupla contagem para efeitos similares não é permitida (ILCD, 2010a).

\section{c. Caracterização}

A contribuição de cada emissão aspecto ambiental para cada impacto é quantificada por meio dos modelos de caracterização. O resultado é expresso em unidades comuns a todas as contribuições de cada impacto, mediante a aplicação de fatores de caracterização (ILCD, 2010a).

As seguintes recomendações se aplicam para a seleção da categoria de impacto, indicadores de categoria e modelos de caracterização (ABNT, 2009b):

- As categorias de impacto devem considerar indicadores e modelos de caracterização sejam aceitos internacionalmente, isto é, sejam baseados em um acordo internacional ou aprovados por uma entidade internacional competente.

- Convém que a escolha de valores e adoção de pressupostos durante a seleção da categoria de impacto, indicadores de categoria e modelos de caracterização seja minimizada.

- Convém que o modelo de caracterização para um indicador de categoria seja cientificamente e tecnicamente válido, esteja baseado em um mecanismo ambiental especifico e identificável e/ou em observação empírica reprodutível.

- Convém que seja identificado o grau de validade científica e técnica do modelo de caracterização e dos fatores de caracterização. 
$\mathrm{Na}$ Figura 2.5, se apresentam os passos a serem seguidos na etapa da caracterização.

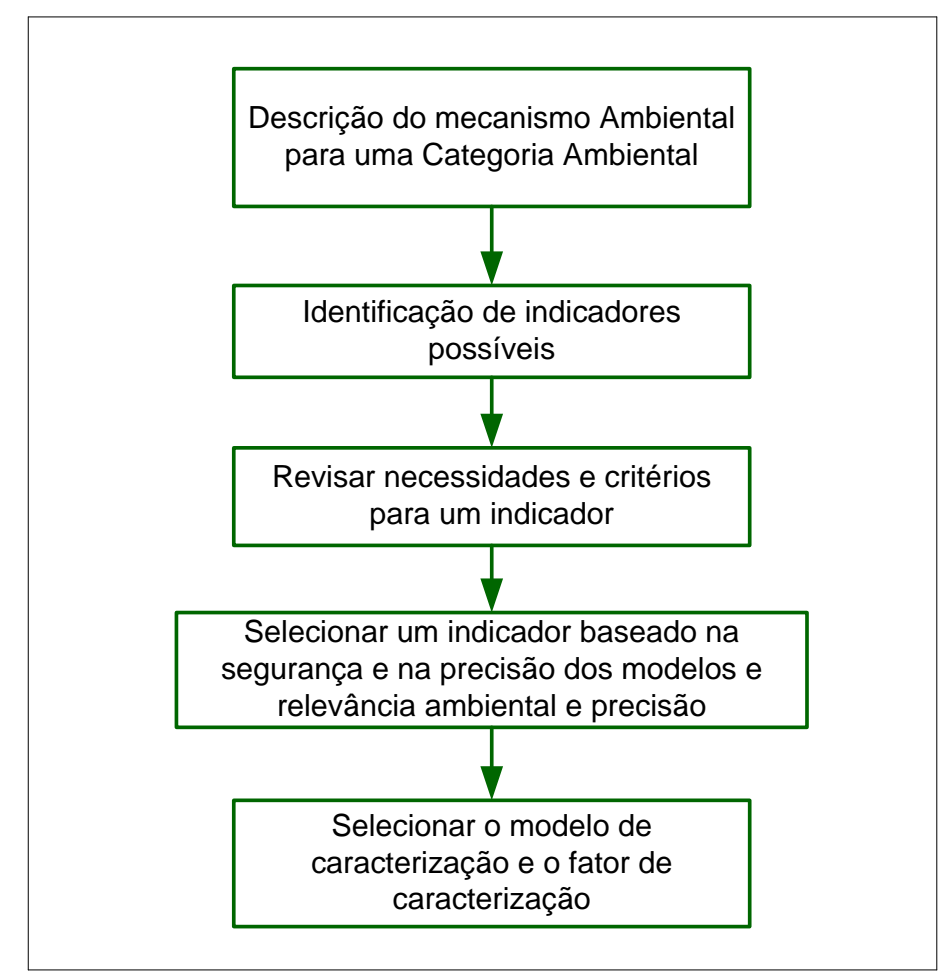

Figura 2. 5 - Os passos da Caracterização (COLIN, 2010).

A descrição do mecanismo ambiental auxilia na visualização das conexões dos aspectos ambientais com os possíveis indicadores que ajudarão na avaliação do impacto. Verificando assim se o indicador a ser utilizado é um bom representante das modificações na propriedade físicas químicas e biológicas do recurso que se quer preservar.

O indicador selecionado deve cumprir com algumas características como ser um bom representante dos pontos finais que se deseja preservar, ser facilmente quantificavel, ser consistente com a estrutura da AICV e com os objetivos e escopo do estudo, deve ser de fácil compreensão para sua aplicação para sua aplicação de não expertos no tema e devem ser internacionalmente aceitos a fim de permitir comparações nos diferentes estudos de ACV.

Finalmente, de acordo com todos os requisitos citados acima se procedera a escolha no método de caracterização que se ajuste melhor. 


\section{d. Normalização}

É o cálculo da magnitude dos resultados dos indicadores de categoria com relação a algum valor de referência. $O$ objetivo da normalização é entender melhor a magnitude relativa para cada resultado de indicador do sistema de produto em estudo (ABNT, 2009b).

\section{e. Ponderação}

A ponderação compreende a atribuição de pesos relativos para cada qual das categorias de impacto adotada. Leva em conta a percepção das partes interessadas em relação à importância relativa das categorias de impacto e no processo de estabelecimento desses mesmos pesos.

Tal como antes comentado, os procedimentos de normalização e ponderação são considerados não obrigatórios pela norma ABNT NBR ISO 14044 (ABNT, 2009b) em virtude do elevado grau de subjetividade a que expõe os resultados da AICV.

Como se observou este item de AICV tem como objetivo a avaliação dos impactos ambientais, dentre os quais se tem a categoria de impacto do Uso do Solo, o qual é de interesse neste trabalho e será desenvolvida no seguinte item 2.3 a seguir.

\subsection{CATEGORIA DE IMPACTO USO DO SOLO}

Os efeitos deste impacto são estritamente regionais. Portanto, esta categoria depende das condições do local onde se está realizando o estudo. Diante disto, torna-se importante que as medidas de avaliação sejam ajustadas às características de cada um dos países (clima, tipos de solos, períodos de chuvas, entre outros).

De maneira geral, pode-se dizer que a modelagem desta categoria de impacto contempla uma avaliação em termos de: a) impacto da transformação do solo inicialmente de um tipo A para um tipo B; b) o tempo de uso no tipo B.

\subsubsection{Definição do Impacto do Uso do Solo}

O impacto de uso do solo é a modificação nas suas propriedades, causadas principalmente pelas intervenções das atividades antrópicas, que ocasionarão 
alterações na habilidade do mesmo em realizar suas funções (SETAC, 2002; BRENTRUP et. al., 2002).

Milà i Canals; Romanya e Cowell (2007) consideram que além das propriedades física, química e biológica do solo dever-se-ia revisar suas funções de acordo com uma subdivisão em termos ecológicos e socioeconômicos, conforme descrito na Tabela 2.1.

\begin{tabular}{|c|c|c|}
\hline TIPO DE FUNÇÃO & TELLER & LINDEIJER \\
\hline Ecológico & $\begin{array}{l}\text { Produção da } \\
\text { biomassa; } \\
\text { Filtragem, } \\
\text { armazenagem e } \\
\text { transporte; } \\
\text { Reserva genética e } \\
\text { proteção da flora e } \\
\text { fauna. }\end{array}$ & $\begin{array}{l}\text { Habitat para a vida não } \\
\text { humana; } \\
\text { Base para os alimentos } \\
\text { e outras produções } \\
\text { bióticas; } \\
\text { Elemento no circuito da } \\
\text { água. }\end{array}$ \\
\hline Socioeconômico & $\begin{array}{l}\text { Suporte para as } \\
\text { moradias dos seres } \\
\text { humanos; } \\
\text { Depósito de materiais; } \\
\text { Proteção e } \\
\text { preservação da } \\
\text { herança cultural. }\end{array}$ & $\begin{array}{l}\text { Habitat para humanos; } \\
\text { Base para os alimentos } \\
\text { e outras produções } \\
\text { bióticas; } \\
\text { Depósito de recursos } \\
\text { abióticos; } \\
\text { Depósito para } \\
\text { desperdícios e } \\
\text { poluentes. }\end{array}$ \\
\hline
\end{tabular}

Estas funções citadas na Tabela 2.1 são de alguma forma preocupações que a população tem a respeito de como o solo contribui em sua qualidade de vida. Logo, estas funções ajudariam na definição do tipo ou tipos de indicadores a serem utilizados para avaliar o impacto do uso do solo.

Deve-se considerar que um indicador de categoria de impacto ambiental é uma representação quantificável da categoria em estudo, necessitando, se possível, de uma construção simples em comparação com a realidade complexa (MILÀ I CANALS et al., 2007). 


\subsubsection{Impactos de Transformação e Ocupação do Solo}

Para uma melhor avaliação da categoria, o impacto de uso do solo deve ser dividido em duas partes, segundo uma divisão que leva em conta os dois processos que acontecem no solo: transformação e ocupação.

\section{a. Impactos de transformação}

Este impacto é causado em decorrência do processo de transformação do solo, o qual causa mudanças nas propriedades do mesmo e são dependentes do tipo de ocupação. Exemplos disso são a drenagem e o enchimento de uma área pantanosa para fazer desta um solo cultivável; ou o desmatamento de uma área para utilização como pista de aeroporto.

A magnitude deste impacto depende da alteração nas propriedades do solo, caracterizando assim o impacto de transformação (BRENTRUP et. al., 2002; SETAC, 2002; MILÀ I CANALS et al., 2007).

Para o cálculo da magnitude do impacto de transformação a Equação 2.1 é adotada.

$$
\mathbf{I}_{\text {trans }}=\mathbf{A}_{\mathrm{oc}} * \mathbf{F C}_{\text {trans }}
$$

Onde:

Itrans : : Impacto de transformação do solo $\left(\mathrm{m}^{2}\right)$;

$A_{o c} \quad:$ Área ocupada $\left(\mathrm{m}^{2}\right)$;

$\mathrm{FC}_{\text {trans }} \quad$ : Fator de caracterização para impactos de transformação.

Considera-se que os danos ocasionados pela transformação acontecem num primeiro momento dentro da área transformada, mas estes danos poderão se estender para as áreas vizinhas.

\section{b. Impactos de Ocupação}

Este impacto é causado pelo tipo de intervenção durante o processo de ocupação. Trate-se da utilização de uma área em decorrência de uma atividade ao longo de um determinado tempo. Tal ação caracteriza o impacto de ocupação, e 
este decorre das atividades dos seres humanos (como no caso das áreas de cultivo, nas áreas destinadas para resíduos, na construção de prédios, entre outros).

O processo de ocupação, além de influir na indisponibilidade da área utilizada, também exerce influencia sobre as propriedades do solo, tais como: habitat para as plantas e animais selvagens, capacidade de filtração, entre outros (SETAC, 2002).

A magnitude deste impacto depende da diferença entre aa qualidade do solo na situação atual em relação à situação de referência (MILÀ I CANALS et al., 2007).

Para o cálculo da magnitude do impacto de ocupação do solo a Equação 2.2 seguir é utilizado.

$$
\mathbf{I}_{\mathrm{oc}}=\mathbf{A}_{\mathrm{oc}} * \mathbf{T}_{\mathrm{oc}} * \mathbf{F C}_{\mathrm{oc}}
$$

Onde:

loc : impacto de ocupação do solo ( $\left.m^{2} a n o\right) ;$

$\mathrm{A}_{\mathrm{oc}} \quad$ : área ocupada $\left(\mathrm{m}^{2}\right)$;

$\mathrm{T}_{\text {oc }} \quad$ : tempo de ocupação do solo (ano);

FC $\quad$ : fator de caracterização para impactos de ocupação.

O impacto de ocupação aumenta na proporção em que o tempo de duração do processo de ocupação ocorre. Do mesmo modo que acontece no impacto de transformação, na ocupação o impacto se restringirá à área ocupada, mas estes danos podem se estender para as áreas vizinhas (SETAC, 2002).

$\mathrm{Na}$ Figura 2.6 se apresenta uma visualização prática dos dois tipos de impactos, resumindo suas características. 


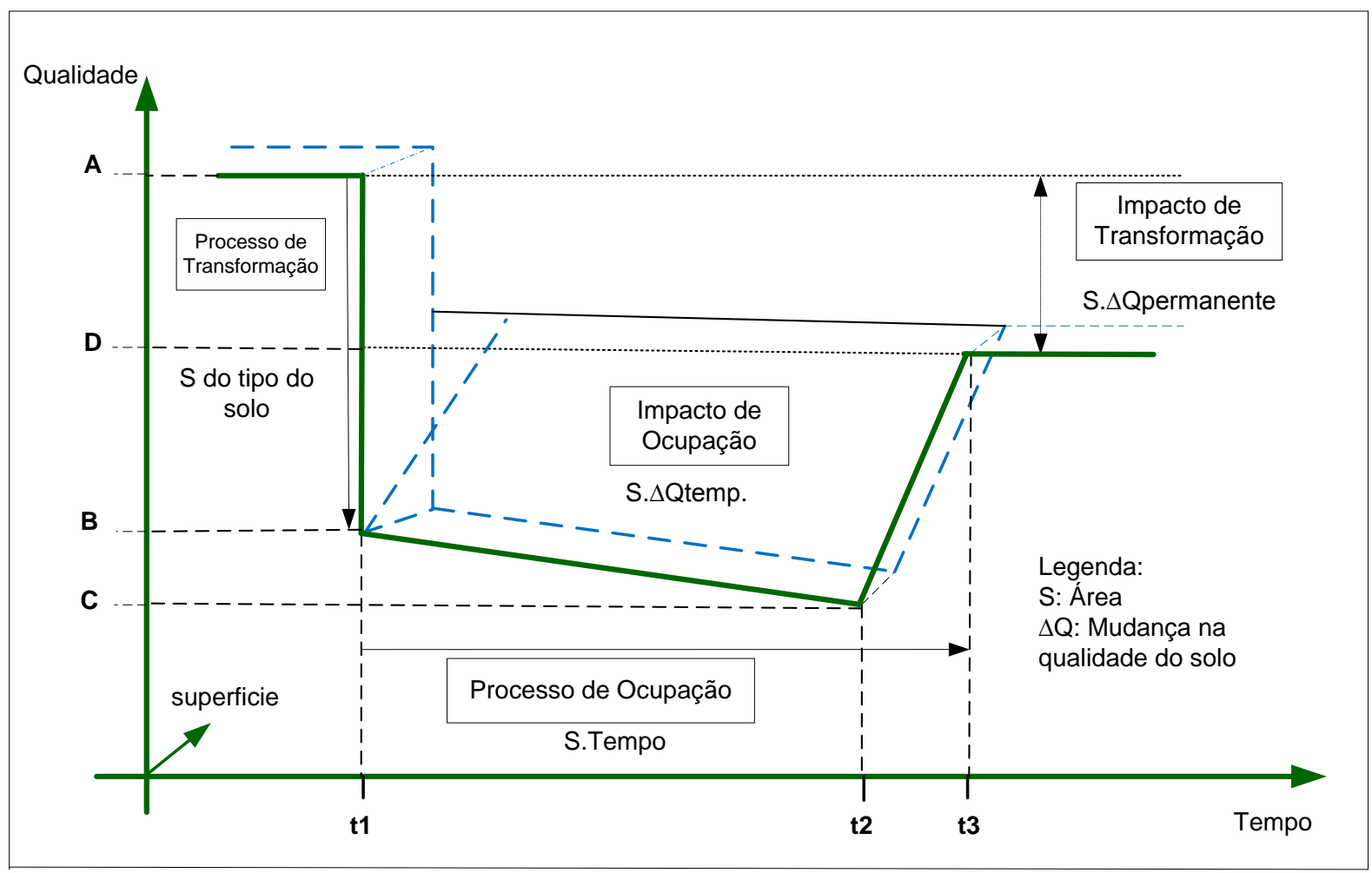

Figura 2. 6 Os Impactos do Uso do Solo (adaptado LINDEIJER, 2002b).

A qualidade do solo é representada pelo eixo vertical, podendo ser expressa por meio de diferentes indicadores como a flora, a fauna, a matéria orgânica do solo, entre outros (LANGLOIS et. al., 2011, LINDEIJER, 2000b; MICHELSEN, 1998; MILÀ I CANALS, 2003). O tempo no qual acontecem os processos é representado pelo eixo horizontal e, finalmente, a área é representada num terceiro eixo. A linha continuada descreve a evolução da qualidade do solo no tempo em diferentes momentos. A transformação inicial se dá no tempo t1, em que se reduz a qualidade do solo de 'A' a 'B'. Se não houvesse subseqüentes processos de ocupação, a "recuperação" espontânea começaria imediatamente no t1 e, portanto, a qualidade iria até D (SETAC, 2002).

Outros trabalhos (LINDEIJER, 2000b; MILÀ I CANALS et al., 2007; SETAC, 2002) explicam que durante o período de $t 1$ a t2 acontece o processo de ocupação, o que predispõe uma perda da qualidade gradual de B para C. Em t2 as atividades foram finalizadas, e partir daí ocorre uma variação da qualidade de $C$ para $D$.

$\mathrm{Na}$ opinião de vários autores, no modelo apresentado na Figura 2.6 (KÖLLNER, 1999; LINDEIJER, 2000a; MICHELSEN, 1998; MILÀ I CANALS, 2003; SCHMIDT, 2008; SETAC, 2002) o tempo de transformação não é considerado, pois 
a duração do processo de transformação é menor se for comparado com as subsequentes ocupações do solo.

Isso é válido porque depois de acontecer mudanças nas propriedades do solo para determinados tipos de ocupações, estas últimas teriam durações por longos períodos; se fosse considerado este tempo haveria grande dificuldade em seu cálculo, em razão de não se ter registro de quando se iniciou e terminou o processo (KOELLNER; ROLAND; SCHOLZ, 2007).

Com respeito ao impacto de ocupação, a Figura 2.6 demonstra uma perda da qualidade gradual do solo, o que significa que o impacto dependerá do estado da qualidade momentânea da área durante o período do processo de ocupação (SETAC, 2002).

Alguns autores (LINDEIJER, 2000b; MICHELSEN, 1998; MILÀ I CANALS, 2003) propuseram assumir que haja uma manutenção da qualidade da área na ocupação, ou seja, que não haja alterações na qualidade do solo e dos indicadores relacionados durante o período de ocupação.

Entretanto, isto faria com que a avaliação do impacto do uso do solo fosse incompleta ao não considerar estas alterações por causa do mesmo processo de ocupação, e também por todo o tempo que essa determinada área ficaria impossibilitada de ser utilizada por outra atividade, causando assim impactos na sociedade.

O estado estável pode ser alcançado após a degradação do estado original do solo e é conhecido como o potencial de recuperação. O processo para obter este potencial de recuperação (de $C$ a $D$ ) é conhecido como re-naturalização.

Segundo Milà i Canals (2003) este processo de re-naturalização pode ser obtido mediante duas opções. A primeira é de maneira natural, deixando o solo se recuperar; a segunda ocorre mediante a utilização de backup tecnologias (MILÀ I CANALS; ROMANYA E COWELL, 2007), que ajudariam na recuperação da qualidade do solo.

Quaisquer destas duas opções podem ocorrer, porém a segunda sucede com maior frequência devido à rapidez com que se necessita de áreas de solo. 


\subsubsection{Estado de referência}

A magnitude dos impactos de transformação e ocupação é medida de acordo com as atividades do solo, bem como em relação ao estado de referência com o qual o estado atual é comparado. Desta forma sua escolha não pode ser arbitrária (SAAD. R. et al, 2011).

Em decorrência dos processos de transformação e ocupação do solo, dificilmente o solo retorna à sua qualidade original. Por isso, o estado de referência é objeto de várias discussões entre pesquisadores que estudam o impacto do uso do solo.

Algumas situações de referência foram desenvolvidas a partir de estudos voltados para a avaliação do uso do solo (MILÀ I CANALS, 2003; SETAC, 2002,).

De forma geral, as seguintes referências têm sido sugeridas:

- O estado natural do solo, antes de qualquer atividade humana;

- O estado do solo imediatamente antes da ocupação em questão;

- O estado do solo após a recuperação (clímax ou estado de equilíbrio do ecossistema).

Esta escolha é necessária no intuito de avaliar os efeitos dos danos causados pelo uso do solo na natureza. Por exemplo: "Como são os efeitos dos danos na natureza se as atividades atuais do sistema econômico são incrementadas pela produção de X unidades de um produto, causando incremento nas emissões?", ou seja, se a produção adicional de 1000 garrafas causa a emissão de $2 \mathrm{Kg}$ de SO2, o efeito do dano de emissão adicional destes dois quilogramas será comparado com a situação de referência antes de acontecer esta produção de 1000 garrafas adicionais, a fim de poder encontrar a rede de efeitos na produção a ser examinada. A mesma lógica deve ser utilizada na categoria de impacto do uso do solo.

Alguns autores (BRANDÃO; MILA I CANALS, 2012; LINDEIJER, 2000b; SAAD. R. et al, 2011;) sugeriram utilizar como estado de referência o estado natural do solo antes de qualquer tipo de intervenção humana. Entretanto, esta opção implicaria a alocação de todos os impactos de transformação desde o começo das atividades humanas à atividade recente (SETAC, 2002; WEIDEMA; LINDEIJER, 2001;). 
Baitz citado por Souza (2011) sugere o estado de referência imediatamente antes da atividade em estudo, opção criticada por alguns autores (LINDEIJER 2000b; SAAD. R. et al, 2011), que explicam que os impactos de uma atividade seriam alocados à atividade seguinte (considerando que o impacto de ocupação seja visto como um impacto que provoca o adiamento do processo de recuperação da área).

Em uma outra corrente, alguns autores (BLONK; LINDEIJER; BROERS, 1997; GOEDKOOP E SPRIENSMA, 2001; MICHELSEN, 1998) propõe como estado de referência a qualidade potencial após a recuperação do solo, a qual é uma forma prática de distinguir mudanças permanentes nas propriedades do solo das mudanças temporais.

Sem embargo calcular este potencial de recuperação é uma tarefa complexa por causa de todas as possíveis variáveis (temperatura, tipo de uso do solo, tipo de solo, tipos de manejos, umidade, períodos de chuvas, entre outros) que podem acompanhar este processo. Para tentar contornar esta adversidade, alguns modelos propõem o emprego de softwares, tais como ROTHC e CENTURY como ferramentas de apoio (MILÀ I CANALS, 2003).

A princípio, a melhor opção de estado de referência seja o potencial de recuperação, mas devido à grande quantidade de dados necessária, esta alternativa fica prejudicada, além da falta de banco de dados e a presença de possíveis cenários diferentes, que acarretariam em muitas subjetividades e imprecisões nos resultados. Devido a esta subjetividade, o estado de referência no estado natural ou o estado antes da transformação e ocupação do solo devem ser considerados pela facilidade na obtenção dos dados em relação ao potencial de recuperação do solo.

\subsubsection{Classes de Uso do Solo}

A maioria dos estudos desenvolvidos na Europa (GOEDKOOP; SPRIENSMA, 1999; KÖLLNER, 2003; LINDEIJER, 2000b; WEIDEMA; LINDEIJER, 2001) usam como base de dados o CORINE para a classificação dos tipos de usos do solo, envolvendo nessa tarefa 29 países na Europa.

A nomenclatura desse sistema de classificação é hierarquizada em três níveis; no nível I compreende as maiores categorias de cobertura da terra, tais como: 
- áreas superficiais;

- áreas agrícolas;

- florestas a áreas semi-naturais;

- áreas úmidas;

- corpos d'água.

No nível Il o enfoque é dado para as coberturas mais detalhadas de cada um dos níveis apresentados acima (estruturas urbanas, terras areáveis, culturas permanentes, pastagens, florestas, áreas úmidas interiores, áreas úmidas litorâneas, entre outros). Finalmente, no nível III informações mais detalhadas de cada item do nível II são tratadas.

No Brasil, este base de dados é fornecido pelo IBGE (Instituto Brasileiro de Geografia e Estatística), mediante o manual técnico de uso da terra. A primeira edição foi lançada em 1999 e a segunda no ano de 2006, sendo que esta última contêm reflexões sobre os conceitos mais atuais da classificação dos tipos de uso do solo, de acordo com a realidade brasileira.

O manual técnico de uso da terra realiza uma síntese do uso do solo, sendo orientada segundo a distribuição geográfica dos recursos, da sua apropriação social e das transformações ambientais, apresentando, ademais, os procedimentos técnicos de levantamento e mapeamento.

A publicação está estruturada em quatro partes: a primeira discute 0 referencial teórico-metodológico desta abordagem, tendo como foco a questão ambiental; a segunda parte contém os princípios básicos que nortearam o levantamento da cobertura e do uso da terra, a nomenclatura utilizada, acompanhada das definições dos termos empregados com base na literatura pertinente e a atuação do IBGE nessa área do conhecimento. Além disto, aborda o sistema de classificação concebido para categorizar os usos e a cobertura do solo; na terceira parte são descritos os métodos, instrumentos e técnicas adotados na análise espacial, distinguindo-se as etapas de trabalho de gabinete e as etapas de trabalho de campo, bem como os procedimentos para elaboração de cartas, mapas, legendas de mapeamento e edições cartográficas em diferentes escalas; a última parte discorre sobre o Sistema de Informação Geográfica (SIG) e o Banco de Dados (IBGE, 2006). 
As classes de cobertura e uso da terra no Brasil são divididas em três níveis. O nível I contém as classes:

- áreas antrópicas não-agrícolas;

- áreas antrópicas agrícolas;

- áreas de vegetação natural;

- água e;

- outras áreas.

O nível II contém as subclasses dos níveis anteriores apresentando informações da cobertura e uso da terra em escala regional. Adicionalmente se tem o nível III, que é mais detalhado e empregado em análises locais, pois apresentam características específicas do solo.

\subsubsection{Tempo de Recuperação do Solo}

Após a ocupação do solo, e se ele não estiver mais sujeito a outras ocupações, existe a possibilidade de sua recuperação. Isto pode ocorrer naturalmente ou de forma assistida pelo homem, e a recuperação ocorre até o momento em que a qualidade alcance o potencial de recuperação (MILÀ I CANALS, 2003) ou a qualidade no estado natural ou a qualidade antes de acontecer o processo de transformação e ocupação do solo (BRANDÃO; MILÀ I CANALS, 2012; GOEDKOOP e SPRIENSMA, 1999; LINDEIJER, 2000a).

Udo de Haes (2006) sugere que os fatores de caracterização em geral sejam definidos considerando-se um tempo infinito. Entretanto, para o caso do impacto do uso do solo isso significaria a recuperação total do solo em qualquer caso.

Pelo contrário, se for considerado um tempo muito pequeno como, por exemplo, um tempo zero, o impacto de ocupação seria superestimado e o de transformação seria subestimado (UDO DE HAES, 2006).

\subsubsection{Mecanismo Ambiental}

Segundo a ABNT NBR ISO 14040 (ABNT, 2009a), o mecanismo ambiental é o sistema de processos físicos, químicos e biológicos para uma determinada categoria de impacto, vinculando os resultados da análise do inventario do ciclo de vida aos indicadores de categoria e aos pontos finais da categoria. 
Outros termos utilizados para nomear os mecanismos ambientais são "Impact Chain" (KÖLLNER, 1997; LINDEIJERb, 2000) e "Environment Pathway" (SETAC, 2002).

Todo método de caracterização deve ser representado por meio de um diagrama, onde são explicados os mecanismos ambientais gerais, que incluem todas as principais intervenções e fluxos que formam parte do modelo.

A transformação e ocupação do solo ocasionarão mudanças nas propriedades do solo, alterando as funções de suporte de vida, a biodiversidade e também produzindo alterações que contribuem para outros tipos de categoria de impacto, como é o caso das mudanças climáticas, eutrofização, nitrificação e a ecotoxicidade. Neste sentido deve-se ter cuidado para não realizar uma dupla contagem no momento da avaliação.

O mecanismo ambiental da categoria uso do solo é apresentado na Figura 2.7 a seguir: 


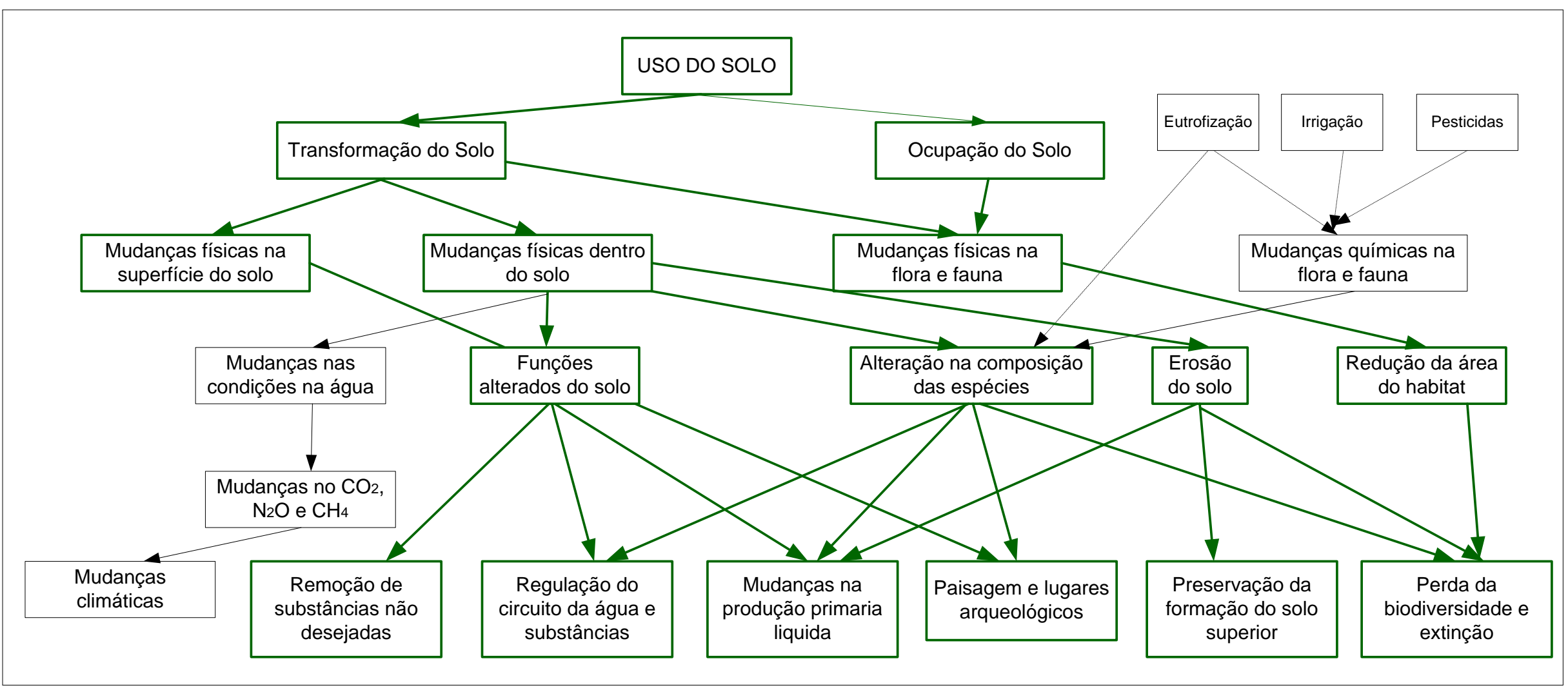

Figura 2. 7 - Mecanismo Ambiental General da Categoria de Impacto de Uso do Solo (Adaptado ILCD, 2010a). 
Como observado na Figura 2.7 existem varias alterações causadas pela transformação e ocupação do solo que direta ou indiretamente ocasionam mudanças em vários pontos; alguns deles relacionados ao Impacto do Uso do Solo e outros a diferentes categorias de impacto (mudanças no $\mathrm{CO}_{2}, \mathrm{~N}_{2} \mathrm{O}$ e $\mathrm{CH}_{4}$ causadas indiretamente pela transformação do solo ocasionarão mudanças climáticas).

Por outro lado, outros tipos de intervenções como irrigação e aplicação de pesticidas ocasionarão indiretamente perda na biodiversidade, alterações nas paisagens, circuito da agua, circuito de substancias, entre outros, que geralmente são alterações atribuídas ao uso do solo.

Por esta razão é necessário ter extremo cuidado para evitar duplas contagens na realização da avaliação deste impacto ambiental do Uso do Solo.

\subsubsection{As Áreas Afetadas pelo Uso do Solo}

Segundo a SETAC (2002), as áreas de proteção afetadas pelos impactos relacionados ao uso do solo são:

- Degradação da biodiversidade;

- Degradação das funções de suporte de vida;

- Degradação dos valores culturais.

A transformação e ocupação do solo causam impactos na biodiversidade e nas funções de suporte de vida, isto porque o propósito da utilização do solo é mantê-lo em condições não naturais, causando assim sua degradação.

\section{a. Biodiversidade}

O termo biodiversidade ou diversidade biológica é definido como (MMA, 2010) a variabilidade entre organismos vivos, de todas as origens, compreendendo, entre outros, ecossistemas terrestres, marinhos e outros aquáticos e os complexos ecológicos dos quais fazem parte, incluindo a diversidade entre indivíduos de uma mesma espécie ou entre espécies diferentes e ecossistemas.

A biodiversidade tem valor intrínseco ${ }^{1}$ no ecossistema (KÖLLNER, 1999), mantendo uma relação estreita com seu funcionamento e regulando a variabilidade

\footnotetext{
${ }^{1}$ Valor intrínseco é o valor que algo contém, independente de sua função secundária ou consequências de sua aplicação, ou seja, seu valor se encontra em si mesmo (LINDEIJER, 2000b).
} 
de seus processos. Portanto, para analisar os impactos do uso do solo, é importante considerar as propriedades físicas, químicas e biológicas como espécies de animais e plantas (MATTSSON; CEDERBERG; BLIX, 2000).

A maior parte dos métodos que avaliam o impacto do uso do solo na biodiversidade justifica o uso das plantas vasculares pela correlação que têm com a área ocupada.

Assim, Arrhenius, em 1921, demonstrou a estreita relação entre o tamanho da área e a diversidade de espécies, expressa por meio da Equação 2.3 (GOEDKOOP; SPRIENSMA, 1999).

$$
S=a^{\star} A^{b}(2.3)
$$

Onde:

S: Diversidade de espécies $\left(\mathrm{m}^{2}\right)$;

a: Fator de riqueza das espécies;
A: Área $\left(m^{2}\right)$;
b: Fator de acumulação de espécies.

Os fatores "a" e "b" são específicos para cada tipo de uso do solo. Além disso, "b" também dependerá do tamanho da área.

A biodiversidade é dividida em três elementos (KÖLLNER, 1999; SETAC, 2002):

- diversidade genética refere-se à mistura de diferentes genes contidos numa população de espécies, e a variação encontrada dentro de diferentes populações de uma mesma espécie;

- diversidade de ecossistemas refere-se à variedade de habitats em uma região ou o mosaico de pequenas parcelas encontradas dentro de uma paisagem;

- diversidade de espécies refere-se à variedade e abundancia de diferentes tipos de organismos que habitam uma área determinada.

Este último elemento diversidade de espécies, é o mais utilizado nos métodos sobre biodiversidade. 


\section{b. Funções de Suporte de Vida (FSV)}

No caso das FSV, estas cumprem papel importante no ecossistema no sentido de manter os processos naturais com o fim de suportar a vida humana e a não humana. Algumas destas funções são: o ciclo de nutrientes, produção da biomassa, capacidade de filtração do solo, regulação do clima, entre outros.

Devido às suas propriedades, o solo dá suporte a várias funções. A seguir apresenta é feita uma descrição breve de algumas dessas funções (MILA E CANALS, ROMANYA e COWELL, 2007).

\section{Reguladores do clima na terra}

O clima na terra é influenciado pelas emissões lançadas na atmosfera, mas o reconhecimento da influência do uso do solo vem aumentando, por causa da função que este exerce como sumidouro do carbono e como emissor de $\mathrm{N}_{2} \mathrm{O}$. Pensando em escala local, temos a cobertura vegetal que é influenciada pelas propriedades do solo (e vice versa) e cumpre um papel importante na influência do clima:

- mudanças na evaporação e transpiração;

- absorção do calor solar;

- velocidade do vento, entre outros.

\section{Manutenção do ciclo das substâncias}

Muitos estágios destes ciclos acontecem dentro e na superfície do solo. Como é o caso da água, cujo processo acontece na superfície, mas também é influenciada pela estrutura e porosidade do solo (MILÀ I CANALS, 2003).

\section{Produção da Biomassa}

A produção da biomassa vai depender da extensão da área produtiva e da capacidade intrínseca do solo, a qual depende da qualidade da camada superior e é conhecida como produtividade do solo.

A produtividade do solo é afetada pelas propriedades do solo, podendo ser destacadas: o conteúdo de nutrientes, a estrutura (permitir a penetração das raízes), a capacidade de retenção da água, a atividade microbiana e a resistência à erosão, a matéria orgânica do solo (MOS), entre outros. 


\subsubsection{Métodos de avaliação de Impacto do Uso do Solo}

Neste ponto realizar é feita uma breve descrição de métodos que avaliam o impacto do uso do solo na Biodiversidade e nas FSV.

\section{a. Métodos para o caso da Biodiversidade}

- Método de Müller-Wenk (1998): Propõe a avaliação do Impacto do Uso do Solo sobre o ecossistema utilizando como parâmetro a porcentagem de espécies de plantas vasculares ameaçadas de extinção tendo como base de dados as listas vermelhas em que as espécies são classificadas em cinco categorias (não ameaçadas de extinção, raras ou potencialmente vulneráveis, em perigo de extinção, extintas e como vulneráveis).

O método apresenta uma análise quantitativa da parcela de solo suíço que deveria ser convertido para uso extensivo, de forma a obter uma redução do número atual de espécies ameaçadas no país, considerando para a avaliação dois tipos de uso do solo natural e não natural (alta e baixa intensidade).

- Método de Goedkoop e Spriensman (2001): Calcula o dano do ecossistema mediante a Fração de Espécies Potencialmente Desaparecidas (PDF).

Os dados para este método de Impacto do Uso do Solo são baseados em dados empíricos, ou seja, em observações de número de espécies de plantas vasculares em diferentes tipos de cobertura de solos, utilizando para isso a classificação de uso de solo segundo a CORINE.

O método propõe a avaliação do impacto do uso do solo a uma escala regional e local.

- Método de Köllner (1999): Mede a riqueza das espécies de plantas vasculares, sendo que estas densidades dependem do tipo de uso do solo na área de estudo, utilizando a base de dados CORINE e outras publicações na Suíça ("Swiss Area Statistics" e "Hegg Atlas of Threatened Vegetation Types"). Duas etapas são feitas no método: uma primeira qualitativa, em que se realiza a correlação entre as atividades de uso do solo e os respectivos impactos ao ecossistema (representado pela perda das espécies);a segunda, 
quantitativa que quantifica os impactos do uso do solo na diversidade de espécies.

- Método de Vogtlander et al. (2004): Propõe a avaliação da Biodiversidade mediante dois parâmetros: riqueza das espécies e a raridade dos ecossistemas utilizando como indicador as plantas vasculares. Utiliza os tipos de uso do solo propostos na base de dados CORINE.

- Método de Schmidt (2008): Utiliza como indicador a diversidade de espécies de plantas vasculares. Para avaliar a Biodiversidade propõe o parâmetro de vulnerabilidade dos ecossistemas.

- Método de Michelsen (2008): Adota a utilização de três parâmetros para avaliar a Biodiversidade: o indicador de escassez do ecossistema, o indicador de vulnerabilidade do ecossistema e as condições da biodiversidade mantida.

Os métodos encontrados na literatura sobre a biodiversidade coincidem na utilização de plantas vasculares como indicadores, pois apresentam um alto grau de correlação com outras espécies. Além disso, ocupam uma posição central na vida terrestre como transmissoras de energia solar (GOEDKOOP; SPRIENSMA, 2001).

A utilização de outros grupos taxonômicos por parte dos autores reduziria as a subjetividade dos resultados destes métodos que utilizam como único indicador as espécies por plantas vasculares. Estes novos grupos taxonômicos deverem ser a nosso modo de ver espécies que sejam nativas e que possam representar a realidade de cada País onde se realiza o estudo.

\section{b. Métodos para o caso das FSV}

- Método de Lindeijer (2000a): Propõe trabalhar com a Free Net Primary Production $^{2}$ (fNPP). A fNPP corresponde a todo o NPP (Net Primary

\footnotetext{
${ }^{2}$ O fNPP é quantidade da biomassa que a natureza pode livremente aplicar para seu próprio desenvolvimento (LANGLOIS et. al., 2011).
} 
Production) que cresceu sobre a área ocupada $A$, menos a parte da NPP que é retirada da área $A$, como produtos da agricultura ou da silvicultura.

O fNPP contribui nas funções de suporte de vida, mediante a produtividade e a capacidade de renovação do solo.

- Método de Mila i Canals (2003): O indicador utilizado no método é MOS, conjunto de compostos orgânicos presentes no solo sendo representado pelos resíduos vegetais em vários estágios de decomposição (FAO, 2005).

$O$ estado de referência utilizado no método é o estado natural do solo. Quanto ao tempo de recuperação, depende das condições da região onde se está realizando a avaliação.

$\mathrm{Na}$ avaliação dos impactos nas FSV são utilizados tipos de uso do solo, tais como: prados e pastagens permanentes, cultivos em longo prazo, entre outros.

- Método de LANCA (2008): O método foi desenvolvido no Departamento de Engenharia do Ciclo de Vida da Universidade de Stuttgart (LBP - GaBi). No método foram escolhidos cinco indicadores para avaliar uso do solo nos serviços do ecossistema, baseados em parâmetros específicos do solo e do clima, tais como tipos de solo, conteúdo de húmus, precipitações ou evapotranspiração.

Para esses parâmetros considerou-se os impactos de transformação e ocupação. O método tem como objetivo quantificar os efeitos dos diferentes usos do solo ou funções do solo, adotando como variáveis a área e o progresso da qualidade.

- Método de Brandão e Mila i Canals (2012): Propõe a utilização de COS, componente principal da MOS, para o cálculo de fatores de caracterização na transformação e ocupação do solo.

Considera que o COS é fortemente influenciado pelo tipo de solo, clima, pela gestão do solo e pelo tipo de uso do solo. 
Devido à quantidade de FSV é difícil conceber um modelo quantitativo que contemple todas estas funções no impacto de transformação e a ocupação do solo, haja vista aa quantidade de indicadores que se propõe a avaliar suas diferentes propriedades.

Diante disto, é importante procurar um método que se ajuste as necessidades da região onde se quer adaptá-lo. Nos métodos encontrados, avalia-se principalmente a produtividade do solo, utilizando para este fim diferentes indicadores como: Free Net Primary Production (fNPP), indicador "Midpoint" da produtividade (LINDEIJER, 2000a) ou a utilização da Matéria Orgânica do Solo (MOS) (MILÀ E CANAL, 2003).

Depois de todo o exposto neste capitulo, pode-se observar que a descrição e avaliação dos impactos ambientais relacionados ao uso do solo é uma tarefa extremamente complexa, uma vez que envolve inúmeras variáveis, parâmetros e indicadores, que em alguns casos são difíceis de serem expressos de forma qualitativa ou quantitativa. Diante deste cenário, ainda não existe uma padronização, ocasionando assim grandes discussões quanto ao seu uso em estudos de ACV.

Este é o caso do Uso do Solo que apresenta dificuldades na sua avaliação uma das causas é a dependência do conhecimento regional, que devido a pouca disponibilidade de dados e a adequação de informações disponíveis se tornaria um fator limitante.

Por tal razão, foram escolhidos os método de Lindeijer (2000a), o Projeto LANCA (2008) e o método de Brandão e Mila i Canals (2012) por oferecerem melhor acessibilidade de informação, requisito fundamental para o estudo e análise dos mesmos. 


\section{METODOLOGIA}

Neste capítulo será descrito quais foram os parâmetros utilizados para a seleção dos métodos aplicados no presente estudo. Após, a descrição destes métodos serão apresentados os critérios para comparação e análise dos mesmos, para auxiliar na definição dos passos a serem adotados para a obtenção de fatores segundo as condições brasileiras na avaliação da categoria de impacto uso do solo.

\subsection{SELEÇÃO DAS REFERÊNCIAS}

Durante a revisão da literatura se observou que o Impacto do Uso do solo atinge a duas grandes áreas que são a Biodiversidade e as FSV, para cada uma delas foram desenvolvidas métodos com o fim de avaliar as mudanças que são ocasionadas pelo uso do solo.

Encontraram-se assim vários métodos, especialmente os que avaliam a área da Biodiversidade realizando-se assim uma breve descrição destes no final do capitulo 2. Estes métodos utilizam vários conceitos relacionados a temas como Ecologia, Biologia, entre outros. Além disso, os indicadores da Biodiversidade como a riqueza das espécies, vulnerabilidade ou raridade dos ecossistemas, são de difícil quantificação, pois requerem conhecimentos aprofundados sobre estes temas para assim conseguir uma visualização mais ampla de como converter estas características a valores numéricos.

Como os conhecimentos sobre estes temas estão fora de foco da área de concentração no qual se desenvolve este trabalho foi adotado que o estudo comtemplaria os métodos sobre as FSV por serem mais quantificáveis e porque tomam em consideração as diversas propriedades (físicas, químicas e biológicas) do solo que influenciam em atividades socioeconômicas do homem.

Para os métodos que avaliam a área de FSV, também se realizaram descrições resumidas de cada um deles, escolhendo-se três para serem comparados e analisados com o fim de obter o método que melhor se ajuste à realidade do Brasil como foi exposto no final do capitulo 2 .

Escolheram-se três métodos, pois se acredita que eles têm uma boa descrição da metodologia empregada assim como também de uma boa qualidade 
de informação que os tornam mais acessíveis. No ponto a seguir estes métodos são detalhados.

\subsection{ESTUDO DOS MÉTODOS}

Neste ponto descrevem-se três métodos que avaliam o Impacto do Uso do Solo nas FSV. Para uma boa compreensão de cada um deles se padronizou a forma da apresentação como é mostrado nos pontos a seguir:

- Indicador utilizado: Aqui é definido o indicador ou indicadores utilizados no método e como este atua no mecanismo ambiental nas FSV.

- Cálculo do impacto de transformação do solo: Aqui se descreve como é realizado no método o cálculo do impacto de transformação de acordo com o indicador utilizado.

- Cálculo do impacto de ocupação do solo: Descreve-se como é realizado no método o cálculo do impacto de ocupação de acordo com o indicador utilizado.

- Estado de referência: Aqui se mostra o estado de referência escolhido em cada um dos métodos e as bases de dados empregadas na obtenção de valores utilizados.

- Tipos de usos do solo: Descreve-se que tipos de usos de solos são empregados e qual base de dado foi utilizada.

- Tempo de Recuperação: Neste ponto se descreve quais são os tempos de recuperação que os autores utilizam ou quais são considerações para o cálculo destes tempos.

É importante ressaltar que os modelos apresentados são aqueles em que foram empregados indicadores que avaliem as FSV. Como se mostro no capítulo anterior, outros indicadores relacionados à qualidade da Biodiversidade são de importância. Entretanto, por uma questão de foco, não serão abordados neste trabalho. 


\subsubsection{Método de Lindeijer (2000a)}

\section{a. Indicador utilizado}

Utiliza como indicador o Free Net Primary Production (fNPP) que em português é a Produção Primaria Liquida (PPL).

Antes de entrar no conceito da PPL, temos que conhecer que de toda a radiação fotossintética ativa, parte é refletida, outra absorvida pela vegetação, parte perdida como calor e outra é convertida pela atividade fotossintética em substâncias orgânicas, este fluxo é conhecido como Produção Primaria Bruta (PPB). Por essa razão o PPB é a quantidade de biomassa produzida através da fotossíntese por unidade de área por tempo pelos vegetais. Geralmente expressa em unidade de energia (exemplo: Joules $\mathrm{m}^{-2} \mathrm{dia}^{-1}$ ) ou de matéria orgânica seca produzida (exemplo: $\mathrm{kg} \mathrm{m}^{-2}$ ano $^{-1}$ ) (ODUM, 2011).

Definido a PPB podemos proceder a definir a PPL que é a taxa de armazenamento de matéria orgânica nos tecidos vegetais, o excedente após a respiração pelas plantas (ODUM, 2011). É dizer, parte desta energia armazenada pela vegetação é utilizada no próprio metabolismo (respiração autotrófica) sendo que o balanço entre a fixação de carbono na fotossíntese - PPB, e aquele perdido pela respiração vegetal $-R$, é a Produção Primaria Liquida (PPL).

Temos, portanto, na Figura 3.1 como é representada a PPL:

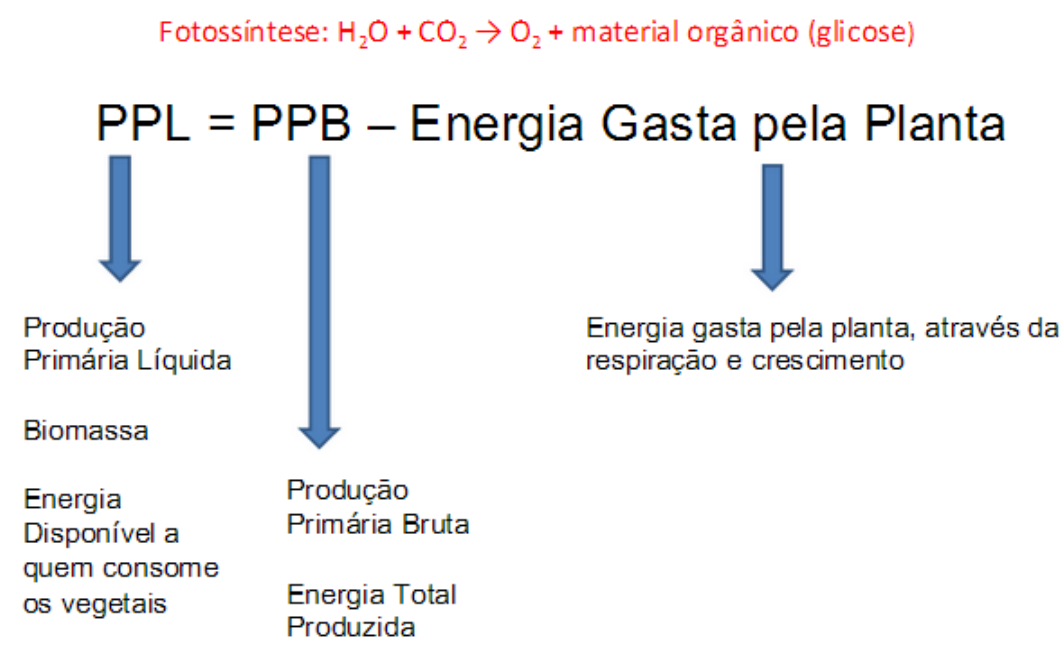

Figura 3. 1 - Conceito do PPL. 
Para determinar a PPL são considerados os itens a seguir (TONELLO, 2007):

- Produção: Incorporação do carbono atmosférico na biomassa vegetal.

- Senescência: Folhas e galhos morrem, mas permanecem ainda presos à planta.

- Separação: o material morto separa-se da planta e é incorporado na camada da serapilheira.

- Decomposição da serapilheira por microrganismos: parte é liberada como $\mathrm{CO}_{2}$ para a atmosfera e parte é incorporada na biomassa microbiana ou no solo como matéria orgânica.

A PPL é utilizada neste método para avaliar as FSV. Este indicador mede a capacidade produtiva e a renovação do solo evitando assim dupla contagem com outros indicadores (como o caso da biodiversidade e mudanças climáticas). Além disso, A PPL tem uma relação linear com a quantidade de biomassa que se acumula no solo, indicando desta forma o nível do ciclo de carbono potencial no solo. Por esses motivos é justificada a utilização deste indicador.

\section{b. Impacto de Transformação}

O impacto nas funções de suporte de vida no caso da transformação é se apresenta na equação 3.1 a seguir.

$$
\mathbf{E C}_{\mathrm{LS}}=\mathbf{A} \times\left(\mathbf{P P L}_{\mathrm{ini}}-\mathbf{P P L}_{\mathrm{fin}}\right)
$$

Onde:

$E_{L s} \quad$ : Impacto de transformação no ecossistema

A : Área ocupada.

$\mathrm{PPL}_{\text {ini }} \quad$ : PPL inicial antes de acontecer a transformação.

$P P L_{\text {fin }} \quad: P P L$ final.

\section{c. Impacto de Ocupação}

A forma de cálculo para os impactos nas funções de suporte de vida no caso da ocupação o que se apresenta na equação 3.2 a seguir: 


$$
\mathbf{E O}_{\mathrm{LS}}=\mathbf{A} \times \mathbf{t} \times\left(\mathbf{P P L}_{\mathrm{ref}}-\mathbf{P P L}_{\mathrm{act}}\right)
$$

Onde:

EO : : Impacto de ocupação no ecossistema.

A : Área ocupada.

t : : Tempo de ocupação.

$P^{P P L_{\text {ref }}} \quad$ :PPL de referência.

PPL $_{\text {act }} \quad$ : PPL atual.

\section{d. Estado de Referência e tipos de uso do solo}

Os valores de referência são extraídos de publicações científicas em artigos, baseado em fatores abióticos importantes tais como: altitude, latitude e quantidade de chuva.

Os valores do PPL são estimados para um número especifico de tipos de uso do solo. Por tanto valores para a ocupação e transformação são gerados.

A seguir na Tabela 3.1 e na Tabela 3.2 são mostrados valores para o PPL (t. $\mathrm{ha}^{-1}$. ano ${ }^{-1}$ ) para o caso da transformação e na ocupação.

Tabela 3. 1 - A PPL para o caso da transformação (t. ha ${ }^{-1}$.ano ${ }^{-1}$ ) (LINDEIJER, 2000a).

\section{CASO DE TESTE}

Extração de areia no solo agrícola da Europa.

Mineração de alumínio em florestas tropicais na Sul América.

Aterro de lixo doméstico no solo agrícola da Europa.
PPL (ini) PPL(fin)

$8 \quad 0-8^{*}$

17

8

*são valores que dependem fortemente da situação local. 
Tabela 3. 2 - A PPL para o caso da ocupação (t. ha-1 .ano $^{-1}$ ) (LINDEIJER, 2000a).

\begin{tabular}{lll}
\multicolumn{1}{c}{ CASO DE TESTE } & PPL (Ref) & PPL (act) \\
\hline $\begin{array}{l}\text { Extração de areia no solo agrícola } \\
\text { da Europa. }\end{array}$ & 8 & 0 \\
\hline $\begin{array}{l}\text { Produção industrial no solo agrícola da } \\
\text { Europa. }\end{array}$ & 8 & 1 \\
\hline $\begin{array}{l}\text { Hidrelétrica nas colinas de Escandinávia. } \\
\text { Rodovias no solo agrícola da Europa. }\end{array}$ & 17 & 0 \\
\hline $\begin{array}{l}\text { Mineração de alumínio em florestas tropicais } \\
\text { na Sul America. }\end{array}$ & 8 & 2 \\
\hline $\begin{array}{l}\text { Colheita de madeira nas colinas de } \\
\text { Escandinávia. }\end{array}$ & 17 & 0 \\
\hline $\begin{array}{l}\text { Aterro de lixo doméstico no solo agrícola da } \\
\text { Europa. }\end{array}$ & 8 & 7 \\
\hline
\end{tabular}

\section{e. Tempo de recuperação}

Não especifica nenhum tempo de recuperação, tempo no qual o solo alcançaria o estado de referência.

\subsubsection{Método de LANCA (2008)}

O modelo foi desenvolvido na universidade de Stuttgart no departamento de Engenharia do Ciclo de vida (LBP - GaBi). No método foram escolhidos cinco indicadores para avaliar uso do solo nos serviços do ecossistema, baseados em parâmetros específicos como clima, tipos de solo, conteúdo de húmus, precipitações, entre outros.

O método tem o objetivo quantificar os efeitos dos diferentes usos e funções do solo, por isso os parâmetros a serem utilizadas são a área e o progresso da qualidade.

\section{a. Indicadores Utilizados}

Utilizaram-se cinco indicadores que serão apresentados a seguir: 


\section{- Resistência na Erosão}

Especifica a habilidade do solo para resistir à erosão que acontece naturalmente. A erosão é dependente da textura do solo e o tipo de uso.

A erosão pode ter influencia negativa sobre a produção biótica potencial e pode contribuir na devastação completa do solo arável.

O cálculo é baseado na equação de perda universal de solo que calcula a erosão hídrica media anual multiplicada por diferentes fatores. Dentre os quais temos os seguintes:

- textura do solo;

- inclinação $\left({ }^{\circ}\right)$;

- precipitações no verão (mm/a);

- tipos de uso do solo;

- conteúdo da estrutura (\%volume);

- conteúdo do húmus (\% em peso);

- tipo de superfície.

Na Figura 3.2 se apresentam os passos a serem realizados para calcular a Resistência da Erosão:

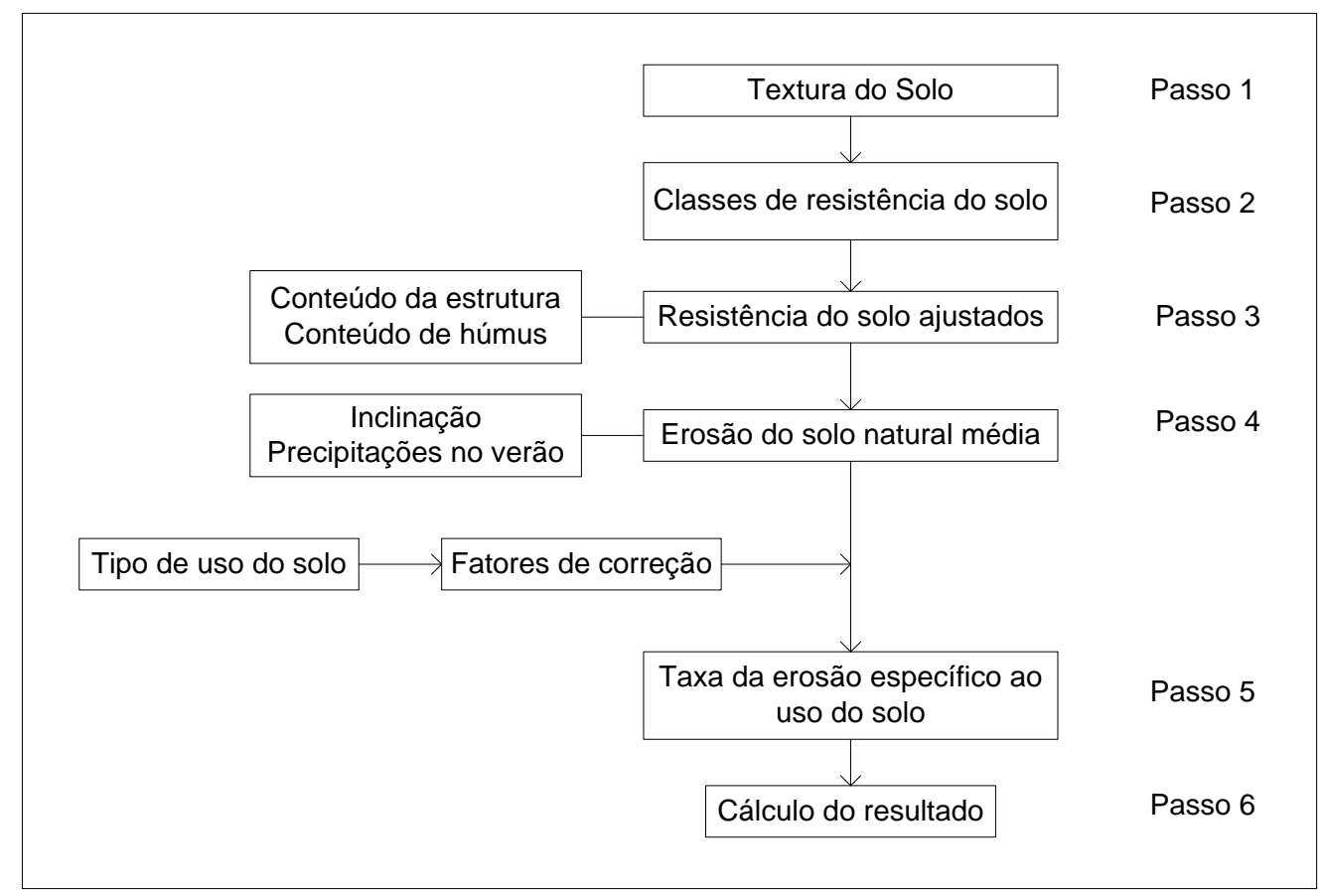

Figura 3. 2 - Passos para o cálculo na Resistência na Erosão 


\section{- Filtração Mecânica}

Capacidade do solo para clarificar mecanicamente uma suspensão. No processo de filtração, suspende-se a sujeira e partículas poluentes são mecanicamente fixadas no solo. A capacidade de filtração é calculada pela quantidade de água capaz de passar no solo em uma determinada unidade de tempo.

Os passos a serem desenvolvidas para o cálculo deste indicador as seguintes entradas são necessários:

- textura do solo;

- $\quad$ superfície de distância de águas subterrâneas (m);

- tipo de uso do solo.

Na Figura 3.3 apresentam-se os passos a serem realizados para calcular a filtração mecânica:

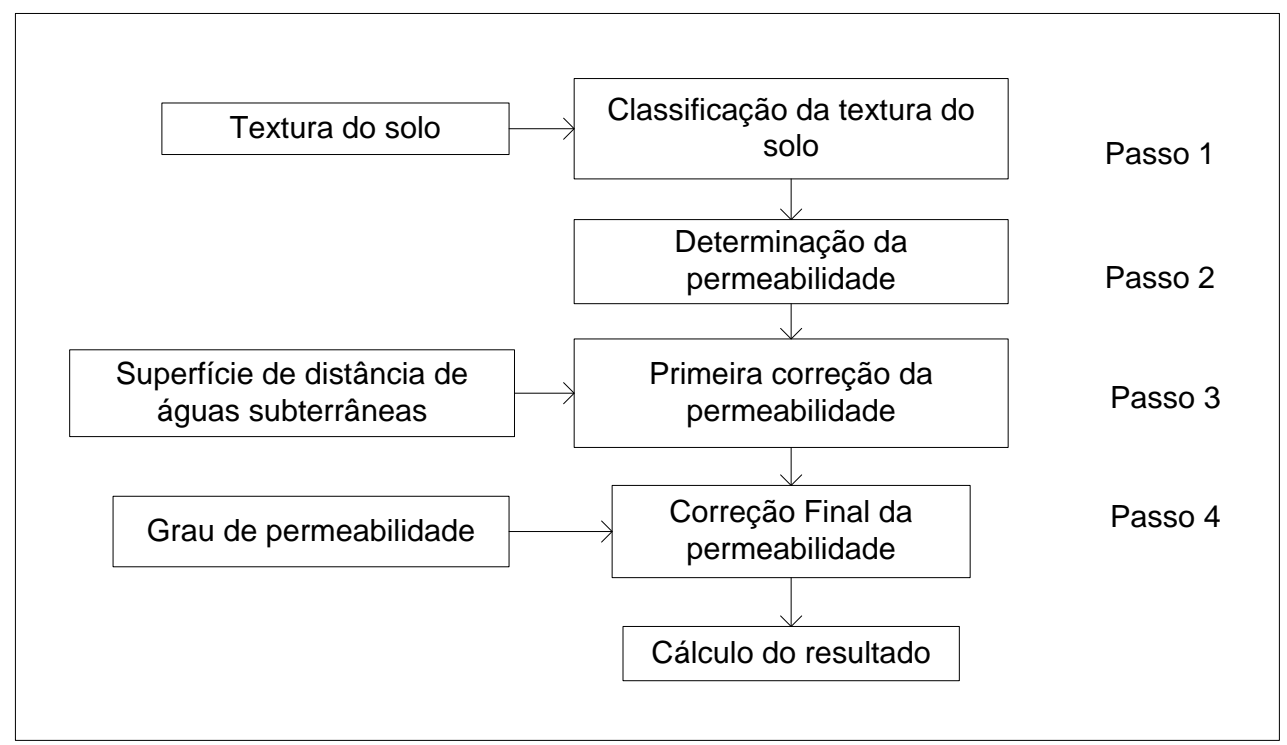

Figura 3. 3 - Passos para o cálculo para a filtração mecânica

\section{- Filtração Física - Química}

Habilidade do solo para absorver substâncias diluídas e na troca de íons dissolvidos. Os passos a serem desenvolvidas para o cálculo deste indicador as seguintes entradas são necessários:

- capacidade de troca de cátions efetiva CECeff (cmol/kgsolo). 
- tipo de uso do solo.

Na Figura 3.4 apresentam-se os passos a serem realizados para calcular a filtração físico-química:

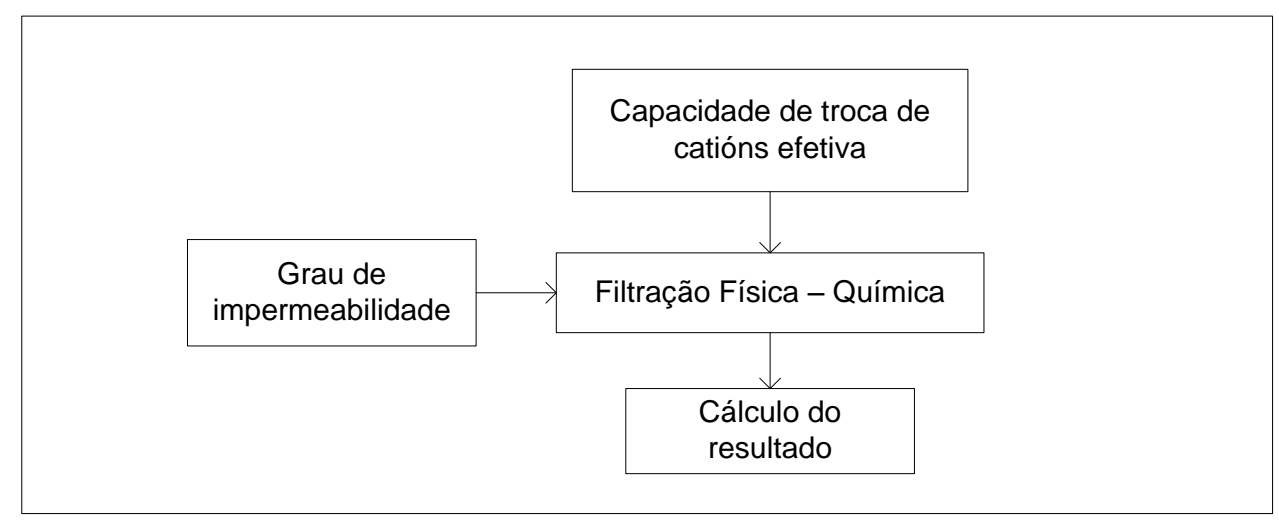

Figura 3. 4-Passos para o cálculo para a filtração físico-química.

\section{- Produção Biótica}

A função principal ecológica da produção da biota é a capacidade que tem o ecossistema de prover biomassa. A produção da biota é calculada através da "Net primary production".

Na Figura 3.5 apresentam-se os passos a serem realizados para calcular o indicador.

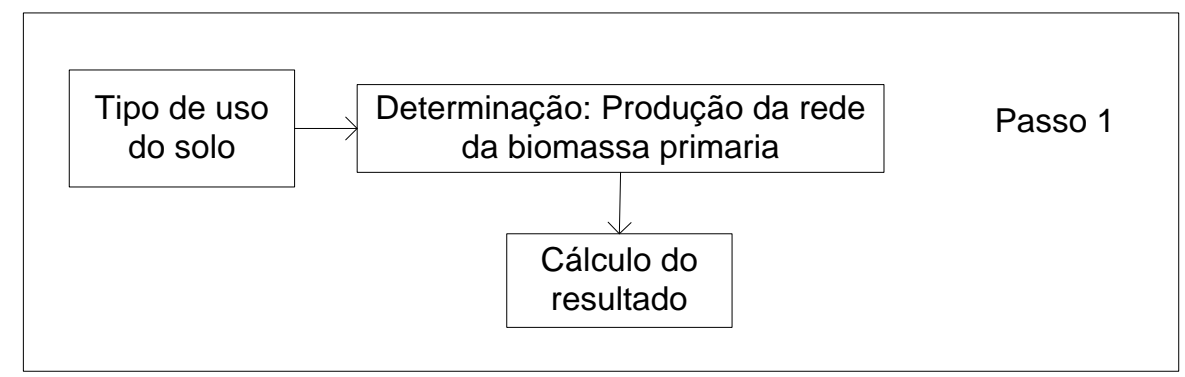

Figura 3. 5 - Passos para o cálculo para a Produção da Biota.

\section{- Reposição de águas subterrâneas}

É habilidade do solo para repor as águas subterrâneas devido à estrutura da vegetação, condições climáticas e camadas permeáveis. As entradas requeridas são as seguintes: 
- textura do solo;

- tipos de uso do solo;

- precipitação;

- evapotranspiração;

- distancias Reposição de águas subterrâneas:

- inclinação.

$\mathrm{Na}$ Figura 3.6 apresentam-se os passos a serem realizados para calcular o indicador.

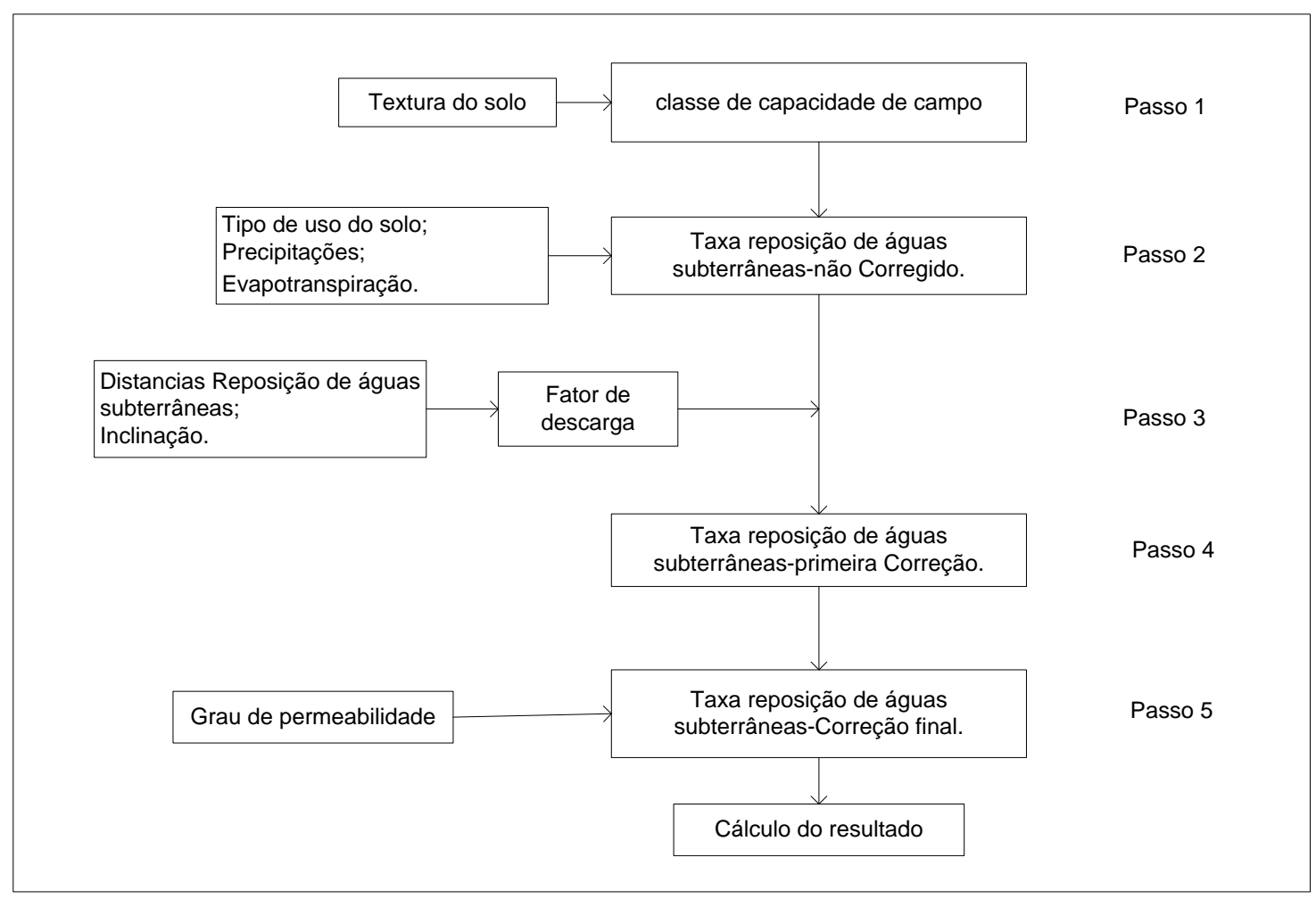

Figura 3. 6 - Passos para o cálculo para Reposição de águas subterrâneas.

\section{b. Impacto de Transformação}

A Equação 3.3 é utilizada para calcular o método que avalia o impacto de transformação:

$$
\mathbf{I}_{\text {trans }, n^{n}}=\left|\Delta \mathbf{Q}_{\text {trans }, n^{n}}\right| * \mathbf{c}=\left|\mathbf{q}_{\mathbf{n}}\left(\mathbf{t}_{4}\right)-\mathbf{q}_{\mathbf{n}}\left(\mathbf{t}_{1}\right)\right| * A * \mathbf{c}
$$

Onde: 
Itrans, $\quad$ :Impacto de transformação para determinado indicador $\mathrm{n}$;

$\Delta Q_{\text {trans, } n} \quad$ : Variação da qualidade durante a transformação com o indicador $\mathrm{n}$;

$q_{n} \quad$ : Qualidade com o indicador $\mathrm{n}$ para um determinado tempo;

A : área utilizada;

c : Fator de caracterização.

\section{c. Impacto de Ocupação}

A Equação 3.4 é utilizada para calcular o método que avalia o impacto de ocupação:

$$
I_{\text {occ } n \text { n }}=\left|\Delta Q_{\text {occin } n}\right| * c=\left(\mid q_{n}(\text { ref })-q_{n}\left(t_{2}\right) \mid * A * t_{\text {use }}\right) * c
$$

Onde:

Iocc,n : : Impacto de ocupação para determinado indicador $\mathrm{n}$;

$\Delta Q_{o c c, n} \quad$ : Variação da qualidade durante a Ocupação com o indicador n;

$q_{n} \quad:$ Qualidade com o indicador $\mathrm{n}$ para um determinado tempo;

A : área utilizada;

$t_{\text {use }} \quad$ : Tempo da ocupação do solo;

c : Fator de caracterização.

O fator de caracterização 'c' utilizado para cada um dos indicadores é dado na Tabela 3.3 a seguir:

Tabela 3. 3 - Escolha dos Fatores de Caracterização (LANCA, 2008).

\begin{tabular}{lcc}
\multicolumn{1}{c}{ INDICADOR } & $\Delta \mathbf{Q}<0$ & $\Delta \mathbf{Q}>\mathbf{0}$ \\
\hline Resistência à Erosão & -1 & 1 \\
\hline Filtração Mecânica & 1 & -1 \\
\hline Filtração Química & 1 & -1 \\
\hline $\begin{array}{l}\text { Reposição de Águas } \\
\text { Subterrâneas }\end{array}$ & 1 & -1 \\
\hline Produção da Biota & 1 & -1 \\
\hline
\end{tabular}

Cada um destes fatores da tabela 3.3 são multiplicados aos resultados calculados com cada um dos indicadores propostos, obtendo assim os benefícios ou estragos causados em cada um deles. 


\section{d. Estado de Referência}

O estado de referência será o estado do solo antes do uso de acordo a cada indicador.

\section{e. Tipos de Uso do Solo}

Existem 36 tipos de solo utilizados, dentre os quais podemos citar: solos de pastagem, agrícolas, urbanos, industriais, entre outros. Estes são mencionados no documento (LANCA, 2008).

\subsubsection{Método de Brandão e Milà i Canals (2012)}

Mencionam que a qualidade do solo está relacionada principalmente com as FSV. Os autores propõem a avaliação da produtividade do solo por ser considerado um serviço do ecossistema importante para a humanidade.

\section{a. Indicador utilizado}

O indicador utilizado no método é a MOS, que é o conjunto de compostos orgânicos presentes no solo sendo representada pelos resíduos vegetais em vários estágios de decomposição (FAO, 2004).

O processo de formação de MOS começa com a síntese de matéria orgânica a partir de $\mathrm{CO} 2$ atmosférico durante o processo de fotossíntese que ocorre nos vegetais (FAO, 2004).

O carbono assim fixado ao longo do crescimento da planta é depois depositado (folhas) ou incorporado (raízes) no solo durante o crescimento e a morte do vegetal.

Para entender melhor este mecanismo na Figura 3.7 apresenta-se o ciclo do carbono no meio ambiente. 


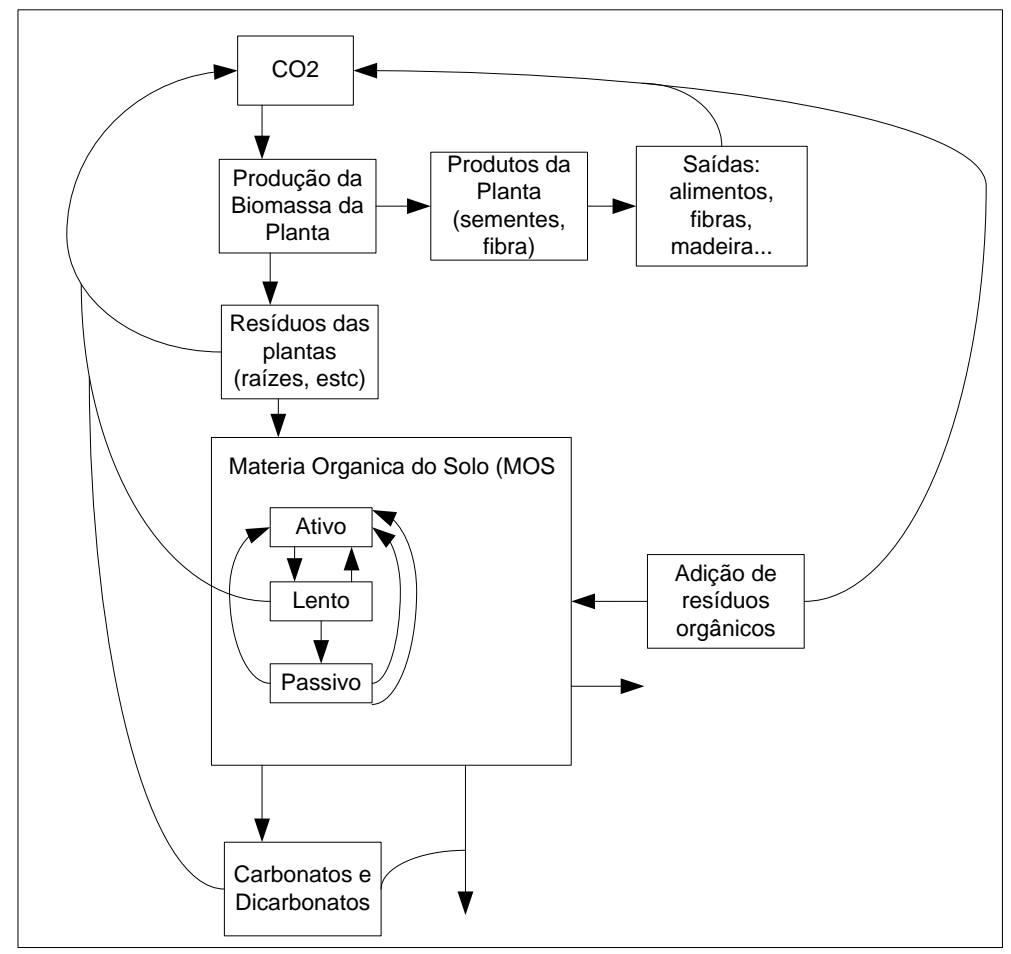

Figura 3. 7 - Ciclo do Carbono (Adaptado MILÀ I CANALS, 2003).

Como mostrado na Figura 3.7, as mudanças no manejo e manutenção dos resíduos culturais podem auxiliar no incremento e restauração dos níveis de carbono orgânico do solo.

A obtenção dos valores da MOS podem ser feitos por (MILA I CANALS, 2003):

- medida diretamente de amostras do solo;

- calculado mediante modelos;

- valores estimados da literatura para diferentes áreas de cultivo.

Por essa razão valores obtidos de amostras devem ser utilizados assim que puder. Mas quando não se tem aceso se procederá à utilização de valore obtidos mediante modelos ou valores encontrados na literatura.

Por outro lado a MOS pode ser expressa mediante a análise do COS (carbono orgânico do solo), que é 58\% da MOS (FAO, 2005).

\section{b. Para o caso da Transformação do solo}

Apresenta-se na Equação 3.3 a seguir: 


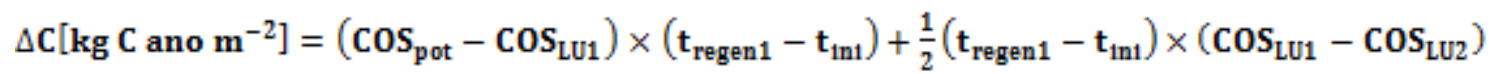

Onde:

$\Delta \mathrm{C} \quad$ : Variação do carbono orgânico do solo.

$\mathrm{COS}_{\text {pot }} \quad$ : Carbono orgânico do solo em um nível potencial.

$\operatorname{COS}_{\text {LU1 }}$ : Carbono orgânico do solo antes da transformação e ocupação do solo.

COS $\quad$ : Carbono orgânico do solo na ocupação do solo.

tregen1 : : Tempo que o sistema necessita para alcançar o COS potencial.

tini : : Momento onde se inicia a transformação e ocupação.

\section{c. Para o caso da Ocupação do solo}

Apresenta-se na Equação 3.4 a seguir:

$$
\Delta \mathrm{C}\left[\mathrm{Kg} \mathrm{C} \text { ano m}^{-2} \mathrm{ano}^{-1}\right]=\frac{\left(\cos _{\mathrm{pot}}-\cos _{\mathrm{LU2}}\right) \times\left(\mathrm{t}_{\mathrm{fin}}-\mathrm{t}_{\mathrm{In}}\right)}{\mathrm{t}_{\mathrm{fin}}-\mathrm{t}_{\mathrm{In}}}(\mathbf{3 . 4})
$$

Onde:

$\Delta \mathrm{C} \quad$ : Variação do carbono orgânico do solo.

$\mathrm{COS}_{\text {pot }} \quad$ : Carbono orgânico do solo em um nível potencial.

COS : Carbono orgânico do solo na ocupação do solo.

$t_{\text {ini }} \quad$ : Momento onde se inicia a transformação e ocupação.

$\mathrm{t}_{\text {fin }} \quad$ : Momento onde termina o uso do solo.

\section{d. Estado de Referência}

O estado de referência utilizado no método é o estado natural do solo de acordo ao tipo de solo, região e clima.

\section{e. Tipos de uso do solo}

O tipo de uso do solo que avalia é principalmente o uso agrícola, prados, pastagens permanentes, colheitas, cultivos em longo prazo, entre outros. 


\section{f. Tempo de Recuperação}

O tempo de recuperação depende das condições biogeográficas da região onde se está realizando a avaliação. Mila i Canals (2003) e a FAO (2004) recomenda a utilização de Softwares que facilita o cálculo destes valores. Na Tabela 3.4 apresenta-se esta lista de Softwares.

Tabela 3. 4 - Softwares que Modelam o Comportamento da MOS (MILA I CANALS, 2003)

\begin{tabular}{lrl}
\multicolumn{1}{c}{ Nome } & Origem & \multicolumn{1}{c}{ Comentário } \\
\hline CANDY & Alemanha & Comportamento do C e N \\
\hline CENTURY & EEUU & $\begin{array}{l}\text { Comportamento C, N, P e S. } \\
\text { Na agricultura, pastagem e } \\
\text { florestas. }\end{array}$ \\
\hline ROTHC & Reino Unido & Modela a dinâmica do C. \\
\hline DAISY & $\begin{array}{c}\text { Dinamarca e } \\
\text { Alemanha }\end{array}$ & Dinâmica do C e N \\
\hline
\end{tabular}

Os dados típicos a ser ingressados nestes modelos são:

- clima - como a temperatura do ar;

- propriedades do solo - como textura;

- manejo do solo - utilização de fertilizantes ou adubo;

- tipo de vegetação - características da matéria orgânica vegetal.

- entre outros.

\subsection{DEFINIÇÃO DOS CRITÉRIOS}

Após o estudo dos métodos do Impacto de Uso do Solo nas FSV, se procedeu a definição de critérios. Que permitiram a comparação entre os métodos com o fim de realizar uma análise e finalmente concluir qual dos métodos oferece melhores vantagens para adaptá-lo as condições brasileiras, esta análise será apresentada no começo do capitulo 4.

Cabe dizer que os dois primeiros critérios foram tirados da literatura (ABNT, 2009a) e os quatro últimos foram definidos após o estudo dos métodos, pois julgamos necessário estes critérios para a escolha. 
Tabela 3. 5 - Critérios para Análise dos Métodos

\section{CRITERIOS}

1. Representação

\section{DEFINIÇÃO}

2. Mecanismo e modelo

3. Disponibilidade de dados

4. Frequência de referência do método
Qual é a área de proteção avaliada e as funções de solo que são estudadas no método.
5. Tipos de uso do solo

6. Tempo de recuperação

7. Estado de referência
Quais são os indicadores e parâmetros utilizados, se eles são representativos.

Se os dados que se precisam para o método são de fácil obtenção. Isso é muito importante, pois sem a disponibilidade de dados não se poderia quantificar este impacto que é o objetivo dos métodos.

Se o método é utilizado como referencia em outros trabalhos, mediante isso se teria uma medida da qualidade de cada um dos métodos.

Que tipos de solos utilizaram ou qual foi a base de dados empregada.

De acordo a que suposições são calculadas estes tempos de recuperação.

O estado no qual se realizarão as comparações com os estados subsequentes no caso do processo de transformação e ocupação do solo.

Como foi dito anteriormente o emprego destes critérios será no capitulo 4 de Resultados e Discussões no qual se justificara a escolha do método de Brandão e Mila i Canals (2012) para ser adequado as condições brasileiras. No ponto a seguir se apresenta a estrutura do modelo a fim de obter os fatores de caracterização utilizando como indicador o COS.

\subsection{ESTRUTURA DO MODELO}

A estrutura apresentada na Figura 3.7 foi utilizada para calcular os fatores de caracterização, segundo as condições brasileiras. 


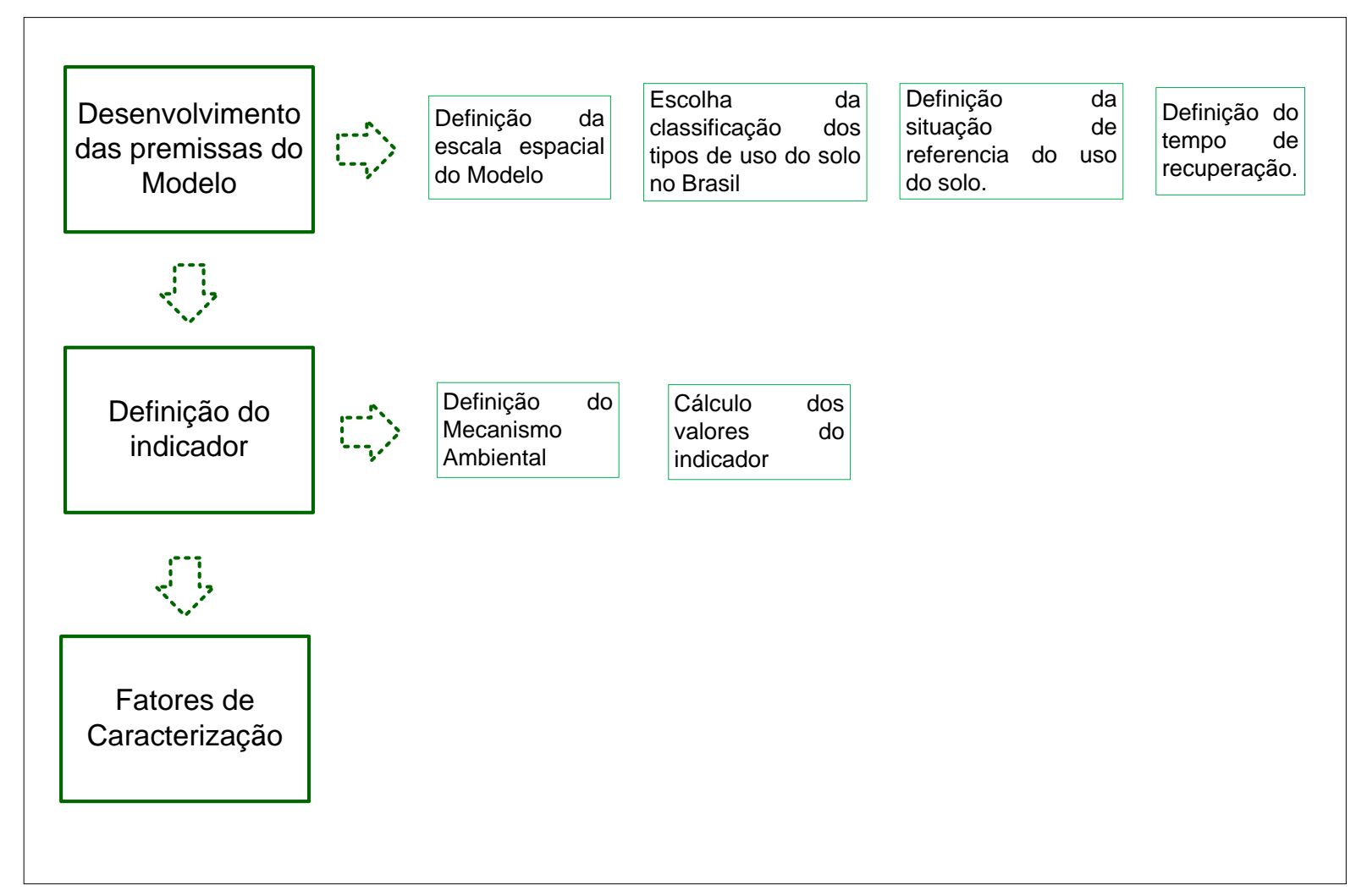

Figura 3. 8 - Estrutura Geral do Modelo

Os passos apresentados na Figura 3.8 serão explicados a seguir:

\subsubsection{Desenvolvimento das premissas do modelo}

Neste ponto se desenvolverá as premissas fundamentais que o modelo necessita para o cálculo dos fatores de caracterização no Brasil.

\section{a. Definição da escala espacial do modelo}

O objetivo deste ponto será definir o Bioma, o tipo de solo e o clima para que desta forma identificar os fatores de ajuste a ser utilizados ANEXO C.

Nesta fase do estudo serão apresentados os biomas brasileiros para nortear, quais os indicadores serão utilizados para escolha do bioma aplicado neste trabalho, sendo que o critério adotado foi o que apresentou maior extensão territorial.

O Ministério do Meio Ambiente (MMA) do Brasil e o IBGE classificam em seis tipos de biomas o território, estes se apresentam na Tabela 3.6 a seguir: 
Tabela 3. 6 - Tipos de Biomas no Brasil (MMA,2010)

\section{BIOMAS} DEFINIÇÃO

\begin{tabular}{ll}
\hline 1. Amazônia & $\begin{array}{l}\text { A Amazônia legal brasileira abrange os estados do Pará, } \\
\text { Amazonas, Maranhão, Goiás, Mato Grosso, Acre, Amapá, } \\
\text { Rondônia e Roraima. }\end{array}$ \\
\hline 2. Caatinga & $\begin{array}{l}\text { Engloba os estados Alagoas, Bahia, Ceará, Maranhão, } \\
\text { Pernambuco, Paraíba, Rio Grande do Norte, Piauí, Sergipe e o } \\
\text { norte de Minas Gerais. }\end{array}$ \\
\hline $\begin{array}{l}\text { 3. Cerrado sua área contínua incide sobre os estados de Goiás, Tocantins, } \\
\text { Mato Grosso, Mato Grosso do Sul, Minas Gerais, Bahia, } \\
\text { Maranhão, Piauí, Rondônia, Paraná, São Paulo e Distrito Federal. }\end{array}$ \\
\hline $\begin{array}{l}\text { 4.Mata } \\
\text { atlântica }\end{array}$ \\
\hline 5. Pampa & O Pampa está restrito ao estado do Rio Grande do Sul. \\
\hline 6. Pantanal & \\
\hline
\end{tabular}

Além dos Biomas presentes no território torna-se necessário identificar os tipos de solo existentes no Brasil como se apresenta no ANEXO B. A seguir na Tabela 3.7 apresenta-se um resumo dos tipos de solo:

Tabela 3. 7 - Tipos de solos no Brasil (EMBRAPA, 2009)

\begin{tabular}{c} 
TIPOS DE SOLO \\
\hline Argissolos \\
\hline Cambissolos \\
\hline Chernossolos \\
\hline Espodossolos \\
\hline Gleissolos \\
\hline Latossolos \\
\hline Luvissolos \\
\hline Neossolos \\
\hline Nitossolos \\
\hline Organossolos \\
\hline Planossolos \\
\hline Plintossolos \\
\hline Vertissolos
\end{tabular}

Como se mostra na Figura 3.7 os tipos de solo presentes são variados. Por essa razão, a escolha de quais serão utilizados dependerá do Bioma a ser estudado e também pelos tipos de solos que são mais apresentados no território brasileiro. 
Por outro lado, também é necessário identificar o clima predominante no Bioma a ser estudado. Na Figura 3.9 se apresentam os climas dominantes no mundo:

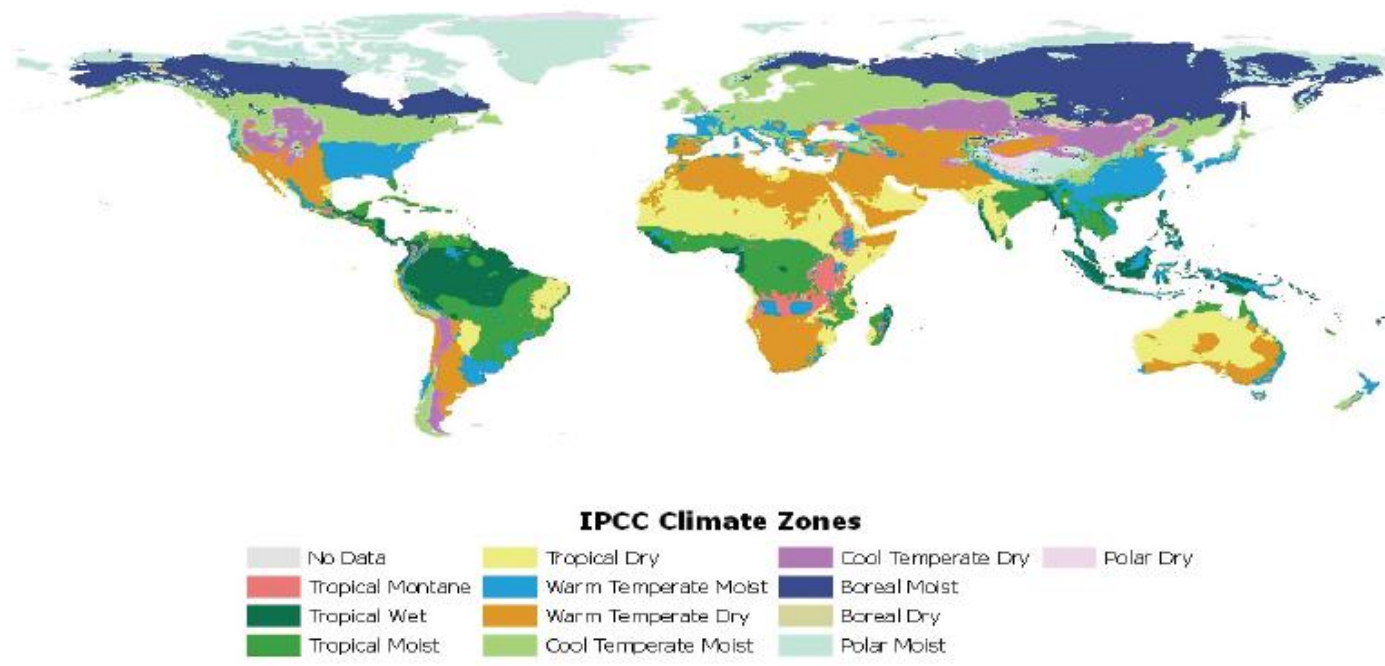

Figura 3. 9 - Climas no mundo (IPCC, 2006)

Os climas presentes no Brasil são: tropical úmido; tropical semi-úmido; úmido temperado quente e úmido como é apresentado na Figura 3.9 (IPCC, 2006).

\section{b. Classificação dos tipos de uso do solo}

Os tipos de usos de solos a ser utilizados serão de acordo com o Manual de Uso da Terra no site IBGE (2006) no ANEXO A se apresenta a lista completa.

\section{c. Definição da situação de referência}

A situação de referência será o estado natural do solo para o caso do Bioma escolhido e a situação antes do processo de transformação e ocupação do solo, estes dados serão extraídos da literatura.

\section{d. Definição do tempo de Recuperação}

O tempo de recuperação utilizado neste trabalho é extraído da literatura, este é o tempo para que o Bioma alcance as mesmas características de qualidade do solo antes de da transformação do solo para um determinado uso. 


\subsubsection{Definição do indicador}

\section{a. Definição do mecanismo ambiental}

Aqui se apresentará como o indicador é afetado pela transformação e ocupação do solo e como a sua alteração no seu teor afetará a FSV.

\section{b. Cálculo dos valores do indicador}

O cálculo dos valores do indicador será segundo o exigido pelo método. Os passos a serem feitos são:

- Valores do indicador COS antes da transformação e ocupação do solo, estes dados serão extraídos da literatura.

- Valores do indicador durante a ocupação do solo serão cálculos mediante a multiplicação dos valores do COS no estado natural com os fatores de ajuste que se apresentam no ANEXO $C$, estes fatores dependem do clima que é predominante do Bioma escolhido, do tipo de uso do solo e da gestão do solo.

\subsubsection{Cálculo dos fatores de caracterização para as condições Brasileiras}

Os fatores de caracterização serão calculados segundo o apresentado pelo método de Brandão e Milà i Canals (2012) utilizando para aquilo valores de COS de acordo com o Bioma escolhido. 


\section{RESULTADOS E DISCUSSÃO}

Neste capítulo, será apresentada a análise dos métodos que avaliam o Uso do Solo nas FSV, os quais foram descritos no Capitulo 3. Também serão apresentadas as premissas adotadas para o modelo, segundo as condições brasileiras.

Finalmente, apresenta-se uma descrição do procedimento para o cálculo dos fatores de caracterização, bem como considerações sobre as restrições dos valores obtidos.

\subsection{COMPARAÇÃO E ANÁLISE DOS MÉTODOS}

Neste ponto será feita a análise dos métodos do Impacto do Uso do Solo para o caso das FSV, esta análise foi desenvolvida de acordo com os critérios definidos.

Como primeiro passo realizou-se uma comparação dos métodos mediante a utilização de uma tabela, na qual se colocou o que é feito em cada um dos métodos segundo cada um dos critérios.

Como segundo passo procedeu-se a análise dos métodos de açodo a cada uma das comparações feitas na tabela.

A seguir na Tabela 4.1 apresenta-se a comparação dos métodos que avaliam o Impacto do Uso do Solo nas FSV. 


\subsubsection{Comparação dos métodos}

Tabela 4. 1 - Comparação dos Métodos que Avaliam o Uso do Solo nas FSV

\begin{tabular}{|c|c|c|c|}
\hline ITEM & Método de Lindeijer & Método GaBi-LANCA & $\begin{array}{l}\text { Método Brandão e Milà i } \\
\text { Canals }\end{array}$ \\
\hline 1. Representação & $\begin{array}{l}\text { Avalia as FSV apontando a } \\
\text { produtividade do solo. } \\
\text { Avalia a quantidade de matéria orgânica } \\
\text { nos tecidos vegetais livres para o } \\
\text { consumo humano ou não humano. }\end{array}$ & 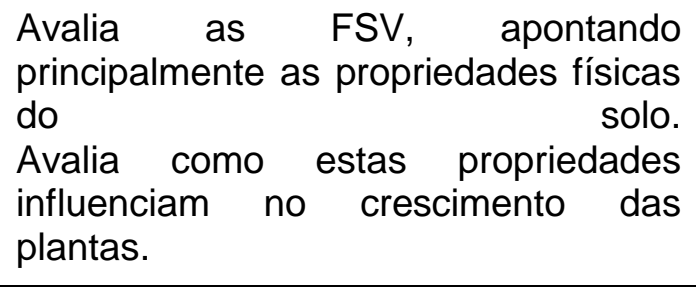 & $\begin{array}{l}\text { Avalia as FSV apontando a } \\
\text { produtividade do solo. } \\
\text { Avalia o conjunto de compostos } \\
\text { orgânicos no solo mediante a } \\
\text { fixação de carbono. }\end{array}$ \\
\hline 2. Mecanismo e Modelo & $\begin{array}{l}\text { Utiliza como indicador a Produção } \\
\text { Primaria } \\
\text { Avalia a FSV produta } \\
\text { No método não se mencionam o } \\
\text { mecanismo ambiental, mas não se teria } \\
\text { outras FSV influenciadas pela } \\
\text { modificação no teor do PPL. }\end{array}$ & $\begin{array}{l}\text { Os indicadores utilizados são: } \\
\text { Resistência na Erosão; Filtração } \\
\text { Mecânica; Filtração Física - Química; } \\
\text { Produção Biótica; Reposição de águas } \\
\text { subterrâneas. } \\
\text { No método não mencionam o } \\
\text { mecanismo ambiental, mas estes } \\
\text { indicadores influenciariam no teor do } \\
\text { PPL influenciando finalmente na } \\
\text { produtividade do solo. }\end{array}$ & $\begin{array}{l}\text { Utiliza como indicador o } \\
\text { carbono orgânico do solo } \\
\text { (COS). } \\
\text { Segundo o mecanismo } \\
\text { ambiental apresentado da MOS } \\
\text { esta influenciaria em outras } \\
\text { FSV (produtividade do solo, } \\
\text { manutenção no ciclo das } \\
\text { substancias, regulação do clima } \\
\text { da terra). }\end{array}$ \\
\hline $\begin{array}{l}\text { 3. Disponibilidade de } \\
\text { dados }\end{array}$ & $\begin{array}{l}\text { Os dados são de difícil obtenção, tanto } \\
\text { que o mesmo autor o menciona. }\end{array}$ & $\begin{array}{l}\text { Mediante equações que modelam } \\
\text { estes indicadores é possível o cálculo, } \\
\text { o qual é um pouco complexo, pois se } \\
\text { dependerão de outros fatores. }\end{array}$ & $\begin{array}{l}\text { Existe banco de dados } \\
\text { mundiais como o caso do } \\
\text { IPCC, 2006; EC, 2010; FAO, } \\
\text { 2004; FAO, 2005. }\end{array}$ \\
\hline
\end{tabular}


4. Tempo de $\quad$ tempo de recuperação que é dado Recuperação

\section{Frequência de
utilização do método \\ 6. Frequência de
utilização do método}

para 0 solo é até que este

recupere a biomassa potencial máxima

Não é mencionado.

e dependerá da latitude e altitude onde

se localiza a região este valores oscila de 50 até 220 anos.

Os tipos de solos mencionados são 6;

áreas urbanas, solo agrícola

pastagem em áreas de alta e baixa

produtividade, zonas desérticas e zonas

de recuperação de áreas

desflorestadas.
O tempo de recuperação dependera de vários fatores (tipo de solo, uso do solo, clima, manejo, umidade) para isto 0 autor recomenda a utilização de vários softwares que ajudariam nos cálculos destes tempos.

Os tipos de uso do solo que utilizada é o agrícola, utilizados são no total 36 dentre pastagem, entre outros.
os quais temos: solos de pastagem, Cabe ressaltar que estes solos utilizados são no total 36 dentre pastagem, entre outros.
os quais temos: solos de pastagem, Cabe ressaltar que estes solos agrícolas, urbanos, industriais, entre são divididos em sub níveis que dependerão tu tipo de manejo.
Este método foi desenvolvido para É mencionado em artigo e sua utilização no software GABi. trabalhos. 


\subsubsection{Análise dos métodos}

Na representacão, os três métodos estudados avaliam a produtividade do solo, talvez isso seja reflexo do cenário atual do mundo, que exige a maior produção de alimentos para atender às demandas de uma população em aumento, e devido à exigência crescente na produção de biomateriais, por parte dos governos e da própria população que exige a criação de materiais que emitam poluentes menos agressivos que os produzidos por fontes não renováveis.

Este panorama exige o bom rendimento dos solos na produção de mais unidades sem que isso cause maiores danos às propriedades do solo e para reduzir a predação de áreas naturais pela expansão dos cultivos. Por estas razões, acreditamos que a avaliação da produtividade do solo é um ponto importante a ser estudado e avaliado.

No mecanismo e modelo, Lindeijer (2000a) utiliza como indicador a Produção Primaria Liquida (PPL) que indica em termos de curto prazo a funcionalidade do sistema, ou seja, a disponibilidade de recursos bióticos. Mas o problema deste indicador seria que ele é totalmente determinado por um tipo de manejo ao qual o solo é submetido (produções intensivas por uso de fertilizantes, entre outros). Os resultados em longo prazo como a habilidade própria do ecossistema em produzir biomassa é deixada de lado.

Brandão e Milà i Canals (2012) propõe a utilização da Matéria Orgânica do Solo (MOS), elemento importante na formação do solo motivo perlo qual este indicador torna-se um elemento chave nas FSV, pois influencia em varias propriedades do solo (erosão, filtração mecânica, fertilidade, entre outros). Devido à dificuldade no processo de coleta de dados da MOS os autores propõe a utilização do carbono orgânico do solo (COS) que representa o 65\% da MOS mostrando assim ser componente essencial da MOS. Ao contrario do PPL a MOS dá resultados a longos prazos dos estragos ou benefícios causados pelo uso do solo. Além disso, a MOS não só mede a produtividade nas FSV também a qualquer alteração do teor de MOS afetará outras funções como a manutenção do ciclo das substancias, do ciclo da água e inclusive a regulação do clima global e local por ser deposito e emissor de $\mathrm{CO}_{2}$. Por todas estes motivos se observa que este indicador já seja MOS ou COS é 
um bom representante das possíveis alterações nas FSV causadas pelo uso do solo.

No caso do projeto LANCA (2008) propõe a utilização de cinco indicadores que avaliam as implicações do uso do solo nas FSV. Três dos indicadores utilizados: erosão, filtração mecânica e filtração físico-química representam a perda física do solo determinando a incorreta atuação do solo em suas funções. Como se observa este método tem como principal preocupação avaliar as propriedades físicas do solo deixando de lado as biológicas que são fundamentais na formação do solo e que de forma direta influenciam nas mesmas propriedades físicas como a erosão e a compactação como mostrado por Milà i Canals (2003) mediante a representação do mecanismo ambiental da MOS.

Diante todo o exposto ressalta-se o bom desempenho da MOS como indicador nas FSV

Disponibilidade de dados, no método de Lindeijer (2000a), os dados da PPL são obtidos mediante trabalhos em diferentes países o que evidencia a dificuldade da obtenção de informação na literatura deste indicador o que é reconhecido pelo mesmo autor.

No projeto LANCA (2008) a utilização de cinco indicadores faz com que seja difícil conseguir dados para todos estes, no mesmo projeto utiliza-se dados gerais que não tomam em conta variáveis locais que influenciariam nestes indicadores.

Brandão e Milà i Canals (2012) propõe o COS que é estudado por varias instituições como a IPCC, a Comissão Européia e a FAO que estudam como este indicador pode ser calculado ajudando assim na obtenção dos dados.

Portanto, observa-se a disponibilidade de dados do COS que ajuda em muito para adaptações em diferentes cenários e realidades biogeográficas dos países.

Tempo de recuperacão, Lindeijer (2000a), realiza uma aproximação de acordo a latitude e a altitude para que o solo recupere as condições potenciais naturais do Bioma.

No projeto LANCA (2008), a forma de cálculo destes tempos não é mencionado. 
Brandão e Milà i Canals (2012), não especificam tempos de recuperação do solo para os diferentes tipos de uso no método, especificando só uma recomendação do IPCC que coloca como tempo de recuperação 20 anos entre solos bióticos, o que pode ser muito longe da realidade de acordo à realidade dos países. Por outro lado Mila i Canals no documento de doutorado (2003) e a FAO (2004) propõe a utilização de Softwares como CENTURY, ROTCH no cálculo destes tempos, o que ajudaria na precisão dos resultados, pois consideram diferentes variáveis (tipo de uso do solo, precipitações, conteúdo de argila, temperatura, entre outros). Porém, a manipulação destes softwares não são de fácil compreensão e a quantidade de dados exigidos para executar os cálculos são difíceis de serem coletados, dificultando desta forma os cálculos destes tempos de recuperação do solo.

Portanto, observa-se que o tempo de recuperação ainda tem que ser mais trabalhado nos métodos, pois é um ponto fraco neles.

Tipo de uso do solo, No método de Lindeijer (2000a) só menciona alguns tipos de uso do solo para os quais coloca valores do PPL.

No projeto LANCA (2008) utiliza tipos de uso do solo da base CORINE.

Quanto Brandão e Milà i Canals (2012) coloca o tipo de uso do solo agrícola como principal na avaliação, não especifica subdivisões deste tipo de uso do solo.

Dessa forma, pode-se dizer que o projeto LANCA (2008) dá uma visualização mais detalhada neste ponto.

Frequência de utilizacão do método, no método de Lindeijer (2000a) não se encontraram registros de sua utilização como referência.

Projeto LANCA (2008) foi desenvolvido com o fim de ser utilizado no Software GaBi o que manifesta seu estudo detalhado.

O método de Brandão e Mila i Canal (2012) é referenciado em trabalhos de ACV (MILÀ I CANALS, 2012) e foi apresentado no "Special forum on Global Land Use Impacts on Biodiversity and Ecosystem Services in LCA" realizado em Bruxelas o ano 2012.

Portanto, observa-se que o projeto LANCA (2008) e o método de Brandão e Milà i Canals (2012) são métodos com solidez conceitual. 


\subsubsection{Escolha do método}

Realizada a análise no item 4.1.2 podemos finalmente concluir que o método de Brandão e Milà i Canals (2012) oferece melhores vantagens para ser utilizado neste trabalho, pois apresenta boas condições nos critérios de mecanismo e principalmente na acessibilidade de dados que ajuda grandemente na possível adaptação para outros países.

O COS é amplamente estudado (IPCC, 2003, 2006; EC, 2010) possibilitando assim a obtenção de valores. Além disso, é um bom representante no mecanismo ambiental das FSV, pois direta ou indiretamente vai influir em varias delas. Portanto, se acredita que a sua utilização é adequada, pois ademais trabalhos (FAO, 2005) demostram que é representativo na avaliação de solos agrícolas.

Além disso, considera-se que a produtividade do solo é um ponto importante para a sociedade.

\subsection{DESENVOLVIMENTO DAS PREMISSAS DO MODELO}

\subsubsection{Definição da escala espacial}

De acordo com o IBGE e MMA (Ministério do Meio Ambiente do Brasil), o Brasil pode ser dividido em seis Biomas. Destes, merecem destaque a Amazônia, o Cerrado e a Mata Atlântica, que juntos ocupam mais de $86 \%$ do território brasileiro (IBGE; MMA, 2012). Uma relação da área ocupada por cada Bioma é apresentada na Tabela 4.1, a seguir:

Tabela 4. 2 - Biomas no Brasil segundo a área ocupada (IBGE; MMA, 2012)

\begin{tabular}{|l|c|c|}
\hline \multicolumn{1}{|c|}{ BIOMA } & $\begin{array}{c}\text { ÁREA APROXIMADA } \\
\left(\mathrm{Km}^{2}\right)\end{array}$ & $\begin{array}{c}\text { FRAÇÃO DA ÁREA } \\
\text { TOTAL DO BRASIL }\end{array}$ \\
\hline Amazônia & $\mathbf{4 1 9 6 , 9 4 3}$ & $\underline{\mathbf{4 9}, \mathbf{2 9} \%}$ \\
\hline Cerrado & 2036,448 & $23,92 \%$ \\
\hline Mata atlântica & 1110,182 & $13,04 \%$ \\
\hline Caatinga & 844,453 & $9,92 \%$ \\
\hline Pampa & 176,496 & $2,07 \%$ \\
\hline Pantanal total & 150,355 & $1,76 \%$ \\
\hline $\begin{array}{l}\text { Área } \\
\text { Brasil }\end{array}$ & 8514,877 & \\
\hline
\end{tabular}


O Bioma escolhido para a coleta de dados foi a Amazônia, que apresenta como clima o tropical úmido (IPCC, 2003, 2006) ocupando o 49\% do território nacional. Considera-se importante a proteção deste Bioma, pois além de ocupar uma porcentagem alta do território, este representa $30 \%$ das florestas tropicais remanescentes do mundo (MMA, 2012). Além disso, mais de 60\% da área total da floresta amazônica está localizada no Brasil (IBGE, 2012).

A Amazônia abrange os estados de Pará, Amazonas, Maranhão, Goiás, Mato Grosso, Acre, Amapá, Rondônia e Roraima totalizando 4.196.943 de $\mathrm{Km}^{2}$ (IBGE; MMA, 2012).

$\mathrm{Na}$ Figura 4.1, apresenta-se como estes Biomas estão distribuídos no território brasileiro.

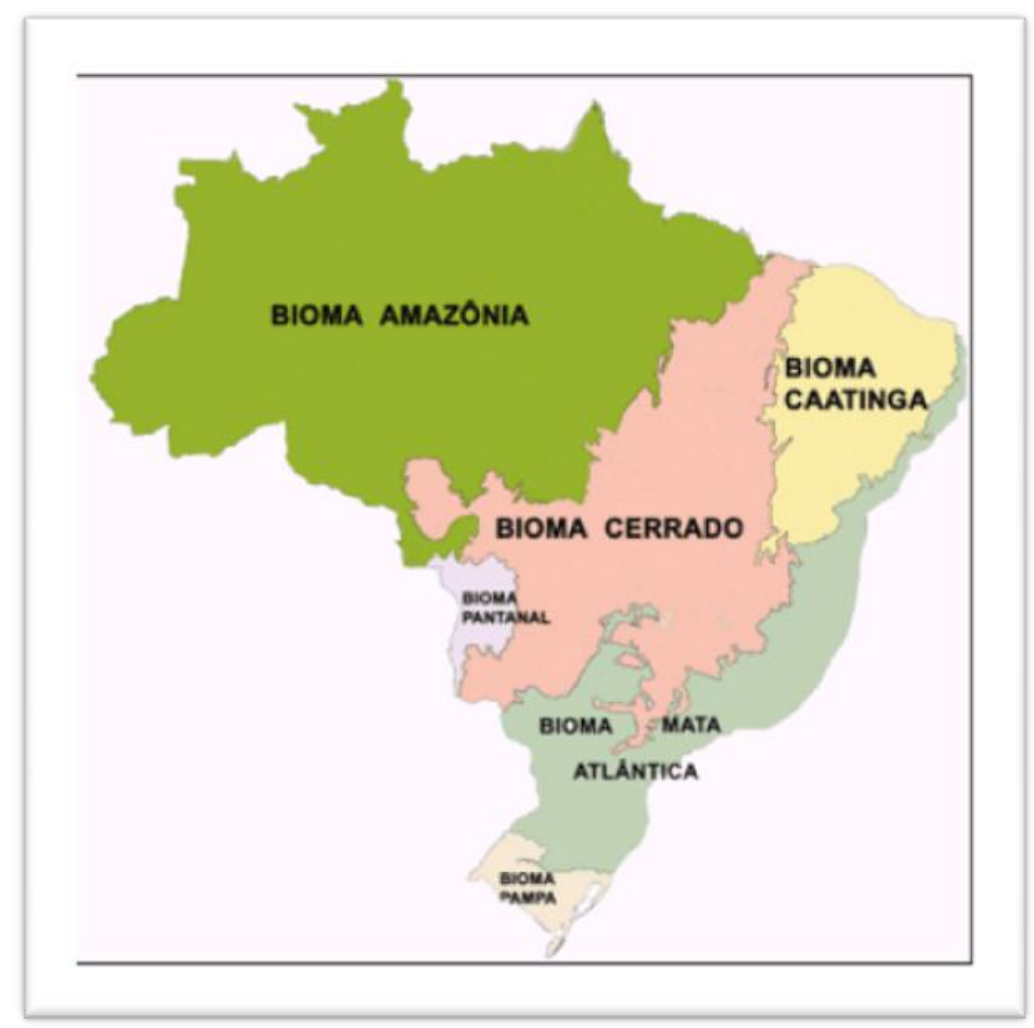

Figura 4. 1 - Localização dos Biomas Brasileiros (IBGE, 2012)

Adicionalmente, informações sobre os tipos de solo no Brasil foram extraídas do Manual de Classificação de Solo elaborados pelo IBGE e a EMBRAPA (Empresa Brasileira de Pesquisa Agropecuária). Mais detalhes são apresentados no ANEXO B (EMBRAPA, 2009). 
$\mathrm{Na}$ Tabela 4.3 apresentam-se a distribuição dos tipos de solos no território brasileiro.

Tabela 4. 3 - Extensão e distribuição dos tipos de solos nas regiões do Brasil (IBGE; EMBRAPA, 2012)

\begin{tabular}{|l|c|c|c|c|c|c|c|}
\hline \multirow{2}{*}{$\begin{array}{l}\text { Tipos de } \\
\text { Solos }\end{array}$} & \multicolumn{4}{|c|}{ Brasil } & \multicolumn{5}{c|}{ Relativa por regiões } \\
\cline { 2 - 8 } & Áreas & Relativo & Norte & Nordeste & $\begin{array}{c}\text { Centro- } \\
\text { Oeste }\end{array}$ & Sudeste & Sul \\
\cline { 2 - 8 } & $\mathbf{k m}^{2}$ & $\%$ & & & $\%$ & & \\
\hline Alissolos & $371.874,5$ & 4,36 & 8,67 & 0,00 & 0,00 & 0,00 & 6,34 \\
\hline Argissolos & $1.713 .853,5$ & $\underline{\mathbf{1 9 , 9 8}}$ & 24,40 & 17,20 & 13,77 & 20,68 & 14,77 \\
\hline Cambissolos & $232.139,2$ & 2,73 & 1,06 & 2,09 & 1,59 & 8,64 & 9,28 \\
\hline Chernossolos & $42.363,9$ & 0,53 & 0,00 & 1,05 & 0,27 & 0,21 & 3,94 \\
\hline Espodossolos & $133.204,9$ & 1,58 & 3,12 & 0,39 & 0,26 & 0,37 & 0,00 \\
\hline Gleissolos & 311445,3 & 3,66 & 6,41 & 0,78 & 2,85 & 0,5 & 0,4 \\
\hline Latossolos & $3.317 .590,3$ & $\underline{\mathbf{3 8 , 7 3}}$ & 33,86 & 31,01 & 52,81 & 56,30 & 24,96 \\
\hline Luvissolos & $225.594,9$ & 2,65 & 2,75 & 7,60 & 0,00 & 0,00 & 0,00 \\
\hline Neossolos & $1.246 .898,9$ & $\underline{\mathbf{1 4 , 5 7}}$ & 8,49 & 27,55 & 16,36 & 9,38 & 23,23 \\
\hline Nitossolos & $119.731,3$ & 1,41 & 0,28 & 0,05 & 1,22 & 2,56 & 11,48 \\
\hline Planossolos & $155.152,1$ & 1,84 & 0,16 & 6,61 & 1,73 & 0,16 & 3,00 \\
\hline Plintossolos & $508.539,4$ & 5,95 & 7,60 & 4,68 & 8,78 & 0,00 & 0,00 \\
\hline Vertissolos & $169.015,3$ & 2,01 & 3,20 & 0,99 & 0,36 & 1,20 & 2,60 \\
\hline
\end{tabular}

$\mathrm{Na}$ Tabela 4.3 destacam-se três tipos de solo, quais sejam: Argissolos, Latossolos e Neossolos. Estes tipos de solo serão utilizados no método juntamente com os Plintossolos, Cambissolos e Gelissolos, todos eles característicos da Amazônia.

\subsubsection{Tipos de Uso de Solos para o Brasil}

As classes de cobertura do uso do solo são definidas no manual do IBGE (2006) Mais detalhes podem ser encontrados no ANEXO A. Na Tabela 4.4, apresenta-se a divisão dos tipos de usos dos solos em dois níveis, conforme citado no ítem 2.3.4 desta dissertação. 
Tabela 4. 4 Classes de Cobertura de Solo no Brasil (IBGE, 2006).

\begin{tabular}{|l|l|}
\hline \multicolumn{1}{|c|}{ NÍVEL I } & \multicolumn{1}{c|}{ NíVEL II } \\
\hline \multirow{2}{*}{ 1. Áreas antrópicas não agrícolas } & Área urbanizada. \\
\cline { 2 - 2 } & Área de mineração. \\
\hline \multirow{2}{*}{ 2. Áreas antrópicas agrícolas } & Cultura temporária. \\
\cline { 2 - 3 } & Cultura permanente. \\
\cline { 2 - 3 } & Pastagem. \\
\cline { 2 - 2 } 3. Áreas de vegetação natural & Silvicultura. \\
\hline \multirow{2}{*}{ 4. Água } & Florestal. \\
\cline { 2 - 3 } & Campestre. \\
\hline 5. Outras Áreas & Copos de água continentais. \\
\cline { 2 - 2 } & Copos de água costeiros. \\
\hline
\end{tabular}

Para o caso deste estudo, serão consideradas as áreas antrópicas agrícolas (culturas permanentes, temporárias, pastagem e silvicultura) e a área de vegetação natural (no caso, com cobertura florestal) para dados da situação de referência.

\subsubsection{Definição da situação de referência}

Os valores de referência a respeito do Carbono Orgânico do Solo (COS) em um nível natural, que serão utilizados para o cálculo dos fatores de caracterização para o caso do Bioma da Amazônia foram extraídos da literatura (LANGE, 2012).

Estes valores citados são apresentados na Tabela 4.5 a seguir:

Tabela 4. 5 - Carbono Orgânico do Solo (COS) no estado natural para o bioma da Amazônia (LANGE, 2012)

\begin{tabular}{llc}
\hline \multicolumn{1}{c}{ Tipo de solo } & $\begin{array}{c}\text { COSnat } \\
\left(\text { tCha }^{-1}\right)\end{array}$ \\
\hline \multirow{3}{*}{ Latossolos } & Amarelo & 84.9 \\
\cline { 2 - 3 } & Vermelho-escuro & 93 \\
\cline { 2 - 3 } & Roxo & 216.5 \\
\cline { 2 - 3 } & Vermelho-amarelo & 105.1 \\
\hline Argissolos & 57.5 \\
\hline Neossolos & 65 \\
\hline Plintossolos & 61.3 \\
\hline
\end{tabular}


Cambissolos 72.95

Gleissolos

97.2

\subsubsection{Definição do tempo de recuperação}

Utilizaram-se tempos encontrados na tese de doutorado de SOUZA (2011), em que propõe varias matrizes com tempos de recuperação para diferentes altitudes e latitudes do Brasil.

Com o fim de obter a latitude e altitude media do bioma da Amazônia realizouse os passos a seguir:

- Primeiro, identificou-se que Bioma Amazônia ocupa a totalidade de cinco unidades da federação (Acre, Amapá, Amazonas, Pará e Roraima), grande parte de Rondônia (98,8\%), mais da metade de Mato Grosso (54\%), além de parte de Maranhão (34\%) e Tocantins (9\%). Para cada um destes estados procurou-se a localização geográfica em termos de altitude e latitude tendo os valores a seguir: Acre (278m e $\left.9^{\circ}\right)$, Amapá (148m e $\left.1^{\circ}\right)$, Amazonas (150m e $\left.7^{\circ}\right)$, Pará $\left(420 \mathrm{~m}\right.$ e $\left.7^{\circ}\right)$, Roraima $\left(921 \mathrm{~m}\right.$ e $\left.4^{\circ}\right)$, Rondônia $\left(602 \mathrm{~m}\right.$ e $\left.12^{\circ}\right)$, Mato Grosso $\left(820 \mathrm{~m}\right.$ e $\left.18^{\circ}\right)$, Maranhão $\left(485 \mathrm{~m}\right.$ e $\left.6^{\circ}\right)$ e Tocantins $\left(693 \mathrm{~m}\right.$ e $\left.11^{\circ}\right)($ IBGE, 2012).

- Segundo, calculou-se o valor médio para a altitude e latitude de todos estes estados sendo $502 \mathrm{~m}$ e $8^{\circ}$ respectivamente.

- Terceiro, segundo os valores calculados acima, se procedeu a procurar os tempos de recuperação fornecidos por Souza (2011), segundo os valores obtidos estes se ajustam aos valores da matriz que tem de 0 a 1000m de altitude e $20^{\circ}$ de latitude.

Tabela 4. 6 - Tempos de regeneração para o caso do Brasil em anos (adaptado de SOUZA, 2011).

\begin{tabular}{ccccc} 
& $\begin{array}{c}\text { Cultura } \\
\text { Temporária }\end{array}$ & $\begin{array}{c}\text { Cultura } \\
\text { Permanente }\end{array}$ & Pastagem & Sivicultura \\
\hline $\begin{array}{c}\text { Cultura } \\
\text { Temporária }\end{array}$ & - & - & - & 49 \\
\hline $\begin{array}{c}\text { Cultura } \\
\text { Permanente }\end{array}$ & - & - & - & 49 \\
\hline Pastagem & - & - & - & 49 \\
\hline
\end{tabular}


Para os casos onde de em tracinho na Tabela 4.6 entre os mesmos tipos de usos do solo se optou por utilizar o valor de 1, isso com o objetivo de não zerar os cálculos dos fatores de caracterização na transformação do solo.

Para os outros casos se utilizou a matriz fornecida por köllner (1999), onde se tem os tipos de uso do solo de agricultura de alta e baixa intensidade e áreas artificiais de alta e baixa intensidade como apresentada na Tabela 4.7.

\section{Tabela 4. 7 - Tempos de regeneração método de köllner em anos (adaptado de} KÖLLNER, 1999).

\begin{tabular}{ccccc} 
& $\begin{array}{c}\text { Agricultura } \\
\text { alta } \\
\text { intensidade }\end{array}$ & $\begin{array}{c}\text { Agricultura } \\
\text { baixa } \\
\text { intensidade }\end{array}$ & $\begin{array}{c}\text { Área } \\
\text { artificial de } \\
\text { alta } \\
\text { intensidade }\end{array}$ & $\begin{array}{c}\text { Área } \\
\text { artificial de } \\
\text { baixa }\end{array}$ \\
\hline $\begin{array}{c}\text { Agricultensidade } \\
\text { intensidade }\end{array}$ & - & 10 & $<1$ & 2 \\
\hline $\begin{array}{c}\text { Agricultura baixa } \\
\text { intensidade }\end{array}$ & $<1$ & - & $<1$ & 2 \\
\hline $\begin{array}{c}\text { Área artificial de } \\
\text { alta intensidade }\end{array}$ & 5 & 10 & - & 2 \\
\hline $\begin{array}{c}\text { Área artificial de } \\
\text { baixa intensidade }\end{array}$ & 2 & 5 & $<1$ & - \\
\hline
\end{tabular}

Com o fim de obter os valores dos tipos de usos do solo da cultura temporária, permanente e pastagem se optou por utilizar valores da Tabela 4.7 os solos agrícolas com alta intensidade para as culturas permanentes, os solos agrícolas com baixa intensidade para as culturas temporárias e o valor médio das áreas artificiais de alta e baixa intensidade para o caso dos solos de pastagem.

Finalmente, se obteve os seguintes tempos de recuperação como mostrados na Tabela 4.8. 
Tabela 4. 8 - Tempos de regeneração para o caso do Brasil em anos (adaptado de SOUZA, 2011; köllner , 2009).

\begin{tabular}{ccccc} 
& $\begin{array}{c}\text { Cultura } \\
\text { Temporária }\end{array}$ & $\begin{array}{c}\text { Cultura } \\
\text { Permanente }\end{array}$ & Pastagem & Sivicultura \\
\hline $\begin{array}{c}\text { Cultura } \\
\text { Temporária }\end{array}$ & - & 1 & 1 & 49 \\
\hline $\begin{array}{c}\text { Cultura } \\
\text { Permanente }\end{array}$ & 9 & - & 1 & 49 \\
\hline Pastagem & 6 & 2 & - & 49 \\
\hline Sivicultura & 2 & 2 & 2 & - \\
\hline
\end{tabular}

\subsection{DEFINIÇÃO DO INDICADOR UTILIZADO}

\subsubsection{Definição do mecanismo ambiental do COS}

A seguir, será apresentado o mecanismo ambiental segundo o qual o uso do solo afetará as FSV. Esta representação foi elaborada mediante a utilização do indicador da Matéria Orgânica do Solo (MOS), que tem como principal componente o COS.

O mecanismo ambiental foi adaptado de MILÀ I CANALS (2003), mantendose a estrutura que representa os impactos dos recursos e do uso do solo. Entretanto, dá-se uma atenção especial aos efeitos sobre as Funções Suporte de Vida causadas pelas alterações no conteúdo da MOS.

A representação do mecanismo ambiental é apresentada na Figura 4.2, a seguir (MILÀ I CANALS, 2003). 


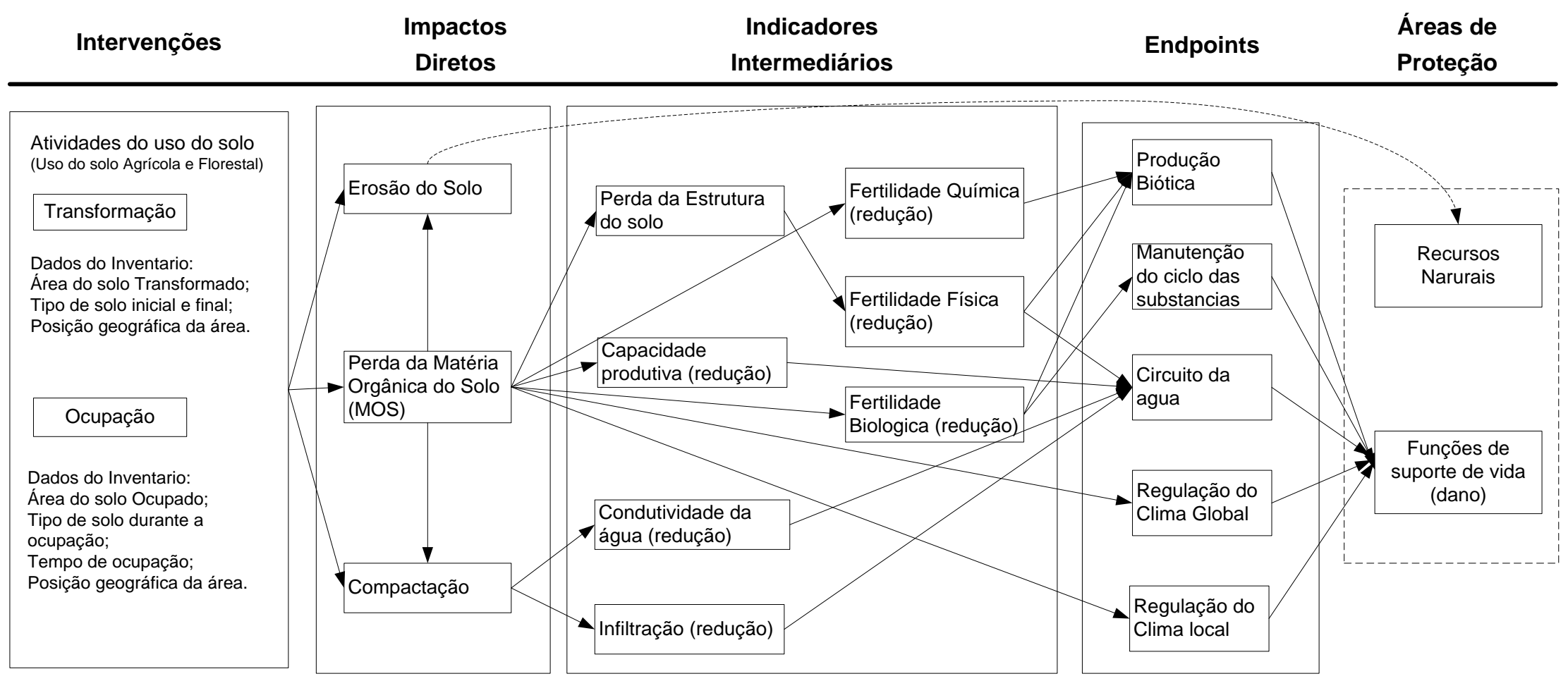

Figura 4. 2 - Mecanismo Ambiental da MOS nas FSV (Adaptado MILÀ I CANALS, 2003). 
Como observado na Figura 4.2, as intervenções causadas pelo homem na transformação e ocupação do solo podem levar a impactos diretos de erosão e compactação do solo. Ainda, podem ocorrer modificações no teor da MOS que, por sua vez, podem desencadear modificações em diferentes elementos intermediários, causando alterações em vários endpoints. Estas mudanças podem ser diretas ou indiretas, como o caso da a produção da biótica, na manutenção do ciclo das substâncias, circuito da água, regulação do clima global e local atingindo assim as FSV.

No caso da produção da Biomassa o solo fornece a estrutura necessária, bem como nutrientes, água e o ar para que as raízes possam penetrá-lo permitindo a boa produtividade do solo. Neste caso, a MOS é a principal responsável para isto, estudos demonstram como a MOS cumpre esta função importante (FAO, 2005).

A MOS contribui na estrutura do solo para formar poros permitindo assim a redução da compactação do solo. Além disto, a MOS ao contribuir com a estrutura do solo ajuda na boa infiltração da água ajudando deste modo no ciclo da água.

Com relação à regulação do clima, o solo é um componente chave do ciclo do carbono. O solo contém duas vezes mais carbono que a atmosfera (TONELLO. 2007). Embora o clima venha sendo afetado pelas grandes emissões provenientes de combustíveis fosseis, a MOS pode atuar como sumidouro ou como emissor de CO2. Quantidades proporcionais de carbono são perdidas por causa da transformação do solo que vai influenciar no clima.

Desta forma, pode-se considerar que a MOS é indicador que afeta varias funções de suporte de vida e, por isso, tem sua importância destacada como indicador.

\subsubsection{Cálculo dos valores do COS}

a. Os valores para o COS antes da transformação e ocupação do solo foram definidos segundo a realidade encontrada para Bioma da Amazônia. Estes dados foram extraídos de LANGE (2012) e são apresentados no ANEXO D.

b. Para o caso dos valores de COS durante a ocupação do solo estes foram calculados segundo o manual publicado pela Comissão Européia, em que fatores de ajustes são multiplicados aos valores do estado natural do solo segundo o tipo de uso do solo e manejo do solo. 
Para identificação dos fatores de ajustes se utilizou os dados descritos na definição da escala espacial e dos tipos de uso do solo que são resumidos a seguir:

- Bioma: Amazônia;

- Clima: Topical úmido;

- Tipos de uso do solo: Cultura temporal, cultura permanente, pastagem, silvicultura.

Estes fatores de ajuste são apresentados no ANEXO C, e os resultados do cálculo dos valores de COS durante a ocupação são apresentados no APÊNDICE X.

\subsection{CÁlCULO dOS FATORES DE CARACTERIZAÇÃo PARA AS CONDIÇÕES BRASILEIRAS}

Como se apresentou de acordo ao método de Brãndao e Mila i Canals (2012), os fatores de caracterização são calculados para o caso da transformação do solo e para o caso da ocupação do solo.

\section{Transformação do Uso do Solo}

$$
\Delta \mathrm{C}\left[\mathrm{tC} \text { ano }{ }^{-2}\right]=\left(\cos _{\mathrm{pot}}-\cos _{\mathrm{LU1}}\right) \times\left(\mathrm{t}_{\mathrm{regen} 1}-\mathrm{t}_{\mathrm{lin}}\right)+\frac{1}{2}\left(\mathrm{t}_{\mathrm{regen} 1}-\mathrm{t}_{\mathrm{tin} 1}\right) \times\left(\cos _{\mathrm{LU1}}-\cos _{\mathrm{LU} 2}\right)
$$

Onde:

$\Delta \mathrm{C} \quad$ : Variação do carbono orgânico do solo.

$\mathrm{COS}_{\text {pot }} \quad$ : Carbono orgânico do solo em um nível potencial.

$\operatorname{COS}_{\mathrm{LU} 1}$ : Carbono orgânico do solo antes da transformação e ocupação do solo.

COS : Carbono orgânico do solo na ocupação do solo.

$t_{\text {regen1 }} \quad$ :Tempo que o sistema necessita para alcançar o COS potencial.

$t_{\text {ini }}$ : Momento onde se inicia a transformação e ocupação.

Ocupação do solo:

$$
\Delta C\left[t C \text { ano m}{ }^{-2} \text { ano }^{-1}\right]=\frac{\left(\cos _{\text {pot }}-\cos _{\text {LU2 }}\right) \times\left(t_{\text {fin }}-t_{\text {ini }}\right)}{t_{\text {fin }}-t_{\text {ini }}}
$$


Onde:

$\Delta \mathrm{C}$

: Variação do carbono orgânico do solo.

$\mathrm{COS}_{\text {pot }} \quad$ : Carbono orgânico do solo em um nível potencial.

COS $\quad$ : Carbono orgânico do solo na ocupação do solo.

$t_{\text {ini }} \quad$ : Momento onde se inicia a transformação e ocupação.

$\mathrm{t}_{\mathrm{fin}} \quad$ : Momento onde termina o uso do solo.

Portanto, nestas equações observa-se que os impactos de transformação estão diretamente relacionados ao tempo de recuperação do solo (trec) e às mudanças do uso do solo. Aos impactos de ocupação, atribui-se o adiamento da recuperação do solo pela utilização durante um determinado período.

Os resultados dos fatores de caracterização calculados para a ocupação e transformação do solo (como se pode observar no APÊNDICE Y,W) apresentam valores positivos e negativos. Isso quer dizer que terá casos nos quais a gestão do solo não levaria à diminuição do teor de COS. Pelo contrario, haveria benefícios ambientais.

Para o cálculo do impacto de transformação, se teria que multiplicar o fator de caracterização de transformação pela área utilizada. Já no caso da ocupação, os valores de caracterização foram calculados para um ano, o que possibilita o cálculo do impacto. Assim, bastaria multiplicar este fator pelo tempo real da ocupação do solo, bem como pela área ocupada.

Os dados de inventario necessários para o cálculo destes impactos serão os a seguir: Tipo de uso solo antes da transformação; tipo de uso do solo depois da transformação; tipo de solo da região; a gestão no solo empregada na ocupação; o tempo de ocupação; e a área utilizada. Todos estes dados são considerados importantes para a realização da avaliação do Impacto do Uso do Solo.

Como se observou no capitulo 3, o Brasil tem três principais Biomas: Amazônia, Cerrado e Mata Atlântica. Entretanto, este trabalho se restringiu à Amazônia, pois a sua extensão no Brasil é importante (cerca de 50\% do território brasileiro). Além disso, vários estudos sobre este Bioma foram encontrados o que facilitou a obtenção de dados. 
Apesar disso, considera-se que a obtenção de fatores de caracterização referentes aos outros Biomas é de importância. No entanto, a falta de dados e informações e um grande limitante.

Ainda, observou-se que a utilização de tipos de uso do solo no nível II facilita o trabalho nos cálculos dos fatores de caracterização e ajuda em grande medida na avaliação regional do impacto do Uso do Solo nas FSV para as condições brasileiras. Mesmo assim, para avaliações mais locais, o trabalho com categorias de uso do solo no nível III faria com que os cálculos fossem mais precisos.

Como se observou para o cálculo de valores de $\mathrm{COS}_{2}$ durante a ocupação, foram utilizados fatores de ajuste que facilitam as aproximações de como o COS mudaria segundo diferentes gestões. Isto acarretaria maior facilidade para a obtenção de mais valores.

Considera-se importante a premissa de que o processo de ocupação mantem constantes as propriedades do solo. Isto porque durante este processo acontecem mudanças favoráveis e também contrárias às propriedades do solo que, em última análise, seriam compensadas, justificando desta forma esta premissa.

Vários autores fazem referência à grande dificuldade de se ter conhecimento da situação do solo antes das transformações e ocupações. Isso foi superado no caso do Bioma da Amazônia devido a trabalhos de mapeamento com ajuda de Sistemas Integrados Geográficos (SIG) que facilitaram a obtenção destes dados (LANGE, 2012).

Os valores de $\mathrm{COS}_{1}$ de cada tipo de solo identificado para a Amazônia foram combinados com todos os tipos de usos de solos (segundo o tipo de solo, gestão do solo) escolhidos no nível II. Tal fato tornou possível a formulação de várias combinações de mudanças de um tipo de uso do solo 1 a um tipo de solo 2. Para cada uma destas combinações, foram obtidos os respectivos fatores de caracterização.

Devido à grande extensão territorial do país e as diferentes condições climáticas conclui-se que a utilização de mais indicadores possibilitaria uma avaliação mais completa dos impactos. Esta necessidade é comprovada pela classificação do solo do território em diferentes biomas e ecorregiões, com características particulares em termos de relevo, vegetação, entre outros. Ao avaliar 
cada uma dessas diferenças vê-se a importância da inclusão de outros indicadores além do COS.

A definição de valores, teve como embasamento varias publicações dentro do Brasil (LANGE, 2012) assim como publicações internacionais (IPCC, 2006; FAO, 2004; FAO, 2005; EC, 2010) o que ajuda em grande medida o trabalho com o indicador.

Entretanto, apesar das limitações deste trabalho, acredita-se que os fatores de caracterização propostos colaborem não somente com a avaliação do impacto sobre as FSV, mas também para o avanço da técnica.

\subsection{RESTRIÇÕES DOS VALORES}

É importante ressaltar que todos os valores dos fatores de caracterização do Impacto do Uso do Solo obtidos são válidos apenas paras as limitações apresentadas ao longo do estudo. Cabe também destacar que os resultados obtidos representam as condições biogeográficas (Clima, tipos de solo) do Bioma da Amazônia.

Outra restrição que observa-se é que estes valores não bom representantes para os casos de solos salinos, os quais devem ser estudados separadamente com métodos apropriados para esse aspecto. 


\section{CONCLUSÕES}

A respeito dos métodos que avaliam o impacto do uso do solo, observou-se que estes consideram principalmente as mudanças de tipos de usos de solos como solos florestais a solos agrícolas, solos de pastagens a solos industriais, entre outros - e desconsideram as mudanças na qualidade durante a ocupação. Isto porque nestes casos estimam-se pequenas mudanças de altas e baixas nas propriedades do solo que no final determinariam se compensando.

O uso do solo influencia em várias FSV resultando isso em divergências na utilização de indicadores, tornando difícil a escolha de um indicador. Neste sentido, a seleção dos indicadores deve focar aqueles que se relacionem de forma mais adequada às FSV e que sejam conforme com as necessidades de avaliação dos países.

Observou-se a necessidade de aprimoramento nas avaliações do Impacto do uso do solo, pois ainda se tem pontos não consolidados como o caso da escolha da situação de referencia e o tempo de recuperação que vão influenciar nos resultados dos métodos.

Este impacto vem cobrando importância desde o ponto de vista da sustentabilidade, pois a sua não preservação faz com que este se esgote, é dizer, que a velocidade de recuperação de suas propriedades não segue o mesmo ritmo de como se vem utilizando este recurso. Desta forma, este impacto deve ser analisado corretamente com o objetivo de preservá-lo para as gerações futuras.

Demonstra-se que a avaliação do Impacto do Uso do Solo mediante a utilização COS é um bom representante, pois é um representante adequado em termos de médio e longo prazo adicionalmente este indicador cobre vários aspectos do impacto nas FSV como foi demonstrado ao longo deste texto. 
Observou-se que o COS é um bom indicador na comparação da produtividade de solos agrícolas Entretanto, a utilização de outros indicadores ajudaria a completeza da avaliação.

Recomenda-se para aproximações mais exatas dos tempos de recuperação e dos valores do COS com a utilização de softwares. Trabalhos como o realizado pela FAO (2004) têm demonstrado a grande contribuição nos cálculos considerando vários fatores que contribuem em mudanças do teor de COS, o que ajuda na precisão nos resultados.

Destaca-se que nem todos os manejos do solo serão prejudiciais no conteúdo do teor do COS tendo casos nos quais o teor de COS sofre alterações favoráveis ajudando assim na produtividade do solo e no incremento do seqüestro de carbono por parte do solo o que implicaria impactos negativos para esse tipo de uso do solo.

Finalmente, acredita-se que este trabalho contribuirá para as avaliações do Impacto do Uso do Solo para o caso das FSV no Brasil, possibilitando sua utilização em futuros estudos de ACV. 


\section{REFERÊNCIAS}

ABNT - ASSOCIAÇÃO BRASILEIRA DE NORMAS TÉCNICAS (ABNT). ABNT NBR ISO 14040: Gestão Ambienta I- Avaliação do Ciclo de Vida Princípios e estrutura. Rio de Janeiro, 2009a.

ABNT - ASSOCIAÇÃO BRASILEIRA DE NORMAS TÉCNICAS (ABNT). ABNT NBR ISO 14044: Gestão Ambienta I- Avaliação do Ciclo de Vida Princípios e estrutura. Rio de Janeiro, 2009b.

ABNT - ASSOCIAÇÃO BRASILEIRA DE NORMAS TÉCNICAS (ABNT). ABNT NBR ISO 14001: Sistema para gestão ambiental - requisitos com orientações para uso. Rio de Janeiro, 2004.

BAUMANN, H.; TILLMANN, A. M. The Hitch Hiker's Guide to LCA: an orientation in Life Cycle Assessment methodology and application. Lund. Editora Studentlitteratur AB.2004. p 73-202.

BLONK, Hans; LINDEIJER, Erwin; BROERS, Joris. Towards a methodology for taking physical degradation of ecosystems into account in LCA. International Journal of Life Cycle Assessment, v. 2, n. 2, p. 91-98. 1997.

BORGER, G. F. Responsabilidade corporativa: a dimensão ética, social e ambiental na gestão das organizações. JÚNIOR, A. V.; DEMAJOROVIC, J. (Org.). Modelos e ferramentas de gestão ambiental: desafios e perspectivas das organizações. $2^{\text {nd }}$ ed. São Paulo: Editora Senac, 2006. p 313 - 336.

BRANDÃO, M.; MILÀ I CANALS, L. Global characterization factors to assess land use impacts o biotic production. The International Journal of Life Cycle Assessment, Alemanha, v.7, n. 6, p. 339-348, 2012.

BRASIL. Lei n' 11.097, de 13 de janeiro de 2005. Dispõe sobre a introdução do biodiesel na matriz energética brasileira. Brasília, 13 de Janeiro de 2005.

BRENTRUP, F.; KÜSTERS, J.; LAMMEL, J.; KUHLMANN, H. Life Cycle Impact Assessment of Land Use Based on the Hemeroby Concept, The International Journal of Life Cycle Assessment, Alemanha, v.7, n. 6, p. 339-348, 2002. 
CHEHEBE, J.R.B. Analise do ciclo de vida de produtos: ferramenta gerencial das ISO 14000. Rio de Janeito: Quality Ed., CNI, 1997.

COLIN B. A. Development of a life cycle impact assessment procedure for life cycle management in South Africa. 2004. (Teses de doutorado). Departamento de engenharia e gestão tecnológica. Petoria University. South Africa.

CORINE. Land cover technical guide. Copenhagen. 2000.

EC - EUROPEAN COMMISSION. Commission decision on guidelines for the calculation of land carbon stocks for the purpose. Official journal of the European Union. Ispra. 2010. p 19-41.

EMBRAPA - Empresa Brasileira de Pesquisa Agropecuária. Disponível em $<$ http://www.embrapa.br/>. Acesso 2012.

EMBRAPA - Empresa Brasileira de Pesquisa Agropecuária. Sistema brasileiro de classificação de solos. EMBRAPA. Brasil, 2009, p. 328-339.

FAO - FOOD AND AGRICULTURE ORGANIZATION OF THE UNITED NATIONS. Assessing carbon stocks and modeling win-win scenarios of carbon sequestration through land-use changes. FAO. Rome. 2004.

FAO - FOOD AND AGRICULTURE ORGANIZATION OF THE UNITED NATIONS. The importance of soil organic matter: key to drought-resistant soil and sustained food production. FAO. Roma. 2005.

GARRAÍN CORDEO D., Desarrollo y Aplicación de las Categorías de Impacto Ambiental de Ruido y de Uso de Suelo en la Metodología de Análisis de Ciclo de Vida. 2009. (Tesis de Doctorado), Departamento de Ingeniería de sistemas Industriales y Diseño y Departamento de Ingeniería Mecánica y Construcción, Universidad de Jaume.

GOEDKOOP, MARK; SPRIENSMA, RENILDE. The Eco-Indicator 99: a damage oriented method for Life Cycle Impact Assessment. Amersfoort: PréConsultants, 2001. $132 \mathrm{p}$.

GOEKOOP, M.; HEIJUNGS, R.; HUIJBREGTS, M.; DE SCHRYVER, A.; STRUIJS, J.; VAM ZELM, R.; RECIPE 2008, A Life Cycle Impact Assessment 
Method Which Comprises Harmonised Category Indicators at the Midpoint and Endpoint Level, Report I: Characterization, Holanda, p. 89-106, 2009.

IBGE, Fundação Instituto Brasileiro de Geografia e Estatística. Disponível em http://www.ibge.gov.br/home/. Acesso em 2012.

IBGE, Fundação Instituto Brasileiro de Geografia e Estatística. Manual Técnico de Uso da Terra. Rio de Janeiro: IBGE, 2006.

ILCD - INTERNATIONAL REFERENCE LIFE CYCLE DATA SYSTEM. Framework and requirements for Life Cycle Impact Assessment models and indicators: provisions. European Union: Joint Research Center; Institute for Environment and Sustainability. 2010a. p 2-15.

ILCD - INTERNATIONAL REFERENCE LIFE CYCLE DATA SYSTEM. General guide for life cycle assessment - provisions and action steps. European Union: Joint Research Center; Institute for Environment and Sustainability. 2010b. p 9-103.

IPCC - INTERGOVERNMENTAL PANEL ON CLIMATE CHANGE. Good practice guidance for land use, land-use change and forestry. Japan. 2003.

IPCC - INTERGOVERNMENTAL PANEL ON CLIMATE CHANGE. Guidelines for national greenhouse gas inventories: agriculture, forestry, and other land use. Kanagawa. Japan. v 4. 2006.

KOELLNER, T.; ROLAND, W.;SCHOL, Z. Assessment of Land Use Impacts on the Natural Environment. The International Journal of Life Cycle Assessment, Berlin v.12, n.1, p.16-23, 2007.

KÖLLNER, T. Species-pool effect potentials (SPEP) as a yardstick to evaluate land-use impacts on biodiversity. Journal of cleaner productions. United States. V.12, p, 1999.

LANCA. Land use indicator value calculation in life cycle assessment: method report. 2008.

LANGE. V. M, A mudança do estoque de carbono por transformação da terra e seu uso no inventario de ciclo de vida de produtos de origem renovável: estudo caso da possível expansão da palma de óleo na Amazônia legal 
brasileira (Teses de mestrado). Departamento engenharia mecânica e de materiais. Universidade tecnológica Federal de Paraná. 2012. Curitiba. p 70-72.

LANGLOIS J.; HÉLIAS A.; DELGENÈS J.; STEYER J. Review on Land Use Considerations in Life Cycle Assessment: Methodological Perspectives for Marine Ecosystems. Towards Life Cycle Sustainanability Management, France, p. 85-96, 2011.

LCI - LIFE CYCLE INITIATIVE - Life Cycle Initiative. Site coorporativo. Disponível em < http://lcinitiative.unep.fr/default.asp?site=lcinit\&page id=9FDF7FDF-261F4F0E-A8E3-5FF4E16B33C2>. Accesso em 2011.

LINDEIJER, E. Biodiversity and life support impacts of land use in LCA, Journal of Cleaner Production, United States, v.8, n.4, p.273-281, 2000a.

LINDEIJER, E. Review of land use impact methodologies, Journal of Cleaner Production, United States, v.8, n.4, p.273-281, 2000b.

MATTSSON, B.; CEDERBERG, C.; BLIX, L. Agricultural land use in life cycle assessment (LCA): case studies of three vegetable oil crops, Journal of Cleaner Production, United States, v.8, n.4, p. 283-292, 2000.

MICHELSEN, O. Assessment of Land Use Impact on Biodiversity: Proposal of a New Methodology Exemplified with Forestry Operations in Norway, The International Journal of Life Cycle Assessment, Alemanha, v.3, n. 1, p. 22-31, 2008.

MILÀ I CANALS; RIGARLSFORD, G. Land use impact assessment of margarine. The International Journal of Life Cycle Assessment. Alemanha. v 15, p. 14261440. 2012

MILÀ I CANALS, L.; ROMANYA, J.; COWELL, J. S. Method for assessing impacts on life support functions (LSF) related to the use of "fertile land" in Life Cycle Assessment (LCA). Journal of Cleaner Production, v 15, p. 1426-1440. 2007.

MILÀ I CANALS, LI. BAUER Ch., DEPESTELE J., DUBREUIL A., KNUCHEL R., GAILLARD G., MICHELSEN O., MÜLLER- WENK R., RYDGREN B., Key Elements in a Framework for Land Use Impact Assessment Within LCA, The International Journal of Life Cycle Assessment, Berlin, v.12, n.1, p. 5-15, 2007. 
MILÀ I CANALS, Llorenç. Contributions to LCA methodology for agricultural systems: Site dependency and soil degradation impact assessment. 2003. $p$ 171-236. Tese (Doutorado) - Curso de Cièncias Ambientais, Departamento de Química, Universidad Autònoma de Barcelona, Barcelona.

MMA - MINISTERIO DO MEIO AMBIENTE DO BRASIL. Disponível em < http://www.mma.gov.br/biodiversidade/biodiversidade-brasileira>. Acesso em: 2010.

ODUM, E. P., Ecologia. Rio de Janeiro: Guanabara Koogan, 2012.

SAAD, R.; MARGNI, M.; KOELLNER, T.; WITTSTOCK, B.; DESCHÊNES, L.; Assessment of Land Use Impacts on Soil Ecological Functions: Development of Spatially Differentiated characterization Factors Within a Canadian Context, The International Journal of Life Cycle Assessment, Alemanha, v.16, n. 3, p. 198$211,2011$.

SCHMIDT. J. H. Development of LCIA characterisation factors for land use impacts on biodiversity. Journal of cleaner productions. United States. n. 16, p. 1929-42. 2008.

SETAC, The Society of Environmental Toxicology and Chemistry. Life Cycle Impact Assessment: striving towards best Practice. Brussels: SETAC, 2002. p 6590.

SILVA, G. A.; KULAY, L.A. Avaliação do Ciclo de Vida. JÚNIOR, A. V.; DEMAJOROVIC, J. (Org.). Modelos e ferramentas de gestão ambiental: desafios e perspectivas das organizações. $2^{\text {nd }}$ ed. São Paulo: Editora Senac, 2006. p $313-336$.

SOUZA. M. D., Proposição de um Modelo de Caracterização para Avaliação de uso da Terra, com Indicadores de Biodiversidade, para o Brasil (Tese de Doutorado), Departamento de Engenharia Ambiental, Universidade de Santa Catarina, Florianópolis, 2010.

TONELLO, V. M. M. Principais aspectos do ciclo biogeoquímico do elemento carbono e seu contexto na atualidade. 2007. Dissertação (Mestrado em Ecologia Aplicada). Universidade de São Paulo. Escola Superior de Agricultura "Luiz de Queiroz" Centro de Energia Nuclear na Agricultura. 
UDO de HAES, H. A. How to approach land use in LCIA or, how to avoid the Cinderella effect? Comments on 'Key Elements in a Framework for Land Use Impact Assessment Within LCA'. International Journal of Life Cycle Assessment, v. 11, n.4, p. $219-221,2006$.

VOGTLÄNDER, Joost G., et al. Characterizing the change of land-use based on flora: application for EIA and LCA. Journal of Cleaner Production, v. 12, p. 4757. 2004.

WAGENDORP T., GULINCK H., COPPIN P., MUYS B., Land use impact evaluation in life cycle assessment based on ecosystem thermodynamics, Journal Energy, United States, v.31, n.1, p. 112-125, 2006.

WEIDEMA, B., LINDEIJER, E. Physical impacts of land use in product life cycle assessment. Final report of the EURENVIRON-LCAGAPS sub-project on land use. Department of Manufacturing Engineering and Management, Technical University of Denmark, 2001. 


\section{ANEXOS}

\section{ANEXO A - Tipos de uso do solo no Brasil}

Tabela A. 1 - Tipos de uso do solo no Brasil (IBGE, 2006)

\begin{tabular}{|c|c|c|}
\hline $\begin{array}{l}\text { NÍVEL I } \\
\text { (CLASSE) }\end{array}$ & $\begin{array}{c}\text { NIVEL II } \\
\text { (SUBCLASSE) }\end{array}$ & $\begin{array}{c}\text { NIVEL III } \\
\text { (UNIDADE) }\end{array}$ \\
\hline \multirow{7}{*}{$\begin{array}{c}\text { Áreas } \\
\text { Antrópicas } \\
\text { não Agrícolas }\end{array}$} & \multirow{5}{*}{$\begin{array}{c}\text { Áreas } \\
\text { Urbanizadas }\end{array}$} & Vilas \\
\hline & & Cidades \\
\hline & & Complexos industriais \\
\hline & & Áreas urbano-industrial \\
\hline & & Outras áreas urbanizadas \\
\hline & \multirow{2}{*}{$\begin{array}{c}\text { Áreas de } \\
\text { Extração } \\
\text { ou Mineração }\end{array}$} & Metálicos \\
\hline & & Não-metálicos \\
\hline \multirow{21}{*}{$\begin{array}{c}\text { Áreas } \\
\text { Antrópicas } \\
\text { Agrícolas }\end{array}$} & \multirow{10}{*}{$\begin{array}{c}\text { Cultura } \\
\text { Temporária }\end{array}$} & Graníferas e cerealíferas \\
\hline & & Bulbos, raízes e tubérculos \\
\hline & & Hortícolas e floríferas \\
\hline & & Espécies temporárias, produtoras de fibras \\
\hline & & Oleaginosas temporárias \\
\hline & & Frutíferas temporárias \\
\hline & & Cana-de-acúcar \\
\hline & & Fumo \\
\hline & & Cultivos temporários diversificados \\
\hline & & Outros cultivos temporários \\
\hline & \multirow{5}{*}{$\begin{array}{c}\text { Cultura } \\
\text { Permanente }\end{array}$} & Frutíferas permanentes \\
\hline & & Frutos secos permanentes \\
\hline & & Espécies permanentes produtoras de flora \\
\hline & & Oleaginosas permanentes \\
\hline & & Cultivos permanentes diversificados \\
\hline & \multirow{3}{*}{ Pastagem } & Pecuária de animais de grande porte \\
\hline & & Pecuária de animais de médio porte \\
\hline & & Pecuária de animais de pequeno porte \\
\hline & \multirow{2}{*}{ Sivicultura } & Reflorestamento \\
\hline & & Cultivo agro-florestal \\
\hline & Outros & Uso não identificado \\
\hline
\end{tabular}


Continuação da tabela A.1

\begin{tabular}{|c|c|c|}
\hline $\begin{array}{l}\text { NÍVEL I } \\
\text { (CLASSE) }\end{array}$ & $\begin{array}{c}\text { NÍVEL II } \\
\text { (SUBCLASSE) }\end{array}$ & $\begin{array}{l}\text { NÍVEL III } \\
\text { (UNIDADE) }\end{array}$ \\
\hline \multirow{19}{*}{$\begin{array}{c}\text { Áreas de } \\
\text { Vegetação } \\
\text { Natural }\end{array}$} & \multirow{8}{*}{ Florestas } & $\begin{array}{l}\text { Unidades de conservação de proteção } \\
\text { integral em área florestal }\end{array}$ \\
\hline & & $\begin{array}{l}\text { Unidade de conservação de uso } \\
\text { sustentável em área florestal }\end{array}$ \\
\hline & & Terra Indígena em área florestal \\
\hline & & Outras áreas protegidas em área florestal \\
\hline & & Áreas militares em área florestal \\
\hline & & Extrativismo vegetal em área florestal \\
\hline & & Extrativismo animal em área florestal \\
\hline & & Uso não identificado em área florestal \\
\hline & \multirow{11}{*}{ Campestre } & $\begin{array}{l}\text { Unidades de conservação de proteção } \\
\text { integral em área campestre }\end{array}$ \\
\hline & & $\begin{array}{l}\text { Unidade de conservação de uso } \\
\text { sustentável em área campestre }\end{array}$ \\
\hline & & Terra Indígena em área campestre \\
\hline & & $\begin{array}{l}\text { Outras áreas protegidas em área } \\
\text { campestre }\end{array}$ \\
\hline & & Áreas militares em área campestre \\
\hline & & Extrativismo vegetal em área campestre \\
\hline & & Extrativismo animal em área campestre \\
\hline & & Uso não identificado em área campestre \\
\hline & & $\begin{array}{l}\text { Pecuária de animais de grande porte em } \\
\text { área campestre }\end{array}$ \\
\hline & & $\begin{array}{l}\text { Pecuária de animais de médio porte em } \\
\text { área campestre }\end{array}$ \\
\hline & & $\begin{array}{l}\text { Pecuária de animais de pequeno porte em } \\
\text { área campestre }\end{array}$ \\
\hline
\end{tabular}


Continuação da tabela A.1

\begin{tabular}{|c|c|c|}
\hline $\begin{array}{l}\text { NÍVEL I } \\
\text { (CLASSE) }\end{array}$ & $\begin{array}{c}\text { NÍVEL II } \\
\text { (SUBCLASSE) }\end{array}$ & $\begin{array}{l}\text { NÍVEL III } \\
\text { (UNIDADE) }\end{array}$ \\
\hline \multirow{10}{*}{ Outras Áreas } & \multirow{10}{*}{$\begin{array}{c}\text { Áreas } \\
\text { Descobertas }\end{array}$} & $\begin{array}{l}\text { Unidade de conservação de proteção } \\
\text { integral em área descoberta }\end{array}$ \\
\hline & & $\begin{array}{l}\text { Unidade de conservação de uso } \\
\text { sustentável em área descoberta }\end{array}$ \\
\hline & & Terra Indígena em área descoberta \\
\hline & & $\begin{array}{l}\text { Outras áreas protegidas em área } \\
\text { descoberta }\end{array}$ \\
\hline & & Àreas militares em área descoberta \\
\hline & & Extrativismo animal em área descoberta \\
\hline & & Uso não identificado em área descoberta \\
\hline & & $\begin{array}{l}\text { Pecuária de animais de grande porte em } \\
\text { área descoberta }\end{array}$ \\
\hline & & $\begin{array}{l}\text { Pecuária de animais de médio porte em } \\
\text { área descoberta }\end{array}$ \\
\hline & & $\begin{array}{l}\text { Pecuária de animais de pequeno porte em } \\
\text { área descoberta }\end{array}$ \\
\hline
\end{tabular}


ANEXO B - Tipos de solos no Brasil

Tabela B. 1 - Tipos de solo no Brasil (EMBRAPA, 2009) NIVEL I NIVEL II Argissolos Bruno Acinzentados

Argissolos Acinzentados

Argissolos Argissolos Amarelos

Argissolos Vermelhos

Argissolos Vermelhos-Amarelos

Cambissolos Húmicos

\begin{tabular}{|c|c|}
\hline Cambissolos & Cambissolos Flúvicos \\
\hline & Cambissolos Haplicos \\
\hline & Chernossolos Rêndzicos \\
\hline Chernossolos & Chernossolos Argilúvicos \\
\hline & Chernossolos Ebânicos \\
\hline & Chernossolos Háplicos \\
\hline & Espodossolos Humilúvico \\
\hline Espodossolos & Espodossolos Ferrilúvico \\
\hline & Espodossolos Ferrihumiúvico \\
\hline & Gleissolos Tiomórficos \\
\hline Aloiccolnc & Gleissolos Sálicos \\
\hline Glelssolos & Gleissolos Melânicos \\
\hline & Gleissolos Hâplicos \\
\hline & Latossolos Brunos \\
\hline I atncenloc & Latossolos Amarelos \\
\hline Lalussulus & Latossolos Vermelhos \\
\hline & Latossolos Vermelhos-Ama \\
\hline
\end{tabular}


Continuação da tabela B.1

\begin{tabular}{|c|c|}
\hline NIVEL I & NIVEL II \\
\hline \multirow{2}{*}{ Luvissolos } & Luvissolos Crômicos \\
\hline & Luvissolos Háplicos \\
\hline \multirow{4}{*}{ Neossolos } & Neossolos Litólicos \\
\hline & Neossolos Flúvicos \\
\hline & Neossolos Regolíticos \\
\hline & Neossolos Quartzarênicos \\
\hline \multirow{3}{*}{ Nitossolos } & Nitossolos Brunos \\
\hline & Nitossolos Vermelhos \\
\hline & Nitossolos Háplicos \\
\hline \multirow{3}{*}{ Organossolos } & Organossolos Tiomórficos \\
\hline & Organossolos Fólicos \\
\hline & Organossolos Háplicos \\
\hline \multirow{2}{*}{ Planossolos } & Planossolos Nátricos \\
\hline & Planossolos Háplicos \\
\hline \multirow{3}{*}{ Plintossolos } & Plintossolos Pétricos \\
\hline & Plintossolos Argilúvicos \\
\hline & Plintossolos Háplicos \\
\hline \multirow{3}{*}{ Vertissolos } & Vertissolos Hifromórficos \\
\hline & Vertissolos Ebânicos \\
\hline & Vertissolos Háplicos \\
\hline
\end{tabular}




\section{ANEXO C - Fatores de Ajuste para o COS segundo Clima, Uso e Gestão do Solo.}

Tabela C. 1 - Fatores para Lavouras (EC, 2010)

\begin{tabular}{|c|c|c|c|c|c|c|}
\hline $\begin{array}{l}\text { Clima da } \\
\text { Região }\end{array}$ & $\begin{array}{c}\text { Uso do } \\
\text { Solo } \\
\text { (Fus) }\end{array}$ & $\begin{array}{c}\text { Gestão do Solo } \\
\left(F_{\mathrm{GS}}\right)\end{array}$ & $\begin{array}{l}\text { Entrada } \\
\qquad\left(F_{E}\right)\end{array}$ & $\left(F_{\mathrm{US}}\right)$ & $\left(F_{\mathrm{GS}}\right)$ & $\left(F_{\mathrm{E}}\right)$ \\
\hline \multirow{15}{*}{$\begin{array}{l}\text { Temperado/ } \\
\text { Boreal, Seco }\end{array}$} & \multirow{15}{*}{ Cultivado } & \multirow{5}{*}{ Cultivo Completo } & Baixo & 0.8 & 1 & 0.95 \\
\hline & & & Médio & 0.8 & 1 & 1 \\
\hline & & & Com alto & & & \\
\hline & & & Estrume & 0.8 & 1 & 1.37 \\
\hline & & & Sem Estrume & 0.8 & 1 & 1.04 \\
\hline & & \multirow{5}{*}{$\begin{array}{l}\text { Preparo } \\
\text { Reduzido }\end{array}$} & Baixo & 0.8 & 1.02 & 0.95 \\
\hline & & & Médio & 0.8 & 1.02 & 1 \\
\hline & & & Com alto & & & \\
\hline & & & Estrume & 0.8 & 1.02 & 1.37 \\
\hline & & & Sem Estrume & 0.8 & 1.02 & 1.04 \\
\hline & & \multirow{5}{*}{ Plantio Direto } & Baixo & 0.8 & 1.1 & 0.95 \\
\hline & & & Médio & 0.8 & 1.1 & 1 \\
\hline & & & Com alto & & & \\
\hline & & & Estrume & 0.8 & 1.1 & 1.37 \\
\hline & & & Sem Estrume & 0.8 & 1.1 & 1.04 \\
\hline \multirow{15}{*}{$\begin{array}{l}\text { Temperado/ } \\
\text { Boreal, } \\
\text { Úmido/ } \\
\text { Úmido }\end{array}$} & \multirow{15}{*}{ Cultivado } & \multirow{5}{*}{ Cultivo Completo } & Baixo & 0.69 & 1 & 0.95 \\
\hline & & & Médio & 0.69 & 1 & 1 \\
\hline & & & Com alto & & & \\
\hline & & & Estrume & 0.69 & 1 & 1.37 \\
\hline & & & Sem Estrume & 0.69 & 1 & 1.04 \\
\hline & & \multirow{5}{*}{$\begin{array}{l}\text { Preparo } \\
\text { Reduzido }\end{array}$} & Baixo & 0.69 & 1.08 & 0.92 \\
\hline & & & Médio & 0.69 & 1.08 & 1 \\
\hline & & & Com alto & & & \\
\hline & & & Estrume & 0.69 & 1.08 & 1.44 \\
\hline & & & Sem Estrume & 0.69 & 1.08 & 1.11 \\
\hline & & \multirow{5}{*}{ Plantio Direto } & Baixo & 0.69 & 1.15 & 0.92 \\
\hline & & & Médio & 0.69 & 1.15 & 1 \\
\hline & & & Com alto & & & \\
\hline & & & Estrume & 0.69 & 1.15 & 1.44 \\
\hline & & & Sem Estrume & 0.69 & 1.15 & 1.11 \\
\hline
\end{tabular}


Continuação da tabela C.1

\begin{tabular}{|c|c|c|c|c|c|c|}
\hline $\begin{array}{l}\text { Clima da } \\
\text { Região }\end{array}$ & $\begin{array}{c}\text { Uso do } \\
\text { Solo } \\
\text { (Fus) }\end{array}$ & $\begin{array}{l}\text { Gestão do Solo } \\
\qquad\left(F_{\mathrm{GS}}\right)\end{array}$ & $\begin{array}{l}\text { Entrada } \\
\qquad\left(F_{\mathrm{E}}\right)\end{array}$ & $\left(F_{\mathrm{US}}\right)$ & $\left(F_{\mathrm{GS}}\right)$ & $\left(F_{\mathrm{E}}\right)$ \\
\hline \multirow{15}{*}{$\begin{array}{l}\text { Tropical, } \\
\text { Seco }\end{array}$} & \multirow{15}{*}{ Cultivado } & \multirow{5}{*}{ Cultivo Completo } & Baixo & 0.58 & 1 & 0.95 \\
\hline & & & Médio & 0.58 & 1 & 1 \\
\hline & & & Com alto & & & \\
\hline & & & Estrume & 0.58 & 1 & 1.37 \\
\hline & & & Sem Estrume & 0.58 & 1 & 1.04 \\
\hline & & \multirow{5}{*}{$\begin{array}{l}\text { Preparo } \\
\text { Reduzido }\end{array}$} & Baixo & 0.58 & 1.09 & 0.95 \\
\hline & & & Médio & 0.58 & 1.09 & 1 \\
\hline & & & Com alto & & & \\
\hline & & & Estrume & 0.58 & 1.09 & 1.37 \\
\hline & & & Sem Estrume & 0.58 & 1.09 & 1.04 \\
\hline & & \multirow{5}{*}{ Plantio Direto } & Baixo & 0.58 & 1.17 & 0.95 \\
\hline & & & Médio & 0.58 & 1.17 & 1 \\
\hline & & & Com alto & & & \\
\hline & & & Estrume & 0.58 & 1.17 & 1.37 \\
\hline & & & Sem Estrume & 0.58 & 1.17 & 1.04 \\
\hline \multirow{15}{*}{$\begin{array}{c}\text { Tropical, } \\
\text { úmido/úmido }\end{array}$} & \multirow{15}{*}{ Cultivado } & \multirow{5}{*}{ Cultivo Completo } & Baixo & 0.48 & 1 & 0.92 \\
\hline & & & Médio & 0.48 & 1 & 1 \\
\hline & & & Com alto & & & \\
\hline & & & Estrume & 0.48 & 1 & 1.44 \\
\hline & & & Sem Estrume & 0.48 & $\overline{1}$ & 1.11 \\
\hline & & \multirow{5}{*}{$\begin{array}{l}\text { Preparo } \\
\text { Reduzido }\end{array}$} & Baixo & 0.48 & 1.15 & 0.92 \\
\hline & & & Médio & 0.48 & 1.15 & 1 \\
\hline & & & Com alto & & & \\
\hline & & & Estrume & 0.48 & 1.15 & 1.44 \\
\hline & & & Sem Estrume & 0.48 & 1.15 & 1.11 \\
\hline & & \multirow{5}{*}{ Plantio Direto } & Baixo & 0.48 & 1.22 & 0.92 \\
\hline & & & Médio & 0.48 & 1.22 & 1 \\
\hline & & & Com alto & & & \\
\hline & & & Estrume & 0.48 & 1.22 & 1.44 \\
\hline & & & Sem Estrume & 0.48 & 1.22 & 1.11 \\
\hline \multirow{10}{*}{$\begin{array}{c}\text { Tropical } \\
\text { Montanhoso }\end{array}$} & \multirow{10}{*}{ Cultivado } & \multirow{5}{*}{ Cultivo Completo } & Baixo & 0.64 & 1 & 0.94 \\
\hline & & & Médio & 0.64 & 1 & 1 \\
\hline & & & Com alto & & & \\
\hline & & & Estrume & 0.64 & 1 & 1.41 \\
\hline & & & Sem Estrume & 0.64 & 1 & 1.08 \\
\hline & & \multirow{5}{*}{$\begin{array}{l}\text { Preparo } \\
\text { Reduzido }\end{array}$} & Baixo & 0.64 & 1.09 & 0.94 \\
\hline & & & Médio & 0.64 & 1.09 & 1 \\
\hline & & & Com alto & & & \\
\hline & & & Estrume & 0.64 & 1.09 & 1.41 \\
\hline & & & Sem Estrume & 0.64 & 1.09 & 1.08 \\
\hline
\end{tabular}


Continuação da tabela C.1

\begin{tabular}{|c|c|c|c|c|c|c|}
\hline \multirow[t]{6}{*}{$\begin{array}{l}\text { Clima da } \\
\text { Região }\end{array}$} & $\begin{array}{c}\text { Uso do } \\
\text { Solo } \\
\text { (Fus) }\end{array}$ & $\begin{array}{c}\text { Gestão do Solo } \\
\left(F_{\mathrm{GS}}\right)\end{array}$ & $\begin{array}{l}\text { Entrada } \\
\qquad\left(F_{\mathrm{E}}\right)\end{array}$ & $\left(F_{\text {US }}\right)$ & $\left(F_{\mathrm{GS}}\right)$ & $\left(F_{\mathrm{E}}\right)$ \\
\hline & & & Baixo & 0.64 & 1.16 & 0.94 \\
\hline & & & Médio & 0.64 & 1.16 & 1 \\
\hline & & Plantio Direto & Com alto & & & \\
\hline & & & Estrume & 0.64 & 1.16 & 1.41 \\
\hline & & & Sem Estrume & 0.64 & 1.16 & 1.08 \\
\hline
\end{tabular}


Tabela C. 2 - Fatores para Safras Perenes, ou seja, culturas plurianuais cujo caule não é geralmente colhido anualmente tal como a talhada de rotação curta e cultivo de óleo de Palma (EC, 2010)

\begin{tabular}{|c|c|c|c|c|c|c|}
\hline $\begin{array}{l}\text { Clima da } \\
\text { Região }\end{array}$ & $\begin{array}{l}\text { Uso do } \\
\text { Solo } \\
\text { (Fus) }\end{array}$ & $\begin{array}{c}\text { Gestão do Solo } \\
\left(F_{\mathrm{GS}}\right)\end{array}$ & $\begin{array}{l}\text { Entrada } \\
\qquad\left(F_{E}\right)\end{array}$ & $\left(F_{\text {us }}\right)$ & $\left(F_{\mathrm{GS}}\right)$ & $\left(F_{\mathrm{E}}\right)$ \\
\hline \multirow{13}{*}{$\begin{array}{l}\text { Temperado/ } \\
\text { Boreal, Seco }\end{array}$} & \multirow{13}{*}{$\begin{array}{c}\text { Safra } \\
\text { Perene }\end{array}$} & \multirow{5}{*}{ Cultivo Completo } & Baixo & 1 & 1 & 0.95 \\
\hline & & & Médio & 1 & 1 & 1 \\
\hline & & & Com alto & & & \\
\hline & & & Estrume & 1 & 1 & 1.37 \\
\hline & & & Sem Estrume & 1 & 1 & 1.04 \\
\hline & & \multirow{4}{*}{$\begin{array}{l}\text { Preparo } \\
\text { Reduzido }\end{array}$} & Baixo & 1 & 1.02 & 0.95 \\
\hline & & & Médio & 1 & 1.02 & 1 \\
\hline & & & $\begin{array}{l}\text { Com alto } \\
\text { Estrume }\end{array}$ & 1 & 1.02 & 1.37 \\
\hline & & & Sem Estrume & 1 & 1.02 & 1.04 \\
\hline & & \multirow{4}{*}{ Plantio Direto } & Baixo & 1 & 1.1 & 0.95 \\
\hline & & & Médio & 1 & 1.1 & 1 \\
\hline & & & $\begin{array}{l}\text { Com alto } \\
\text { Estrume }\end{array}$ & 1 & 1.1 & 1.37 \\
\hline & & & Sem Estrume & 1 & 1.1 & 1.04 \\
\hline \multirow{14}{*}{$\begin{array}{c}\text { Temperado/ } \\
\text { Boreal, Úmido/ } \\
\text { Úmido }\end{array}$} & \multirow{14}{*}{$\begin{array}{c}\text { Safra } \\
\text { Perene }\end{array}$} & \multirow{5}{*}{ Cultivo Completo } & Baixo & 1 & 1 & 0.92 \\
\hline & & & Médio & 1 & 1 & 1 \\
\hline & & & Com alto & & & \\
\hline & & & Estrume & 1 & 1 & 1.44 \\
\hline & & & Sem Estrume & 1 & 1 & 1.11 \\
\hline & & \multirow{4}{*}{$\begin{array}{l}\text { Preparo } \\
\text { Reduzido }\end{array}$} & Baixo & 1 & 1.08 & 0.92 \\
\hline & & & Médio & 1 & 1.08 & 1 \\
\hline & & & $\begin{array}{l}\text { Com alto } \\
\text { Estrume }\end{array}$ & 1 & 1.08 & 1.44 \\
\hline & & & Sem Estrume & 1 & 1.08 & 1.11 \\
\hline & & \multirow{5}{*}{ Plantio Direto } & Baixo & 1 & 1.15 & 0.92 \\
\hline & & & Médio & 1 & 1.15 & 1 \\
\hline & & & Com alto & & & \\
\hline & & & Estrume & 1 & 1.15 & 1.44 \\
\hline & & & Sem Estrume & 1 & 1.15 & 1.11 \\
\hline
\end{tabular}


Continuação da tabela C.2

\begin{tabular}{|c|c|c|c|c|c|c|}
\hline $\begin{array}{l}\text { Clima da } \\
\text { Região }\end{array}$ & $\begin{array}{c}\text { Uso do Solo } \\
\text { (Fus })\end{array}$ & $\begin{array}{c}\text { Gestão do Solo } \\
\left(F_{\mathrm{GS}}\right)\end{array}$ & $\begin{array}{l}\text { Entrada } \\
\qquad\left(F_{\mathrm{E}}\right)\end{array}$ & $\left(F_{\mathrm{US}}\right)$ & $\left(F_{\mathrm{GS}}\right)$ & $\left(F_{\mathrm{E}}\right)$ \\
\hline \multirow{14}{*}{ Tropical, seco } & \multirow{14}{*}{$\begin{array}{l}\text { Safra } \\
\text { Perene }\end{array}$} & \multirow{5}{*}{ Cultivo Completo } & Baixo & 1 & 1 & 0.95 \\
\hline & & & Médio & 1 & 1 & 1 \\
\hline & & & Com alto & & & \\
\hline & & & Estrume & 1 & 1 & 1.37 \\
\hline & & & Sem Estrume & 1 & 1 & 1.04 \\
\hline & & \multirow{4}{*}{$\begin{array}{l}\text { Preparo } \\
\text { Reduzido }\end{array}$} & Baixo & 1 & 1.09 & 0.95 \\
\hline & & & Médio & 1 & 1.09 & 1 \\
\hline & & & $\begin{array}{l}\text { Com alto } \\
\text { Estrume }\end{array}$ & 1 & 1.09 & 1.37 \\
\hline & & & Sem Estrume & 1 & 1.09 & 1.04 \\
\hline & & \multirow{5}{*}{ Plantio Direto } & Baixo & 1 & 1.17 & 0.95 \\
\hline & & & Médio & 1 & 1.17 & 1 \\
\hline & & & Com alto & & & \\
\hline & & & Estrume & 1 & 1.17 & 1.37 \\
\hline & & & Sem Estrume & 1 & 1.17 & 1.04 \\
\hline \multirow{14}{*}{$\begin{array}{l}\text { Tropical, Úmido/ } \\
\text { Úmido }\end{array}$} & \multirow{14}{*}{$\begin{array}{l}\text { Safra } \\
\text { Perene }\end{array}$} & \multirow{5}{*}{ Cultivo Completo } & Baixo & 1 & 1 & 0.92 \\
\hline & & & Médio & 1 & 1 & 1 \\
\hline & & & Com alto & & & \\
\hline & & & Estrume & 1 & 1 & 1.44 \\
\hline & & & Sem Estrume & 1 & 1 & 1.11 \\
\hline & & \multirow{4}{*}{$\begin{array}{l}\text { Preparo } \\
\text { Reduzido }\end{array}$} & Baixo & 1 & 1.15 & 0.92 \\
\hline & & & Médio & 1 & 1.15 & 1 \\
\hline & & & $\begin{array}{l}\text { Com alto } \\
\text { Estrume }\end{array}$ & 1 & 1.15 & 1.44 \\
\hline & & & Sem Estrume & 1 & 1.15 & 1.11 \\
\hline & & \multirow{5}{*}{ Plantio Direto } & Baixo & 1 & 1.22 & 0.92 \\
\hline & & & Médio & 1 & 1.22 & 1 \\
\hline & & & Com alto & & & \\
\hline & & & Estrume & 1 & 1.22 & 1.44 \\
\hline & & & Sem Estrume & 1 & 1.22 & 1.11 \\
\hline \multirow{15}{*}{$\begin{array}{c}\text { Tropical } \\
\text { Montanhoso }\end{array}$} & \multirow{15}{*}{$\begin{array}{l}\text { Safra } \\
\text { Perene }\end{array}$} & \multirow{5}{*}{ Cultivo Completo } & Baixo & 1 & 1 & 0.94 \\
\hline & & & Médio & 1 & 1 & 1 \\
\hline & & & Com alto & & & \\
\hline & & & Estrume & 1 & 1 & 1.41 \\
\hline & & & Sem Estrume & 1 & 1 & 1.08 \\
\hline & & \multirow{5}{*}{$\begin{array}{l}\text { Preparo } \\
\text { Reduzido }\end{array}$} & Baixo & 1 & 1.09 & 0.94 \\
\hline & & & Médio & 1 & 1.09 & 1 \\
\hline & & & Com alto & & & \\
\hline & & & Estrume & 1 & 1.09 & 1.41 \\
\hline & & & Sem Estrume & 1 & 1.09 & 1.08 \\
\hline & & \multirow{5}{*}{ Plantio Direto } & Baixo & 1 & 1.16 & 0.94 \\
\hline & & & Médio & 1 & 1.16 & 1 \\
\hline & & & Com alto & & & \\
\hline & & & Estrume & 1 & 1.16 & 1.41 \\
\hline & & & Sem Estrume & 1 & 1.16 & 1.08 \\
\hline
\end{tabular}


Tabela C. 3 - Fatores na Pradaria e nas Savanas (EC, 2010)

\begin{tabular}{|c|c|c|c|c|c|c|}
\hline $\begin{array}{l}\text { Clima da } \\
\text { Região }\end{array}$ & $\begin{array}{l}\text { Uso do } \\
\text { Solo } \\
\text { (Fus) }\end{array}$ & $\begin{array}{c}\text { Gestão do } \\
\text { Solo } \\
\left(F_{\mathrm{GS}}\right)\end{array}$ & $\begin{array}{c}\text { Entrada } \\
\qquad\left(F_{E}\right)\end{array}$ & $\left(F_{\text {US }}\right)$ & $\left(F_{\mathrm{GS}}\right)$ & $\left(F_{\mathrm{E}}\right)$ \\
\hline \multirow{6}{*}{$\begin{array}{l}\text { Temperado/ } \\
\text { Boreal, Seco }\end{array}$} & \multirow{6}{*}{ Pradaria } & \multirow{2}{*}{ Melhorado } & Médio & 1 & 1.14 & 1 \\
\hline & & & Alto & 1 & 1.14 & 1.11 \\
\hline & & $\begin{array}{l}\text { Gestão } \\
\text { Nominal }\end{array}$ & Médio & 1 & 1 & 1 \\
\hline & & Moderadamente & & & & \\
\hline & & Degradado & Médio & 1 & 0.95 & 1 \\
\hline & & $\begin{array}{c}\text { Severamente } \\
\text { Degradada }\end{array}$ & Médio & 1 & 0.7 & 1 \\
\hline \multirow{7}{*}{$\begin{array}{c}\text { Temperado/ } \\
\text { Boreal, } \\
\text { Úmido/ } \\
\text { Úmido }\end{array}$} & \multirow{7}{*}{ Pradaria } & \multirow{2}{*}{ Melhorado } & Médio & 1 & 1.14 & 1 \\
\hline & & & Alto & 1 & 1.14 & 1.11 \\
\hline & & $\begin{array}{l}\text { Gestão } \\
\text { Nominal }\end{array}$ & Médio & 1 & 1 & 1 \\
\hline & & Moderadamente & & & & \\
\hline & & Degradado & Médio & 1 & 0.95 & 1 \\
\hline & & Severamente & & & & \\
\hline & & Degradada & Médio & 1 & 0.7 & 1 \\
\hline \multirow{6}{*}{$\begin{array}{l}\text { Tropical, } \\
\text { seco }\end{array}$} & \multirow{6}{*}{ Pradaria } & \multirow{2}{*}{ Melhorado } & Médio & 1 & 1.17 & 1 \\
\hline & & & Alto & 1 & 1.17 & 1.11 \\
\hline & & $\begin{array}{l}\text { Gestão } \\
\text { Nominal }\end{array}$ & Médio & 1 & 1 & 1 \\
\hline & & $\begin{array}{c}\text { Moderadamente } \\
\text { Degradado }\end{array}$ & Médio & 1 & 0.97 & 1 \\
\hline & & Severamente & & & & \\
\hline & & Degradada & Médio & 1 & 0.7 & 1 \\
\hline \multirow{6}{*}{$\begin{array}{l}\text { Tropical, } \\
\text { Úmido/ } \\
\text { Úmido }\end{array}$} & \multirow{6}{*}{ Savana } & \multirow{2}{*}{ Melhorado } & Médio & 1 & 1.17 & 1 \\
\hline & & & Alto & 1 & 1.17 & $\overline{1.11}$ \\
\hline & & $\begin{array}{l}\text { Gestão } \\
\text { Nominal }\end{array}$ & Médio & 1 & 1 & 1 \\
\hline & & $\begin{array}{c}\text { Moderadamente } \\
\text { Degradado }\end{array}$ & Médio & 1 & 0.97 & 1 \\
\hline & & Severamente & & & & \\
\hline & & Degradada & Médio & 1 & 0.7 & 1 \\
\hline \multirow{7}{*}{$\begin{array}{c}\text { Tropical } \\
\text { Montanhoso }\end{array}$} & \multirow{7}{*}{ Pradaria } & \multirow{2}{*}{ Melhorado } & Médio & 1 & 1.16 & 1 \\
\hline & & & Alto & 1 & 1.16 & 1.11 \\
\hline & & $\begin{array}{l}\text { Gestão } \\
\text { Nominal }\end{array}$ & Médio & 1 & 1 & 1 \\
\hline & & Moderadamente & & & & \\
\hline & & Degradado & Médio & 1 & 0.96 & 1 \\
\hline & & Severamente & & & & \\
\hline & & Degradada & Médio & 1 & 0.7 & 1 \\
\hline
\end{tabular}


Tabela C. 4 - Fatores para Florestas tendo menos de 10\% de Cobertura Dossel (EC, 2010)

\begin{tabular}{|c|c|c|c|c|c|c|}
\hline $\begin{array}{l}\text { Clima da } \\
\text { Região }\end{array}$ & $\begin{array}{l}\text { Uso do Solo } \\
\text { (Fus })\end{array}$ & $\begin{array}{c}\text { Gestão } \\
\text { do Solo } \\
\left(F_{G S}\right)\end{array}$ & $\begin{array}{l}\text { Entrada } \\
\qquad\left(F_{E}\right)\end{array}$ & $\left(F_{\text {US }}\right)$ & $\left(F_{\mathrm{GS}}\right)$ & $\left(F_{\mathrm{E}}\right)$ \\
\hline Todos & $\begin{array}{l}\text { Floresta Nativa } \\
\text { (Não degrada) }\end{array}$ & $\mathrm{n} / \mathrm{a}$ & $\mathrm{n} / \mathrm{a}$ & 1 & & \\
\hline Todos & Floresta Manejada & Todos & Todos & 1 & 1 & 1 \\
\hline \multirow{2}{*}{$\begin{array}{l}\text { Tropical, } \\
\text { Úmido/ } \\
\text { Seco }\end{array}$} & $\begin{array}{c}\text { Terras não cultivadas no } \\
\text { deslocamento de cultivos } \\
\text { curtos }\end{array}$ & $\mathrm{n} / \mathrm{a}$ & $\mathrm{n} / \mathrm{a}$ & 0.64 & & \\
\hline & $\begin{array}{c}\text { Terras não cultivadas no } \\
\text { deslocamento de cultivos } \\
\text { maduros }\end{array}$ & $\mathrm{n} / \mathrm{a}$ & $\mathrm{n} / \mathrm{a}$ & 0.8 & & \\
\hline \multirow{2}{*}{$\begin{array}{l}\text { Temperado/ } \\
\text { Boreal, } \\
\text { úmido/Seco }\end{array}$} & $\begin{array}{c}\text { Terras não cultivadas no } \\
\text { deslocamento de cultivos } \\
\text { curtos }\end{array}$ & $\mathrm{n} / \mathrm{a}$ & $\mathrm{n} / \mathrm{a}$ & 1 & & \\
\hline & $\begin{array}{l}\text { Terras não cultivadas no } \\
\text { deslocamento de cultivos } \\
\text { maduros }\end{array}$ & $\mathrm{n} / \mathrm{a}$ & $\mathrm{n} / \mathrm{a}$ & 1 & & \\
\hline
\end{tabular}


ANEXO D: Carbono orgânico do solo antes da transformação solo $\left(\operatorname{COS}_{1}\right)$.

Tabela D. 1 - Carbono orgânico do solo antes da transformação $\operatorname{COS}_{1}$ (tC/ha) (LANGE, 2012)

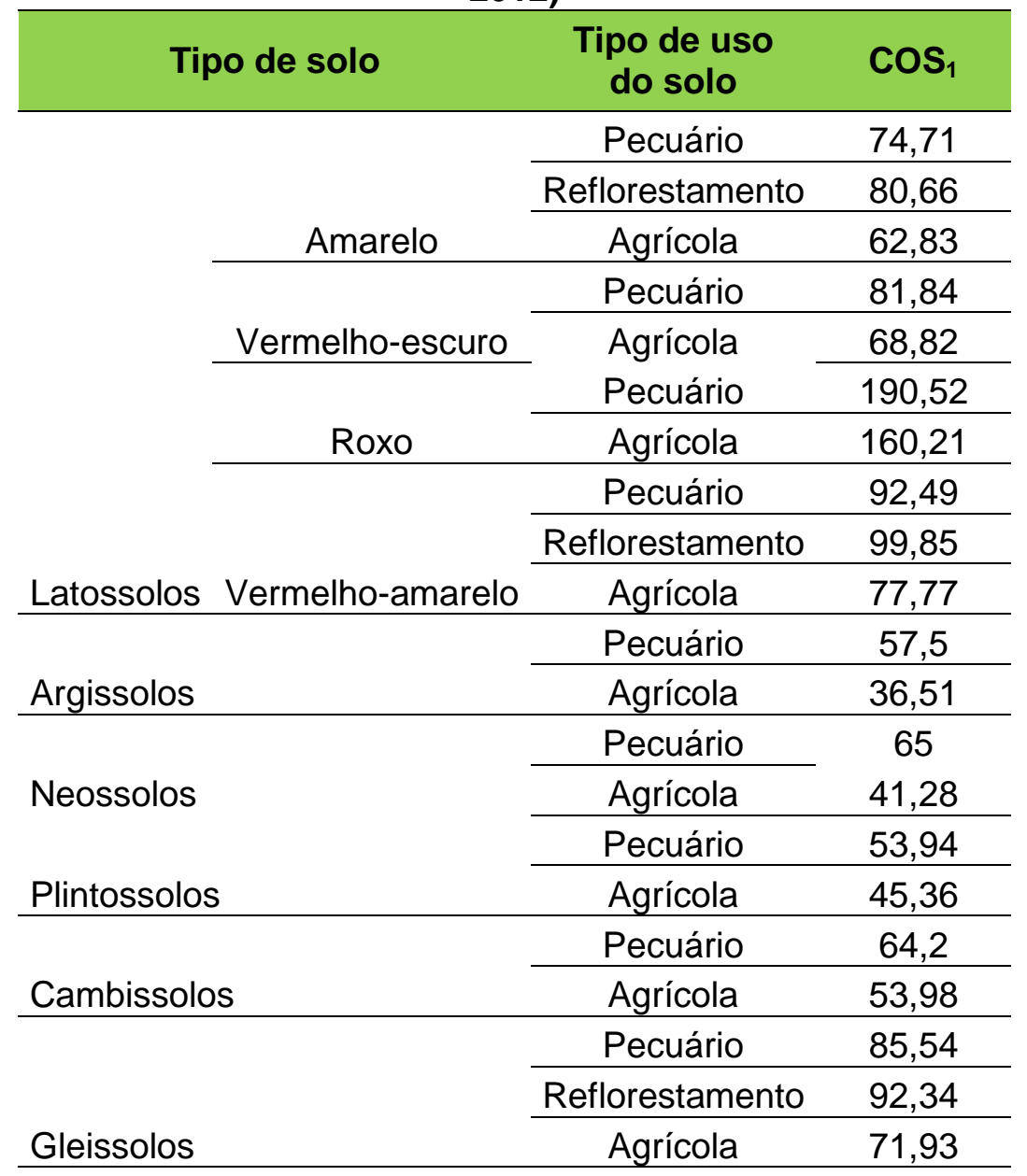




\section{APÊNDICE}

\section{APÊNDICE X - Carbono Orgânico do Solo após a transformação $\left(\mathrm{COS}_{2}\right)$}

Tabela X. 1 - $\cos$ no $t_{2}$ (tC/ha)

\begin{tabular}{|c|c|c|c|c|c|}
\hline Item & Tipo de Solo & $\begin{array}{l}\text { Tipo de uso } \\
\text { do solo }\end{array}$ & $\begin{array}{l}\text { Manejo do } \\
\text { Solo }\end{array}$ & $\begin{array}{c}\text { Ingresso } \\
\text { de } \\
\text { adubo }\end{array}$ & $\begin{array}{c}\text { Valores } \\
\text { de } \\
\mathrm{COS}_{2}\end{array}$ \\
\hline 1 & \multirow{22}{*}{ Latossolos Amarelo } & \multirow{9}{*}{$\begin{array}{l}\text { Cultura } \\
\text { temporária }\end{array}$} & \multirow{3}{*}{$\begin{array}{l}\text { Cultivo } \\
\text { completo }\end{array}$} & Com adubo & 59 \\
\hline 2 & & & & Médio & 41 \\
\hline 3 & & & & Sem adubo & 45 \\
\hline 4 & & & \multirow{3}{*}{$\begin{array}{l}\text { Preparo } \\
\text { reduzido }\end{array}$} & Com adubo & 67 \\
\hline 5 & & & & Médio & 47 \\
\hline 6 & & & & Sem adubo & 52 \\
\hline 7 & & & \multirow{3}{*}{$\begin{array}{l}\text { Plantio } \\
\text { direto }\end{array}$} & Com adubo & 72 \\
\hline 8 & & & & Médio & 50 \\
\hline 9 & & & & Sem adubo & 55 \\
\hline 10 & & \multirow{9}{*}{$\begin{array}{l}\text { Cultura } \\
\text { Permanente }\end{array}$} & \multirow{3}{*}{$\begin{array}{l}\text { Cultivo } \\
\text { completo }\end{array}$} & Com adubo & 122 \\
\hline 11 & & & & Médio & 85 \\
\hline 12 & & & & Sem adubo & 94 \\
\hline 13 & & & \multirow{3}{*}{$\begin{array}{l}\text { Preparo } \\
\text { reduzido }\end{array}$} & Com adubo & 141 \\
\hline 14 & & & & Médio & 98 \\
\hline 15 & & & & Sem adubo & 108 \\
\hline 16 & & & \multirow{3}{*}{$\begin{array}{l}\text { Plantio } \\
\text { direto }\end{array}$} & Com adubo & 149 \\
\hline 17 & & & & Médio & 104 \\
\hline 18 & & & & Sem adubo & 115 \\
\hline 19 & & \multirow{4}{*}{ Pastagem } & \multirow{2}{*}{ Melhorado } & Alto & 99 \\
\hline 20 & & & & Médio & 110 \\
\hline 21 & & & $\begin{array}{l}\text { Moderadamente } \\
\text { degradado }\end{array}$ & Médio & 82 \\
\hline 22 & & & $\begin{array}{l}\text { Severamente } \\
\text { degradado }\end{array}$ & Médio & 59 \\
\hline 23 & \multirow{2}{*}{ Latossolos Amarelo } & \multirow{2}{*}{ Sivicultura } & $\begin{array}{l}\text { Terras não } \\
\text { cultivadas no } \\
\text { deslocamento de } \\
\text { cultivos curtos }\end{array}$ & Médio & 54 \\
\hline 24 & & & $\begin{array}{l}\text { Terras não } \\
\text { cultivadas no } \\
\text { eslocamento de } \\
\text { cultivos maduros }\end{array}$ & Médio & 68 \\
\hline
\end{tabular}


Continuação da Tabela X.1

\begin{tabular}{|c|c|c|c|c|c|}
\hline Item & Tipo de Solo & $\begin{array}{l}\text { Tipo de uso } \\
\text { do solo }\end{array}$ & $\begin{array}{l}\text { Manejo do } \\
\text { Solo }\end{array}$ & $\begin{array}{l}\text { Ingresso de } \\
\text { adubo }\end{array}$ & $\begin{array}{c}\text { Valores } \\
\text { de } \\
\mathrm{COS}_{2}\end{array}$ \\
\hline 25 & \multirow{24}{*}{ Latossolos Vermelho } & \multirow{9}{*}{$\begin{array}{l}\text { Cultura } \\
\text { temporária }\end{array}$} & \multirow{3}{*}{$\begin{array}{l}\text { Cultivo } \\
\text { completo }\end{array}$} & Com adubo & 64 \\
\hline 26 & & & & Médio & 45 \\
\hline 27 & & & & Sem adubo & 50 \\
\hline 28 & & & \multirow{3}{*}{$\begin{array}{l}\text { Preparo } \\
\text { reduzido }\end{array}$} & Com adubo & 74 \\
\hline 29 & & & & Médio & 51 \\
\hline 30 & & & & Sem adubo & 57 \\
\hline 31 & & & \multirow{3}{*}{$\begin{array}{l}\text { Plantio } \\
\text { direto }\end{array}$} & Com adubo & 78 \\
\hline 32 & & & & Médio & 54 \\
\hline 33 & & & & Sem adubo & 60 \\
\hline 34 & & \multirow{9}{*}{$\begin{array}{c}\text { Cultura } \\
\text { Permanente }\end{array}$} & \multirow{3}{*}{$\begin{array}{l}\text { Cultivo } \\
\text { completo }\end{array}$} & Com adubo & 134 \\
\hline 35 & & & & Médio & 93 \\
\hline 36 & & & & Sem adubo & 103 \\
\hline 37 & & & & Com adubo & 154 \\
\hline 38 & & & $\begin{array}{l}\text { Preparo } \\
\text { reduzido }\end{array}$ & Médio & 107 \\
\hline 39 & & & & Sem adubo & 119 \\
\hline 40 & & & & Com adubo & 163 \\
\hline 41 & & & Plantio & Médio & 113 \\
\hline 42 & & & & Sem adubo & 126 \\
\hline 43 & & \multirow{4}{*}{ Pastagem } & \multirow{2}{*}{ Melhorado } & Alto & 109 \\
\hline 44 & & & & Médio & 121 \\
\hline 45 & & & $\begin{array}{l}\text { Moderadamente } \\
\text { degradado }\end{array}$ & Médio & 90 \\
\hline 46 & & & $\begin{array}{l}\text { Severamente } \\
\text { degradado }\end{array}$ & Médio & 65 \\
\hline 47 & & \multirow{2}{*}{ Sivicultura } & $\begin{array}{l}\text { Terras não } \\
\text { cultivadas no } \\
\text { deslocamento de } \\
\text { cultivos curtos }\end{array}$ & Médio & 60 \\
\hline 48 & & & $\begin{array}{l}\text { Terras não } \\
\text { cultivadas no } \\
\text { eslocamento de } \\
\text { cultivos maduros }\end{array}$ & Médio & 74 \\
\hline
\end{tabular}


Continuação da Tabela X.1

\begin{tabular}{|c|c|c|c|c|c|}
\hline Item & Tipo de Solo & $\begin{array}{l}\text { Tipo de uso } \\
\text { do solo }\end{array}$ & $\begin{array}{l}\text { Manejo do } \\
\text { Solo }\end{array}$ & $\begin{array}{l}\text { Ingresso de } \\
\text { adubo }\end{array}$ & $\begin{array}{c}\text { Valores } \\
\text { de } \\
\mathrm{COS}_{2}\end{array}$ \\
\hline 49 & \multirow{24}{*}{ Latossolos } & \multirow{9}{*}{$\begin{array}{l}\text { Cultura } \\
\text { temporária }\end{array}$} & \multirow{3}{*}{$\begin{array}{l}\text { Cultivo } \\
\text { completo }\end{array}$} & Com adubo & 150 \\
\hline 50 & & & & Médio & 104 \\
\hline 51 & & & & Sem adubo & 115 \\
\hline 52 & & & \multirow{3}{*}{$\begin{array}{l}\text { Preparo } \\
\text { reduzido }\end{array}$} & Com adubo & 172 \\
\hline 53 & & & & Médio & 120 \\
\hline 54 & & & & Sem adubo & 133 \\
\hline 55 & & & \multirow{3}{*}{$\begin{array}{l}\text { Plantio } \\
\text { direto }\end{array}$} & Com adubo & 183 \\
\hline 56 & & & & Médio & 127 \\
\hline 57 & & & & Sem adubo & 141 \\
\hline 58 & & \multirow{9}{*}{$\begin{array}{l}\text { Cultura } \\
\text { Permanente }\end{array}$} & \multirow{3}{*}{$\begin{array}{l}\text { Cultivo } \\
\text { completo }\end{array}$} & Com adubo & 312 \\
\hline 59 & & & & Médio & 217 \\
\hline 60 & & & & Sem adubo & 240 \\
\hline 61 & & & \multirow{3}{*}{$\begin{array}{l}\text { Preparo } \\
\text { reduzido }\end{array}$} & Com adubo & 359 \\
\hline 62 & & & & Médio & 249 \\
\hline 63 & & & & Sem adubo & 276 \\
\hline 64 & & & \multirow{3}{*}{$\begin{array}{l}\text { Plantio } \\
\text { direto }\end{array}$} & Com adubo & 380 \\
\hline 65 & & & & Médio & 264 \\
\hline 66 & & & & Sem adubo & 293 \\
\hline 67 & & \multirow{4}{*}{ Pastagem } & \multirow{2}{*}{ Melhorado } & Alto & 253 \\
\hline 68 & & & & Médio & 281 \\
\hline 69 & & & $\begin{array}{l}\text { Moderadamente } \\
\text { degradado }\end{array}$ & Médio & 210 \\
\hline 70 & & & $\begin{array}{l}\text { Severamente } \\
\text { degradado }\end{array}$ & Médio & 152 \\
\hline 71 & & \multirow[b]{2}{*}{ Sivicultura } & $\begin{array}{l}\text { Terras não } \\
\text { cultivadas no } \\
\text { deslocamento de } \\
\text { cultivos curtos }\end{array}$ & Médio & 139 \\
\hline 72 & & & $\begin{array}{l}\text { Terras não } \\
\text { cultivadas no } \\
\text { eslocamento de } \\
\text { cultivos maduros }\end{array}$ & Médio & 173 \\
\hline
\end{tabular}


Continuação da Tabela X.1

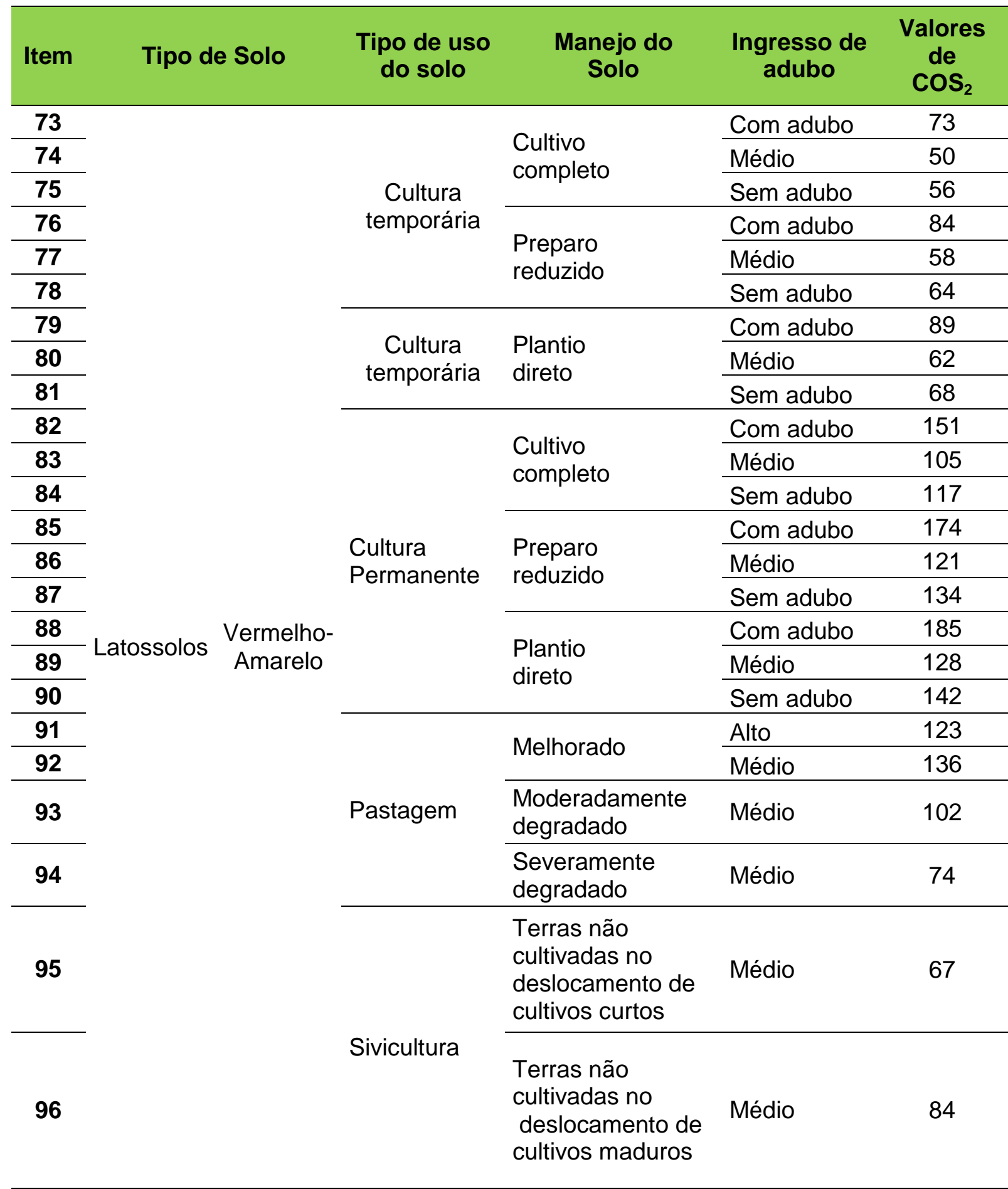


Continuação da Tabela X.1

\begin{tabular}{|c|c|c|c|c|c|}
\hline Item & Tipo de Solo & $\begin{array}{l}\text { Tipo de uso } \\
\text { do solo }\end{array}$ & $\begin{array}{l}\text { Manejo do } \\
\text { Solo }\end{array}$ & $\begin{array}{l}\text { Ingresso de } \\
\text { adubo }\end{array}$ & $\begin{array}{c}\text { Valores } \\
\text { de } \\
\text { COS }_{2}\end{array}$ \\
\hline 97 & \multirow{24}{*}{ Argissolos } & \multirow{9}{*}{$\begin{array}{l}\text { Cultura } \\
\text { temporária }\end{array}$} & \multirow{3}{*}{$\begin{array}{l}\text { Cultivo } \\
\text { completo }\end{array}$} & Com adubo & 40 \\
\hline 98 & & & & Médio & 28 \\
\hline 99 & & & & Sem adubo & 31 \\
\hline 100 & & & \multirow{3}{*}{$\begin{array}{l}\text { Preparo } \\
\text { reduzido }\end{array}$} & Com adubo & 46 \\
\hline 101 & & & & Médio & 32 \\
\hline 102 & & & & Sem adubo & 35 \\
\hline 103 & & & \multirow{3}{*}{$\begin{array}{l}\text { Plantio } \\
\text { direto }\end{array}$} & Com adubo & 48 \\
\hline 104 & & & & Médio & 34 \\
\hline 105 & & & & Sem adubo & 37 \\
\hline 106 & & \multirow{9}{*}{$\begin{array}{l}\text { Cultura } \\
\text { Permanente }\end{array}$} & \multirow{3}{*}{$\begin{array}{l}\text { Cultivo } \\
\text { completo }\end{array}$} & Com adubo & 83 \\
\hline 107 & & & & Médio & 58 \\
\hline 108 & & & & Sem adubo & 64 \\
\hline 109 & & & \multirow{3}{*}{$\begin{array}{l}\text { Preparo } \\
\text { reduzido }\end{array}$} & Com adubo & 95 \\
\hline 110 & & & & Médio & 66 \\
\hline 111 & & & & Sem adubo & 73 \\
\hline 112 & & & \multirow{3}{*}{$\begin{array}{l}\text { Plantio } \\
\text { direto }\end{array}$} & Com adubo & 101 \\
\hline 113 & & & & Médio & 70 \\
\hline 114 & & & & Sem adubo & 78 \\
\hline 115 & & \multirow{4}{*}{ Pastagem } & \multirow{2}{*}{ Melhorado } & Alto & 67 \\
\hline 116 & & & & Médio & 75 \\
\hline 117 & & & $\begin{array}{l}\text { Moderadamente } \\
\text { degradado }\end{array}$ & Médio & 56 \\
\hline 118 & & & $\begin{array}{l}\text { Severamente } \\
\text { degradado }\end{array}$ & Médio & 40 \\
\hline 119 & & \multirow{2}{*}{ Sivicultura } & $\begin{array}{l}\text { Terras não } \\
\text { cultivadas no } \\
\text { deslocamento de } \\
\text { cultivos curtos }\end{array}$ & Médio & 37 \\
\hline 120 & & & $\begin{array}{l}\text { Terras não } \\
\text { cultivadas no } \\
\text { eslocamento de } \\
\text { cultivos maduros }\end{array}$ & Médio & 46 \\
\hline
\end{tabular}


Continuação da Tabela X.1

\begin{tabular}{|c|c|c|c|c|c|}
\hline Item & Tipo de Solo & $\begin{array}{l}\text { Tipo de uso } \\
\text { do solo }\end{array}$ & $\begin{array}{l}\text { Manejo do } \\
\text { Solo }\end{array}$ & $\begin{array}{l}\text { Ingresso de } \\
\text { adubo }\end{array}$ & $\begin{array}{c}\text { Valores } \\
\text { de } \\
\mathrm{COS}_{2}\end{array}$ \\
\hline 121 & \multirow{24}{*}{ Neossolos } & \multirow{9}{*}{$\begin{array}{l}\text { Cultura } \\
\text { temporária }\end{array}$} & \multirow{3}{*}{$\begin{array}{l}\text { Cultivo } \\
\text { completo }\end{array}$} & Com adubo & 45 \\
\hline 122 & & & & Médio & 31 \\
\hline 123 & & & & Sem adubo & 35 \\
\hline 124 & & & \multirow{3}{*}{$\begin{array}{l}\text { Preparo } \\
\text { reduzido }\end{array}$} & Com adubo & 52 \\
\hline 125 & & & & Médio & 36 \\
\hline 126 & & & & Sem adubo & 40 \\
\hline 127 & & & \multirow{3}{*}{$\begin{array}{l}\text { Plantio } \\
\text { direto }\end{array}$} & Com adubo & 55 \\
\hline 128 & & & & Médio & 38 \\
\hline 129 & & & & Sem adubo & 42 \\
\hline 130 & & \multirow{9}{*}{$\begin{array}{l}\text { Cultura } \\
\text { Permanente }\end{array}$} & \multirow{3}{*}{$\begin{array}{l}\text { Cultivo } \\
\text { completo }\end{array}$} & Com adubo & 94 \\
\hline 131 & & & & Médio & 65 \\
\hline 132 & & & & Sem adubo & 72 \\
\hline 133 & & & \multirow{3}{*}{$\begin{array}{l}\text { Preparo } \\
\text { reduzido }\end{array}$} & Com adubo & 108 \\
\hline 134 & & & & Médio & 75 \\
\hline 135 & & & & Sem adubo & 83 \\
\hline 136 & & & \multirow{3}{*}{$\begin{array}{l}\text { Plantio } \\
\text { direto }\end{array}$} & Com adubo & 114 \\
\hline 137 & & & & Médio & 79 \\
\hline 138 & & & & Sem adubo & 88 \\
\hline 139 & & \multirow{4}{*}{ Pastagem } & \multirow{2}{*}{ Melhorado } & Alto & 76 \\
\hline 140 & & & & Médio & 84 \\
\hline 141 & & & $\begin{array}{l}\text { Moderadamente } \\
\text { degradado }\end{array}$ & Médio & 63 \\
\hline 142 & & & $\begin{array}{l}\text { Severamente } \\
\text { degradado }\end{array}$ & Médio & 46 \\
\hline 143 & & & $\begin{array}{l}\text { Terras não } \\
\text { cultivadas no } \\
\text { deslocamento de } \\
\text { cultivos curtos }\end{array}$ & Médio & 42 \\
\hline 144 & & Sivicultura & $\begin{array}{l}\text { Terras não } \\
\text { cultivadas no } \\
\text { deslocamento de } \\
\text { cultivos maduros }\end{array}$ & Médio & 52 \\
\hline
\end{tabular}


Continuação da Tabela X.1

\begin{tabular}{|c|c|c|c|c|c|}
\hline Item & Tipo de Solo & $\begin{array}{l}\text { Tipo de uso } \\
\text { do solo }\end{array}$ & $\begin{array}{l}\text { Manejo do } \\
\text { Solo }\end{array}$ & $\begin{array}{l}\text { Ingresso de } \\
\text { adubo }\end{array}$ & $\begin{array}{c}\text { Valores } \\
\text { de } \\
\mathrm{COS}_{2}\end{array}$ \\
\hline 145 & \multirow{24}{*}{ Pintossolos } & \multirow{9}{*}{$\begin{array}{l}\text { Cultura } \\
\text { temporária }\end{array}$} & \multirow{3}{*}{$\begin{array}{l}\text { Cultivo } \\
\text { completo }\end{array}$} & Com adubo & 42 \\
\hline 146 & & & & Médio & 29 \\
\hline 147 & & & & Sem adubo & 33 \\
\hline 148 & & & \multirow{3}{*}{$\begin{array}{l}\text { Preparo } \\
\text { reduzido }\end{array}$} & Com adubo & 49 \\
\hline 149 & & & & Médio & 34 \\
\hline 150 & & & & Sem adubo & 38 \\
\hline 151 & & & \multirow{3}{*}{$\begin{array}{l}\text { Plantio } \\
\text { direto }\end{array}$} & Com adubo & 52 \\
\hline 152 & & & & Médio & 36 \\
\hline 153 & & & & Sem adubo & 40 \\
\hline 154 & & \multirow{9}{*}{$\begin{array}{l}\text { Cultura } \\
\text { Permanente }\end{array}$} & \multirow{3}{*}{$\begin{array}{l}\text { Cultivo } \\
\text { completo }\end{array}$} & Com adubo & 88 \\
\hline 155 & & & & Médio & 61 \\
\hline 156 & & & & Sem adubo & 68 \\
\hline 157 & & & \multirow{3}{*}{$\begin{array}{l}\text { Preparo } \\
\text { reduzido }\end{array}$} & Com adubo & 102 \\
\hline 158 & & & & Médio & 70 \\
\hline 159 & & & & Sem adubo & 78 \\
\hline 160 & & & \multirow{3}{*}{$\begin{array}{l}\text { Plantio } \\
\text { direto }\end{array}$} & Com adubo & 108 \\
\hline 161 & & & & Médio & 75 \\
\hline 162 & & & & Sem adubo & 83 \\
\hline 163 & & \multirow{4}{*}{ Pastagem } & \multirow{2}{*}{ Melhorado } & Alto & 72 \\
\hline 164 & & & & Médio & 80 \\
\hline 165 & & & $\begin{array}{l}\text { Moderadamente } \\
\text { degradado }\end{array}$ & Médio & 59 \\
\hline 166 & & & $\begin{array}{l}\text { Severamente } \\
\text { degradado }\end{array}$ & Médio & 43 \\
\hline 167 & & & $\begin{array}{l}\text { Terras não } \\
\text { cultivadas no } \\
\text { deslocamento de } \\
\text { cultivos curtos }\end{array}$ & Médio & 39 \\
\hline 168 & & Sivicultura & $\begin{array}{l}\text { Terras não } \\
\text { cultivadas no } \\
\text { deslocamento de } \\
\text { cultivos maduros }\end{array}$ & Médio & 49 \\
\hline
\end{tabular}


Continuação da Tabela X.1

\begin{tabular}{|c|c|c|c|c|c|}
\hline Item & Tipo de Solo & $\begin{array}{l}\text { Tipo de uso } \\
\text { do solo }\end{array}$ & $\begin{array}{l}\text { Manejo do } \\
\text { Solo }\end{array}$ & $\begin{array}{l}\text { Ingresso de } \\
\text { adubo }\end{array}$ & $\begin{array}{c}\text { Valores } \\
\text { de } \\
\mathrm{COS}_{2}\end{array}$ \\
\hline 169 & \multirow{24}{*}{ Cambissolos } & \multirow{9}{*}{$\begin{array}{l}\text { Cultura } \\
\text { temporária }\end{array}$} & \multirow{3}{*}{$\begin{array}{l}\text { Cultivo } \\
\text { completo }\end{array}$} & Com adubo & 50 \\
\hline 170 & & & & Médio & 35 \\
\hline 171 & & & & Sem adubo & 39 \\
\hline 172 & & & \multirow{3}{*}{$\begin{array}{l}\text { Preparo } \\
\text { reduzido }\end{array}$} & Com adubo & 58 \\
\hline 173 & & & & Médio & 40 \\
\hline 174 & & & & Sem adubo & 45 \\
\hline 175 & & & \multirow{3}{*}{$\begin{array}{l}\text { Plantio } \\
\text { direto }\end{array}$} & Com adubo & 62 \\
\hline 176 & & & & Médio & 43 \\
\hline 177 & & & & Sem adubo & 47 \\
\hline 178 & & \multirow{9}{*}{$\begin{array}{l}\text { Cultura } \\
\text { Permanente }\end{array}$} & \multirow{3}{*}{$\begin{array}{l}\text { Cultivo } \\
\text { completo }\end{array}$} & Com adubo & 105 \\
\hline 179 & & & & Médio & 73 \\
\hline 180 & & & & Sem adubo & 81 \\
\hline 181 & & & \multirow{3}{*}{$\begin{array}{l}\text { Preparo } \\
\text { reduzido }\end{array}$} & Com adubo & 121 \\
\hline 182 & & & & Médio & 84 \\
\hline 183 & & & & Sem adubo & 93 \\
\hline 184 & & & \multirow{3}{*}{$\begin{array}{l}\text { Plantio } \\
\text { direto }\end{array}$} & Com adubo & 128 \\
\hline 185 & & & & Médio & 89 \\
\hline 186 & & & & Sem adubo & 99 \\
\hline 187 & & \multirow{4}{*}{ Pastagem } & \multirow{2}{*}{ Melhorado } & Alto & 85 \\
\hline 188 & & & & Médio & 95 \\
\hline 189 & & & $\begin{array}{l}\text { Moderadamente } \\
\text { degradado }\end{array}$ & Médio & 71 \\
\hline 190 & & & $\begin{array}{l}\text { Severamente } \\
\text { degradado }\end{array}$ & Médio & 51 \\
\hline 191 & & & $\begin{array}{l}\text { Terras não } \\
\text { cultivadas no } \\
\text { deslocamento de } \\
\text { cultivos curtos }\end{array}$ & Médio & 47 \\
\hline 192 & & Sivicultura & $\begin{array}{l}\text { Terras não } \\
\text { cultivadas no } \\
\text { deslocamento de } \\
\text { cultivos maduros }\end{array}$ & Médio & 58 \\
\hline
\end{tabular}


Continuação da Tabela X.1

\begin{tabular}{|c|c|c|c|c|c|}
\hline Item & Tipo de Solo & $\begin{array}{l}\text { Tipo de uso } \\
\text { do solo }\end{array}$ & $\begin{array}{l}\text { Manejo do } \\
\text { Solo }\end{array}$ & $\begin{array}{l}\text { Ingresso de } \\
\text { adubo }\end{array}$ & $\begin{array}{c}\text { Valores } \\
\text { de } \\
\mathrm{COS}_{2}\end{array}$ \\
\hline 193 & \multirow{24}{*}{ Gleissolos } & \multirow{9}{*}{$\begin{array}{l}\text { Cultura } \\
\text { temporária }\end{array}$} & \multirow{3}{*}{$\begin{array}{l}\text { Cultivo } \\
\text { completo }\end{array}$} & Com adubo & 67 \\
\hline 194 & & & & Médio & 47 \\
\hline 195 & & & & Sem adubo & 52 \\
\hline 196 & & & \multirow{3}{*}{$\begin{array}{l}\text { Preparo } \\
\text { reduzido }\end{array}$} & Com adubo & 77 \\
\hline 197 & & & & Médio & 54 \\
\hline 198 & & & & Sem adubo & 60 \\
\hline 199 & & & \multirow{3}{*}{$\begin{array}{l}\text { Plantio } \\
\text { direto }\end{array}$} & Com adubo & 82 \\
\hline 200 & & & & Médio & 57 \\
\hline 201 & & & & Sem adubo & 63 \\
\hline 202 & & \multirow{9}{*}{$\begin{array}{l}\text { Cultura } \\
\text { Permanente }\end{array}$} & \multirow{3}{*}{$\begin{array}{l}\text { Cultivo } \\
\text { completo }\end{array}$} & Com adubo & 140 \\
\hline 203 & & & & Médio & 97 \\
\hline 204 & & & & Sem adubo & 108 \\
\hline 205 & & & \multirow{3}{*}{$\begin{array}{l}\text { Preparo } \\
\text { reduzido }\end{array}$} & Com adubo & 161 \\
\hline 206 & & & & Médio & 112 \\
\hline 207 & & & & Sem adubo & 124 \\
\hline 208 & & & \multirow{3}{*}{$\begin{array}{l}\text { Plantio } \\
\text { direto }\end{array}$} & Com adubo & 171 \\
\hline 209 & & & & Médio & 119 \\
\hline 210 & & & & Sem adubo & 132 \\
\hline 211 & & \multirow{4}{*}{ Pastagem } & \multirow{2}{*}{ Melhorado } & Alto & 114 \\
\hline 212 & & & & Médio & 126 \\
\hline 213 & & & $\begin{array}{l}\text { Moderadamente } \\
\text { degradado }\end{array}$ & Médio & 94 \\
\hline 214 & & & $\begin{array}{l}\text { Severamente } \\
\text { degradado }\end{array}$ & Médio & 68 \\
\hline 215 & & \multirow[b]{2}{*}{ Sivicultura } & $\begin{array}{l}\text { Terras não } \\
\text { cultivadas no } \\
\text { deslocamento de } \\
\text { cultivos curtos }\end{array}$ & Médio & 62 \\
\hline 216 & & & $\begin{array}{l}\text { Terras não } \\
\text { cultivadas no } \\
\text { deslocamento de } \\
\text { cultivos maduros }\end{array}$ & Médio & 78 \\
\hline
\end{tabular}




\section{APÊNDICE Y - Fator de caracterização para a transformação do solo}

Tabela Y. 1 - Fatores de caracterização para a transformação $\left(\mathrm{tCha}^{-1} a \mathrm{ano}^{-1}\right)$

\begin{tabular}{|c|c|c|c|c|c|c|c|c|c|c|}
\hline Item & $\begin{array}{l}\text { cos } \\
\text { pot }\end{array}$ & $\begin{array}{l}\text { COS1 } \\
\text { Past }\end{array}$ & $\cos 2$ & $\begin{array}{l}\text { SOCpot- } \\
\text { SOC1 }\end{array}$ & $\begin{array}{l}\text { SOC1- } \\
\text { SOC2 }\end{array}$ & Fctrans & $\begin{array}{l}\text { Cos1 } \\
\text { Siv }\end{array}$ & $\begin{array}{l}\text { SOCpot- } \\
\text { SOC1 }\end{array}$ & $\begin{array}{l}\text { SOC1- } \\
\text { SOC2 }\end{array}$ & Fctrans \\
\hline 1 & & 74,71 & 59 & 10,19 & 16 & 18,2 & 80,66 & 4,24 & 22 & 746,2 \\
\hline 2 & & 74,71 & 41 & 10,19 & 34 & 27,2 & 80,66 & 4,24 & 40 & 1185,5 \\
\hline 3 & & 74,71 & 45 & 10,19 & 29 & 24,9 & 80,66 & 4,24 & 35 & 1075,7 \\
\hline 4 & & 74,71 & 67 & 10,19 & 7 & 13,8 & 80,66 & 4,24 & 13 & 530,5 \\
\hline 5 & & 74,71 & 47 & 10,19 & 28 & 24,1 & 80,66 & 4,24 & 34 & 1035,7 \\
\hline 6 & & 74,71 & 52 & 10,19 & 23 & 21,5 & 80,66 & 4,24 & 29 & 909,4 \\
\hline 7 & & 74,71 & 72 & 10,19 & 3 & 11,7 & 80,66 & 4,24 & 9 & 429,9 \\
\hline 8 & & 74,71 & 50 & 10,19 & 25 & 22,7 & 80,66 & 4,24 & 31 & 965,9 \\
\hline 9 & & 74,71 & 55 & 10,19 & 20 & 20,0 & 80,66 & 4,24 & 25 & 831,9 \\
\hline 10 & & 74,71 & 122 & 10,19 & -48 & $-13,6$ & 80,66 & 4,24 & -42 & $-811,3$ \\
\hline 11 & & 74,71 & 85 & 10,19 & -10 & 5,1 & 80,66 & 4,24 & -4 & 103,9 \\
\hline 12 & & 74,71 & 94 & 10,19 & -20 & 0,4 & 80,66 & 4,24 & -14 & $-124,9$ \\
\hline 13 & & 74,71 & 141 & 10,19 & -66 & $-22,8$ & 80,66 & 4,24 & -60 & $-1260,6$ \\
\hline 14 & & 74,71 & 98 & 10,19 & -23 & $-1,3$ & 80,66 & 4,24 & -17 & $-208,1$ \\
\hline 15 & & 74,71 & 108 & 10,19 & -34 & $-6,6$ & 80,66 & 4,24 & -28 & $-471,3$ \\
\hline 16 & & 74,71 & 149 & 10,19 & -74 & $-27,0$ & 80,66 & 4,24 & -68 & $-1470,3$ \\
\hline 17 & & 74,71 & 104 & 10,19 & -29 & $-4,2$ & 80,66 & 4,24 & -23 & $-353,7$ \\
\hline 18 & & 74,71 & 115 & 10,19 & -40 & $-9,9$ & 80,66 & 4,24 & -34 & $-632,9$ \\
\hline 19 & & 74,71 & 99 & 10,19 & -25 & $-2,1$ & 80,66 & 4,24 & -19 & $-249,7$ \\
\hline 20 & & 74,71 & 110 & 10,19 & -36 & $-7,6$ & 80,66 & 4,24 & -30 & $-517,4$ \\
\hline 21 & & 74,71 & 82 & 10,19 & -8 & 6,4 & 80,66 & 4,24 & -2 & 166,3 \\
\hline 22 & & 74,71 & 59 & 10,19 & 15 & 17,8 & 80,66 & 4,24 & 21 & 727,9 \\
\hline 23 & & 74,71 & 54 & 10,19 & 20 & 40,8 & 80,66 & 4,24 & 26 & 17,4 \\
\hline 24 & & 74,71 & 68 & 10,19 & 7 & 27,2 & 80,66 & 4,24 & 13 & 10,6 \\
\hline
\end{tabular}


Continuação da Tabela Y.1

\begin{tabular}{|c|c|c|c|c|c|c|c|c|c|}
\hline Item & $\begin{array}{c}\text { cos } \\
\text { pot }\end{array}$ & $\begin{array}{l}\text { COS1 } \\
\text { Cult } \\
\text { Temp }\end{array}$ & $\begin{array}{l}\text { SOCpot- } \\
\text { SOC1 }\end{array}$ & $\begin{array}{l}\text { SOC1- } \\
\text { SOC2 }\end{array}$ & Fctrans & $\begin{array}{l}\text { COS1 } \\
\text { Cult } \\
\text { Perm } \\
\end{array}$ & $\begin{array}{l}\text { SOCpot- } \\
\text { SOC1 }\end{array}$ & $\begin{array}{l}\text { Soc1- } \\
\text { Soc2 }\end{array}$ & Fctrans \\
\hline 1 & & 62,83 & 22,07 & 4 & 24,1 & 62,83 & 22,07 & 4 & 24,1 \\
\hline 2 & & 62,83 & 22,07 & 22 & 33,1 & 62,83 & 22,07 & 22 & 33,1 \\
\hline 3 & & 62,83 & 22,07 & 18 & 30,9 & 62,83 & 22,07 & 18 & 30,9 \\
\hline 4 & & 62,83 & 22,07 & -5 & 19,7 & 62,83 & 22,07 & -5 & 19,7 \\
\hline 5 & & 62,83 & 22,07 & 16 & 30,1 & 62,83 & 22,07 & 16 & 30,1 \\
\hline 6 & & 62,83 & 22,07 & 11 & 27,5 & 62,83 & 22,07 & 11 & 27,5 \\
\hline 7 & & 62,83 & 22,07 & -9 & 17,7 & 62,83 & 22,07 & -9 & 17,7 \\
\hline 8 & & 62,83 & 22,07 & 13 & 28,6 & 62,83 & 22,07 & 13 & 28,6 \\
\hline 9 & & 62,83 & 22,07 & 8 & 25,9 & 62,83 & 22,07 & 8 & 25,9 \\
\hline 10 & & 62,83 & 22,07 & -59 & $-68,8$ & 62,83 & 22,07 & -59 & $-7,6$ \\
\hline 11 & & 62,83 & 22,07 & -22 & 99,3 & 62,83 & 22,07 & -22 & 11,0 \\
\hline 12 & & 62,83 & 22,07 & -31 & 57,3 & 62,83 & 22,07 & -31 & 6,4 \\
\hline 13 & & 62,83 & 22,07 & -78 & $-151,3$ & 62,83 & 22,07 & -78 & $-16,8$ \\
\hline 14 & & 62,83 & 22,07 & -35 & 42,0 & 62,83 & 22,07 & -35 & 4,7 \\
\hline 15 & & 62,83 & 22,07 & -46 & $-6,3$ & 62,83 & 22,07 & -46 & $-0,7$ \\
\hline 16 & & 62,83 & 22,07 & -86 & $-189,8$ & 62,83 & 22,07 & -86 & $-21,1$ \\
\hline 17 & & 62,83 & 22,07 & -41 & 15,3 & 62,83 & 22,07 & -41 & 1,7 \\
\hline 18 & & 62,83 & 22,07 & -52 & $-36,0$ & 62,83 & 22,07 & -52 & $-4,0$ \\
\hline 19 & & 62,83 & 22,07 & -37 & 22,9 & 62,83 & 22,07 & -37 & 7,6 \\
\hline 20 & & 62,83 & 22,07 & -47 & $-9,9$ & 62,83 & 22,07 & -47 & $-3,3$ \\
\hline 21 & & 62,83 & 22,07 & -20 & 73,9 & 62,83 & 22,07 & -20 & 24,6 \\
\hline 22 & & 62,83 & 22,07 & 3 & 142,6 & 62,83 & 22,07 & 3 & 47,5 \\
\hline 23 & & 62,83 & 22,07 & 8 & 52,6 & 62,83 & 22,07 & 8 & 52,6 \\
\hline 24 & & 62,83 & 22,07 & -5 & 39,1 & 62,83 & 22,07 & -5 & 39,1 \\
\hline
\end{tabular}


Continuação da Tabela Y.1

\begin{tabular}{|c|c|c|c|c|c|c|c|c|c|c|c|c|c|c|}
\hline Item & $\begin{array}{l}\text { cos } \\
\text { pot }\end{array}$ & $\begin{array}{l}\text { COS1 } \\
\text { Past }\end{array}$ & cos2 & $\begin{array}{c}\text { SOCpot- } \\
\text { SOC1 }\end{array}$ & $\begin{array}{l}\text { SOC1- } \\
\text { SOC2 }\end{array}$ & Fctrans & $\begin{array}{c}\text { COS1 } \\
\text { Cult } \\
\text { Temp }\end{array}$ & $\begin{array}{c}\text { SOCpot- } \\
\text { SOC1 }\end{array}$ & $\begin{array}{l}\text { SOC1- } \\
\text { SOC2 }\end{array}$ & Fctrans & $\begin{array}{c}\text { COS1 } \\
\text { Cult Perm }\end{array}$ & $\begin{array}{c}\text { SOCpot- } \\
\text { SOC1 }\end{array}$ & $\begin{array}{l}\text { SOC1- } \\
\text { SOC2 }\end{array}$ & FCtrans \\
\hline 25 & \multirow{24}{*}{93} & 81,84 & 64 & 11,16 & 18 & 19,9 & 68,82 & 24,18 & 5 & 26,4 & 68,82 & 24,18 & 5 & 26,4 \\
\hline 26 & & 81,84 & 45 & 11,16 & 37 & 29,8 & 68,82 & 24,18 & 24 & 36,3 & 68,82 & 24,18 & 24 & 36,3 \\
\hline 27 & & 81,84 & 50 & 11,16 & 32 & 27,3 & 68,82 & 24,18 & 19 & 33,8 & 68,82 & 24,18 & 19 & 33,8 \\
\hline 28 & & 81,84 & 74 & 11,16 & 8 & 15,1 & 68,82 & 24,18 & -5 & 21,6 & 68,82 & 24,18 & -5 & 21,6 \\
\hline 29 & & $\begin{array}{l}81,84 \\
\end{array}$ & 51 & 11,16 & 31 & 26,4 & 68,82 & 24,18 & 17 & 32,9 & 68,82 & 24,18 & 17 & 32,9 \\
\hline 30 & & 81,84 & 57 & 11,16 & 25 & 23,6 & 68,82 & 24,18 & 12 & 30,1 & 68,82 & 24,18 & 12 & 30,1 \\
\hline 31 & & 81,84 & 78 & 11,16 & 3 & 12,9 & 68,82 & 24,18 & -10 & 19,4 & 68,82 & 24,18 & -10 & 19,4 \\
\hline 32 & & 81,84 & 54 & 11,16 & 27 & 24,8 & 68,82 & 24,18 & 14 & 31,4 & 68,82 & 24,18 & 14 & 31,4 \\
\hline 33 & & 81,84 & 60 & 11,16 & 21 & 21,9 & 68,82 & 24,18 & 8 & 28,4 & 68,82 & 24,18 & 8 & 28,4 \\
\hline 34 & & 81,84 & 134 & 11,16 & -52 & $-14,9$ & 68,82 & 24,18 & -65 & $-75,3$ & 68,82 & 24,18 & -65 & $-8,4$ \\
\hline 35 & & 81,84 & 93 & 11,16 & -11 & 5,6 & 68,82 & 24,18 & -24 & 108,8 & 68,82 & 24,18 & -24 & 12,1 \\
\hline 36 & & 81,84 & 103 & 11,16 & -21 & 0,5 & 68,82 & 24,18 & -34 & 62,8 & 68,82 & 24,18 & -34 & 7,0 \\
\hline 37 & & 81,84 & 154 & 11,16 & -72 & $-24,9$ & 68,82 & 24,18 & -85 & $-165,7$ & 68,82 & 24,18 & -85 & $-18,4$ \\
\hline 38 & & 81,84 & 107 & 11,16 & -25 & $-1,4$ & 68,82 & 24,18 & -38 & 46,0 & 68,82 & 24,18 & -38 & 5,1 \\
\hline 39 & & 81,84 & 119 & 11,16 & -37 & $-7,3$ & 68,82 & 24,18 & -50 & $-6,9$ & 68,82 & 24,18 & -50 & $-0,8$ \\
\hline 40 & & 81,84 & 163 & 11,16 & -82 & $-29,6$ & 68,82 & 24,18 & -95 & $-207,9$ & 68,82 & 24,18 & -95 & $-23,1$ \\
\hline 41 & & 81,84 & 113 & 11,16 & -32 & $-4,7$ & 68,82 & 24,18 & -45 & 16,7 & 68,82 & 24,18 & -45 & 1,9 \\
\hline 42 & & 81,84 & 126 & 11,16 & -44 & $-10,9$ & 68,82 & 24,18 & -57 & $-39,4$ & 68,82 & 24,18 & -57 & $-4,4$ \\
\hline 43 & & 81,84 & 109 & 11,16 & -27 & $-2,3$ & 68,82 & 24,18 & -40 & 25,1 & 68,82 & 24,18 & -40 & 8,4 \\
\hline 44 & & 81,84 & 121 & 11,16 & -39 & $-8,3$ & 68,82 & 24,18 & -52 & $-10,8$ & 68,82 & 24,18 & -52 & $-3,6$ \\
\hline 45 & & 81,84 & 90 & 11,16 & -8 & 7,0 & 68,82 & 24,18 & -21 & 80,9 & 68,82 & 24,18 & -21 & 27,0 \\
\hline 46 & & 81,84 & 65 & 11,16 & 17 & 19,5 & 68,82 & 24,18 & 4 & 156,2 & 68,82 & 24,18 & 4 & 52,1 \\
\hline 47 & & 81,84 & 60 & 11,16 & 22 & 44,6 & 68,82 & 24,18 & 9 & 57,7 & 68,82 & 24,18 & 9 & 57,7 \\
\hline 48 & & 81,84 & 74 & 11,16 & 7 & 29,8 & 68,82 & 24,18 & -6 & 42,8 & 68,82 & 24,18 & -6 & 42,8 \\
\hline
\end{tabular}




\begin{tabular}{|c|c|c|c|c|c|c|c|c|c|c|c|c|c|c|}
\hline Item & $\begin{array}{l}\text { COS } \\
\text { pot }\end{array}$ & $\begin{array}{c}\text { COS1 } \\
\text { Past }\end{array}$ & cos2 & $\begin{array}{c}\text { SOCpot- } \\
\text { SOC1 }\end{array}$ & $\begin{array}{l}\text { SOC1- } \\
\text { SOC2 }\end{array}$ & Fctrans & $\begin{array}{c}\text { COS1 } \\
\text { Cult } \\
\text { Temp }\end{array}$ & $\begin{array}{c}\text { soCpot- } \\
\text { SOC1 }\end{array}$ & $\begin{array}{l}\text { SOC1- } \\
\text { SOC2 }\end{array}$ & Fctrans & $\begin{array}{c}\text { COS1 } \\
\text { Cult } \\
\text { Perm }\end{array}$ & $\begin{array}{c}\text { SOCpot- } \\
\text { SOC1 }\end{array}$ & $\begin{array}{l}\text { SOC1- } \\
\text { SOC2 }\end{array}$ & FCtrans \\
\hline 49 & & 190,52 & 150 & 25,98 & 41 & 46,4 & 160,21 & 56,29 & 11 & 61,6 & 160,21 & 56,29 & 11 & 61,6 \\
\hline 50 & & 190,52 & 104 & 25,98 & 87 & 69,3 & 160,21 & 56,29 & 56 & 84,4 & 160,21 & 56,29 & 56 & 84,4 \\
\hline 51 & & 190,52 & 115 & 25,98 & 75 & 63,6 & 160,21 & 56,29 & 45 & 78,7 & 160,21 & 56,29 & 45 & 78,7 \\
\hline 52 & & 190,52 & 172 & 25,98 & 18 & 35,2 & 160,21 & 56,29 & -12 & 50,3 & 160,21 & 56,29 & -12 & 50,3 \\
\hline 53 & & 190,52 & 120 & 25,98 & 71 & 61,5 & 160,21 & 56,29 & 41 & 76,6 & 160,21 & 56,29 & 41 & 76,6 \\
\hline 54 & & 190,52 & 133 & 25,98 & 58 & 54,9 & 160,21 & 56,29 & 28 & 70,1 & 160,21 & 56,29 & 28 & 70,1 \\
\hline 55 & & 190,52 & 183 & 25,98 & 8 & 30,0 & 160,21 & 56,29 & -22 & 45,1 & 160,21 & 56,29 & -22 & 45,1 \\
\hline 56 & & 190,52 & 127 & 25,98 & 64 & 57,8 & 160,21 & 56,29 & 33 & 73,0 & 160,21 & 56,29 & 33 & 73,0 \\
\hline 57 & & 190,52 & 141 & 25,98 & 50 & 50,9 & 160,21 & 56,29 & 19 & 66,0 & 160,21 & 56,29 & 19 & 66,0 \\
\hline 58 & & 190,52 & 312 & 25,98 & -121 & $-34,6$ & 160,21 & 56,29 & -152 & $-175,4$ & 160,21 & 56,29 & -152 & $-19,5$ \\
\hline 59 & & 190,52 & 217 & 25,98 & -26 & 13,0 & 160,21 & 56,29 & -56 & 253,3 & 160,21 & 56,29 & -56 & 28,1 \\
\hline 60 & 17 & 190,52 & 240 & 25,98 & -50 & 1,1 & 160,21 & 56,29 & -80 & 146,1 & 160,21 & 56,29 & -80 & 16,2 \\
\hline 61 & & 190,52 & 359 & 25,98 & $\begin{array}{l}-168 \\
\end{array}$ & $-58,0$ & 160,21 & 56,29 & -198 & $-385,8$ & 160,21 & 56,29 & -198 & $-42,9$ \\
\hline 62 & & 190,52 & 249 & 25,98 & -58 & $-3,2$ & 160,21 & 56,29 & -89 & 107,2 & 160,21 & 56,29 & -89 & 11,9 \\
\hline 63 & & 190,52 & 276 & 25,98 & -86 & $-16,9$ & 160,21 & 56,29 & -116 & $-16,1$ & 160,21 & 56,29 & -116 & $-1,8$ \\
\hline 64 & & 190,52 & 380 & 25,98 & -190 & $-68,9$ & 160,21 & 56,29 & -220 & $-484,0$ & 160,21 & 56,29 & -220 & $-53,8$ \\
\hline 65 & & 190,52 & 264 & 25,98 & -74 & $-10,8$ & 160,21 & 56,29 & -104 & 39,0 & 160,21 & 56,29 & -104 & 4,3 \\
\hline 66 & & 190,52 & 293 & 25,98 & -103 & $-25,4$ & 160,21 & 56,29 & -133 & $-91,8$ & 160,21 & 56,29 & -133 & $-10,2$ \\
\hline 67 & & 190,52 & 253 & 25,98 & -63 & $-5,4$ & 160,21 & 56,29 & -93 & 58,5 & 160,21 & 56,29 & -93 & 19,5 \\
\hline 68 & & 190,52 & 281 & 25,98 & -91 & $-19,3$ & 160,21 & 56,29 & -121 & $-25,1$ & 160,21 & 56,29 & -121 & $-8,4$ \\
\hline 69 & & 190,52 & 210 & 25,98 & -19 & 16,2 & 160,21 & 56,29 & -50 & 188,4 & 160,21 & 56,29 & -50 & 62,8 \\
\hline 70 & & 190,52 & 152 & 25,98 & 39 & 45,5 & 160,21 & 56,29 & 9 & 363,7 & 160,21 & 56,29 & 9 & 121,2 \\
\hline 71 & & 190,52 & 139 & 25,98 & 52 & 103,9 & 160,21 & 56,29 & 22 & 134,2 & 160,21 & 56,29 & 22 & 134,2 \\
\hline 72 & & 190,52 & 173 & 25,98 & 17 & 69,3 & 160,21 & 56,29 & -13 & 99,6 & 160,21 & 56,29 & -13 & 99,6 \\
\hline
\end{tabular}


Continuação da Tabela Y.1

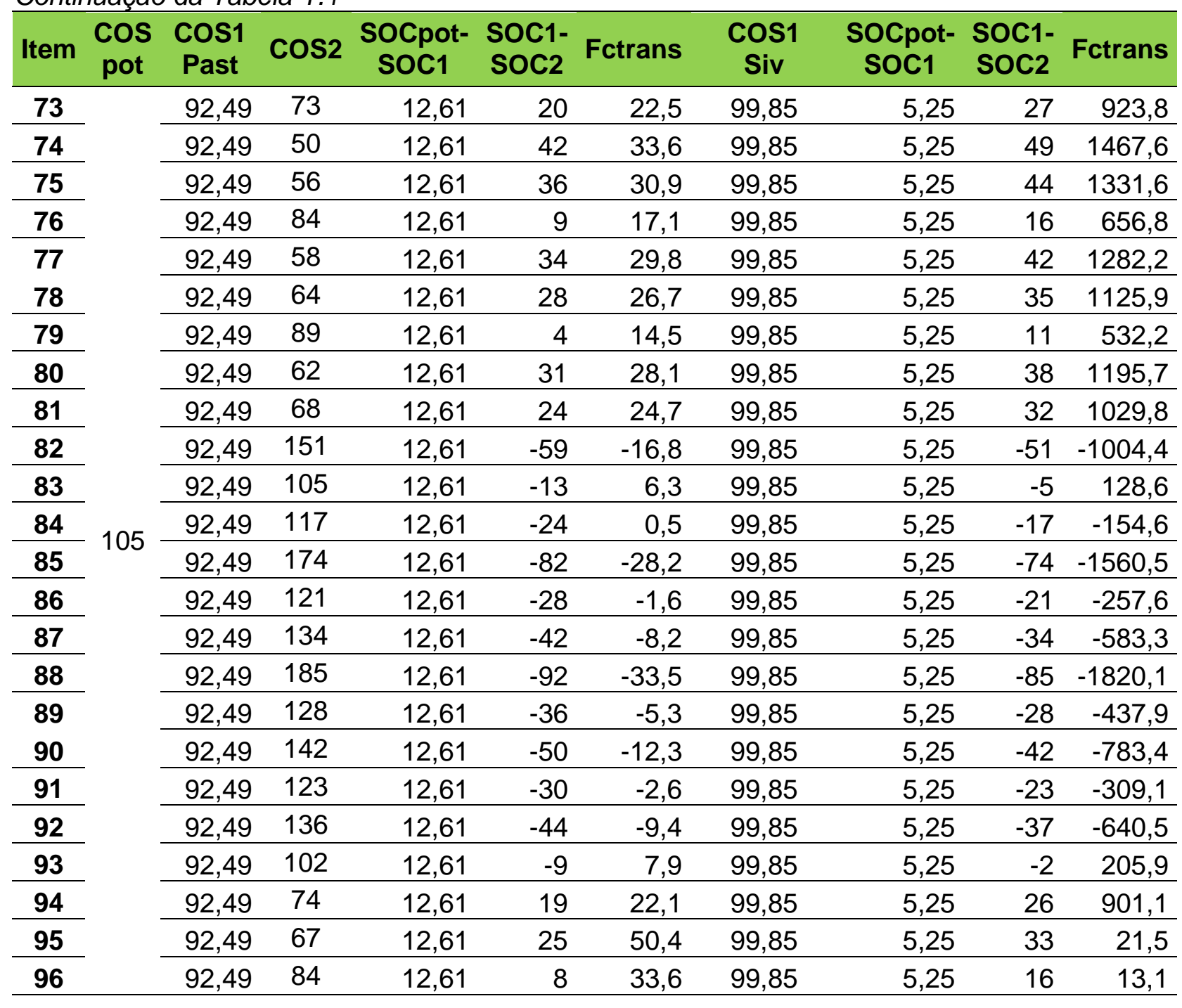


Continuação da Tabela Y.1

\begin{tabular}{|c|c|c|c|c|c|c|c|c|c|}
\hline Item & $\begin{array}{c}\text { CO } \\
\text { S } \\
\text { pot }\end{array}$ & $\begin{array}{c}\text { COS1 } \\
\text { Cult } \\
\text { Temp } \\
\end{array}$ & $\begin{array}{c}\text { SOCpot } \\
- \\
\text { soc1 }\end{array}$ & $\begin{array}{c}\text { SOC1 } \\
- \\
\text { SOC2 } \\
\end{array}$ & $\begin{array}{c}\text { Fctran } \\
\mathrm{s}\end{array}$ & $\begin{array}{c}\text { COS1 } \\
\text { Cult } \\
\text { Perm } \\
\end{array}$ & $\begin{array}{c}\text { SoCpot } \\
- \\
\text { soc1 }\end{array}$ & $\begin{array}{c}\text { SOC1 } \\
- \\
\text { soc2 } \\
\end{array}$ & $\begin{array}{c}\text { Fctran } \\
\mathbf{s}\end{array}$ \\
\hline 73 & \multirow{24}{*}{105} & 77,77 & 27,33 & 5 & 29,9 & 77,77 & 27,33 & 5 & 29,9 \\
\hline 74 & & 77,77 & 27,33 & 27 & 41,0 & 77,77 & 27,33 & 27 & 41,0 \\
\hline 75 & & 77,77 & 27,33 & 22 & 38,2 & 77,77 & 27,33 & 22 & 38,2 \\
\hline 76 & & 77,77 & 27,33 & -6 & 24,4 & 77,77 & 27,33 & -6 & 24,4 \\
\hline 77 & & 77,77 & 27,33 & 20 & 37,2 & 77,77 & 27,33 & 20 & 37,2 \\
\hline 78 & & 77,77 & 27,33 & 13 & 34,0 & 77,77 & 27,33 & 13 & 34,0 \\
\hline 79 & & 77,77 & 27,33 & -11 & 21,9 & 77,77 & 27,33 & -11 & 21,9 \\
\hline 80 & & 77,77 & 27,33 & 16 & 35,4 & 77,77 & 27,33 & 16 & 35,4 \\
\hline 81 & & 77,77 & 27,33 & 9 & 32,1 & 77,77 & 27,33 & 9 & 32,1 \\
\hline 82 & & 77,77 & 27,33 & -74 & $-85,1$ & 77,77 & 27,33 & -74 & $-9,5$ \\
\hline 83 & & 77,77 & 27,33 & -27 & 123,0 & 77,77 & 27,33 & -27 & 13,7 \\
\hline 84 & & 77,77 & 27,33 & -39 & 71,0 & 77,77 & 27,33 & -39 & 7,9 \\
\hline 85 & & 77,77 & 27,33 & -96 & $-187,3$ & 77,77 & 27,33 & -96 & $-20,8$ \\
\hline 86 & & 77,77 & 27,33 & -43 & 52,0 & 77,77 & 27,33 & -43 & 5,8 \\
\hline 87 & & 77,77 & 27,33 & -56 & $-7,8$ & 77,77 & 27,33 & -56 & $-0,9$ \\
\hline 88 & & 77,77 & 27,33 & -107 & $-234,9$ & 77,77 & 27,33 & -107 & $-26,1$ \\
\hline 89 & & 77,77 & 27,33 & -50 & 18,9 & 77,77 & 27,33 & -50 & 2,1 \\
\hline 90 & & 77,77 & 27,33 & -65 & $-44,5$ & 77,77 & 27,33 & -65 & $-4,9$ \\
\hline 91 & & 77,77 & 27,33 & -45 & 28,4 & 77,77 & 27,33 & -45 & 9,5 \\
\hline 92 & & 77,77 & 27,33 & -59 & $-12,2$ & 77,77 & 27,33 & -59 & $-4,1$ \\
\hline 93 & & 77,77 & 27,33 & -24 & 91,4 & 77,77 & 27,33 & -24 & 30,5 \\
\hline 94 & & 77,77 & 27,33 & 4 & 176,6 & 77,77 & 27,33 & 4 & 58,9 \\
\hline 95 & & 77,77 & 27,33 & 11 & 65,2 & 77,77 & 27,33 & 11 & 65,2 \\
\hline 96 & & 77,77 & 27,33 & -6 & 48,4 & 77,77 & 27,33 & -6 & 48,4 \\
\hline
\end{tabular}


Continuação da Tabela Y.1

\begin{tabular}{|c|c|c|c|c|c|c|c|c|c|c|c|c|c|c|}
\hline Item & $\begin{array}{l}\text { COS } \\
\text { pot }\end{array}$ & $\begin{array}{l}\text { COS1 } \\
\text { Past }\end{array}$ & cos2 & $\begin{array}{l}\text { SOCpot- } \\
\text { SOC1 }\end{array}$ & $\begin{array}{l}\text { SOC1- } \\
\text { SOC2 }\end{array}$ & Fctrans & $\begin{array}{c}\text { COS1 } \\
\text { Cult } \\
\text { Temp }\end{array}$ & $\begin{array}{c}\text { SOCpot- } \\
\text { SOC1 }\end{array}$ & $\begin{array}{l}\text { SOC1- } \\
\text { SOC2 }\end{array}$ & Fctrans & $\begin{array}{c}\text { COS1 } \\
\text { Cult Perm }\end{array}$ & $\begin{array}{c}\text { SOCpot- } \\
\text { SOC1 }\end{array}$ & $\begin{array}{l}\text { SOC1- } \\
\text { SOC2 }\end{array}$ & FCtrans \\
\hline 97 & & 57,5 & 40 & 0 & 18 & 8,9 & 36,51 & 20,99 & -3 & 19,4 & 36,51 & 20,99 & -3 & 19,4 \\
\hline 98 & & 57,5 & 28 & 0 & 30 & 15,0 & 36,51 & 20,99 & 9 & 25,4 & 36,51 & 20,99 & 9 & 25,4 \\
\hline 99 & & 57,5 & 31 & 0 & 27 & 13,4 & 36,51 & 20,99 & 6 & 23,9 & 36,51 & 20,99 & 6 & 23,9 \\
\hline 100 & & 57,5 & 46 & 0 & 12 & 5,9 & 36,51 & 20,99 & -9 & 16,4 & 36,51 & 20,99 & -9 & 16,4 \\
\hline 101 & & 57,5 & 32 & 0 & 26 & 12,9 & 36,51 & 20,99 & 5 & 23,4 & 36,51 & 20,99 & 5 & 23,4 \\
\hline 102 & & 57,5 & 35 & 0 & 22 & 11,1 & 36,51 & 20,99 & 1 & 21,6 & 36,51 & 20,99 & 1 & 21,6 \\
\hline 103 & & 57,5 & 48 & 0 & 9 & 4,5 & 36,51 & 20,99 & -12 & 15,0 & 36,51 & 20,99 & -12 & 15,0 \\
\hline 104 & & 57,5 & 34 & 0 & 24 & 11,9 & 36,51 & 20,99 & 3 & 22,4 & 36,51 & 20,99 & 3 & 22,4 \\
\hline 105 & & 57,5 & 37 & 0 & 20 & 10,1 & 36,51 & 20,99 & -1 & 20,6 & 36,51 & 20,99 & -1 & 20,6 \\
\hline 106 & & 57,5 & 83 & 0 & -25 & $-12,7$ & 36,51 & 20,99 & -46 & $-19,4$ & 36,51 & 20,99 & -46 & $-2,2$ \\
\hline 107 & & 57,5 & 58 & 0 & 0 & 0,0 & 36,51 & 20,99 & -21 & 94,5 & 36,51 & 20,99 & -21 & 10,5 \\
\hline 108 & & 57,5 & 64 & 0 & -6 & $-3,2$ & 36,51 & 20,99 & -27 & 66,0 & 36,51 & 20,99 & -27 & 7,3 \\
\hline 109 & & 57,5 & 95 & 0 & -38 & $-18,9$ & 36,51 & 20,99 & -59 & $-75,3$ & 36,51 & 20,99 & -59 & $-8,4$ \\
\hline 110 & & 57,5 & 66 & 0 & -9 & $-4,3$ & 36,51 & 20,99 & -30 & 55,6 & 36,51 & 20,99 & -30 & 6,2 \\
\hline 111 & & 57,5 & 73 & 0 & -16 & $-7,9$ & 36,51 & 20,99 & -37 & 22,9 & 36,51 & 20,99 & -37 & 2,5 \\
\hline$\overline{112}$ & & 57,5 & 101 & 0 & -44 & $-21,8$ & 36,51 & 20,99 & -65 & $-101,4$ & 36,51 & 20,99 & -65 & $-11,3$ \\
\hline 113 & & 57,5 & 70 & 0 & -13 & $-6,3$ & 36,51 & 20,99 & -34 & 37,5 & 36,51 & 20,99 & -34 & 4,2 \\
\hline 114 & & 57,5 & 78 & 0 & -20 & $-10,2$ & 36,51 & 20,99 & -41 & 2,8 & 36,51 & 20,99 & -41 & 0,3 \\
\hline 115 & & 57,5 & 67 & 0 & -10 & $-4,9$ & 36,51 & 20,99 & -31 & 50,5 & 36,51 & 20,99 & -31 & 5,6 \\
\hline 116 & & 57,5 & 75 & 0 & -17 & $-8,6$ & 36,51 & 20,99 & -38 & 11,4 & 36,51 & 20,99 & -38 & 3,8 \\
\hline 117 & & 57,5 & 56 & 0 & 2 & 0,9 & 36,51 & 20,99 & -19 & 68,1 & 36,51 & 20,99 & -19 & 22,7 \\
\hline 118 & & 57,5 & 40 & 0 & 17 & 8,6 & 36,51 & 20,99 & -4 & 114,7 & 36,51 & 20,99 & -4 & 38,2 \\
\hline 119 & & 57,5 & 37 & 0 & 21 & 20,7 & 36,51 & 20,99 & 0 & 41,7 & 36,51 & 20,99 & 0 & 41,7 \\
\hline 120 & & 57,5 & 46 & 0 & 12 & 11,5 & 36,51 & 20,99 & -9 & 32,5 & 36,51 & 20,99 & -9 & 32,5 \\
\hline
\end{tabular}


Continuação da Tabela Y.1

\begin{tabular}{|c|c|c|c|c|c|c|c|c|c|c|c|c|c|c|}
\hline Item & $\begin{array}{l}\text { cos } \\
\text { pot }\end{array}$ & $\begin{array}{l}\text { COS1 } \\
\text { Past }\end{array}$ & cos2 & $\begin{array}{c}\text { SOCpot- } \\
\text { SOC1 }\end{array}$ & $\begin{array}{l}\text { SOC1- } \\
\text { SOC2 }\end{array}$ & Fctrans & $\begin{array}{c}\text { COS1 } \\
\text { Cult } \\
\text { Temp }\end{array}$ & $\begin{array}{c}\text { SOCpot- } \\
\text { SOC1 }\end{array}$ & $\begin{array}{l}\text { SOC1- } \\
\text { SOC2 }\end{array}$ & Fctrans & $\begin{array}{c}\text { COS1 } \\
\text { Cult } \\
\text { Perm }\end{array}$ & $\begin{array}{c}\text { SOCpot- } \\
\text { SOC1 }\end{array}$ & $\begin{array}{l}\text { SOC1- } \\
\text { SOC2 }\end{array}$ & FCtrans \\
\hline 121 & \multirow{24}{*}{65} & 65 & 45 & 0 & 20 & 10,0 & 41,28 & 23,72 & -4 & 21,9 & 41,28 & 23,72 & -4 & 21,9 \\
\hline 122 & & 65 & 31 & 0 & 34 & 16,9 & 41,28 & 23,72 & 10 & 28,8 & 41,28 & 23,72 & 10 & 28,8 \\
\hline 123 & & 65 & 35 & 0 & 30 & 15,2 & 41,28 & 23,72 & 7 & 27,0 & 41,28 & 23,72 & 7 & 27,0 \\
\hline 124 & & 65 & 52 & 0 & 13 & 6,7 & 41,28 & 23,72 & -10 & 18,5 & 41,28 & 23,72 & -10 & 18,5 \\
\hline 125 & & 65 & 36 & 0 & 29 & 14,6 & 41,28 & 23,72 & 5 & 26,4 & 41,28 & 23,72 & 5 & 26,4 \\
\hline 126 & & 65 & 40 & 0 & 25 & 12,6 & 41,28 & 23,72 & 1 & 24,4 & 41,28 & 23,72 & 1 & 24,4 \\
\hline 127 & & 65 & 55 & 0 & 10 & 5,1 & 41,28 & 23,72 & -14 & 17,0 & 41,28 & 23,72 & -14 & 17,0 \\
\hline 128 & & 65 & 38 & 0 & 27 & 13,5 & 41,28 & 23,72 & 3 & 25,3 & 41,28 & 23,72 & 3 & 25,3 \\
\hline 129 & & 65 & 42 & 0 & 23 & 11,4 & 41,28 & 23,72 & -1 & 23,2 & 41,28 & 23,72 & -1 & 23,2 \\
\hline 130 & & 65 & 94 & 0 & -29 & $-14,3$ & 41,28 & 23,72 & -52 & $-22,0$ & 41,28 & 23,72 & -52 & $-2,4$ \\
\hline 131 & & 65 & 65 & 0 & 0 & 0,0 & 41,28 & 23,72 & -24 & 106,7 & 41,28 & 23,72 & -24 & 11,9 \\
\hline 132 & & 65 & 72 & 0 & -7 & $-3,6$ & 41,28 & 23,72 & -31 & 74,6 & 41,28 & 23,72 & -31 & 8,3 \\
\hline 133 & & 65 & 108 & 0 & -43 & $-21,3$ & 41,28 & 23,72 & -66 & $-85,1$ & 41,28 & 23,72 & -66 & $-9,5$ \\
\hline 134 & & 65 & 75 & 0 & -10 & $-4,9$ & 41,28 & 23,72 & -33 & 62,9 & 41,28 & 23,72 & -33 & 7,0 \\
\hline 135 & & 65 & 83 & 0 & -18 & $-9,0$ & 41,28 & 23,72 & -42 & 25,9 & 41,28 & 23,72 & -42 & 2,9 \\
\hline 136 & & 65 & 114 & 0 & -49 & $-24,6$ & 41,28 & 23,72 & -73 & $-114,6$ & 41,28 & 23,72 & -73 & $-12,7$ \\
\hline 137 & & 65 & 79 & 0 & -14 & $-7,2$ & 41,28 & 23,72 & -38 & 42,4 & 41,28 & 23,72 & -38 & 4,7 \\
\hline 138 & & 65 & 88 & 0 & -23 & $-11,5$ & 41,28 & 23,72 & -47 & 3,1 & 41,28 & 23,72 & -47 & 0,3 \\
\hline 139 & & 65 & 76 & 0 & -11 & $-5,5$ & 41,28 & 23,72 & -35 & 57,0 & 41,28 & 23,72 & -35 & 6,3 \\
\hline 140 & & 65 & 84 & 0 & -19 & $-9,7$ & 41,28 & 23,72 & -43 & 12,9 & 41,28 & 23,72 & -43 & 4,3 \\
\hline 141 & & 65 & 63 & 0 & 2 & 1,0 & 41,28 & 23,72 & -22 & 77,0 & 41,28 & 23,72 & -22 & 25,7 \\
\hline 142 & & 65 & 46 & 0 & 20 & 9,8 & 41,28 & 23,72 & -4 & 129,7 & 41,28 & 23,72 & -4 & 43,2 \\
\hline 143 & & 65 & 42 & 0 & 23 & 23,4 & 41,28 & 23,72 & 0 & 47,1 & 41,28 & 23,72 & 0 & 47,1 \\
\hline 144 & & 65 & 52 & 0 & 13 & 13,0 & 41,28 & 23,72 & -11 & 36,7 & 41,28 & 23,72 & -11 & 36,7 \\
\hline
\end{tabular}


Continuação da Tabela Y.1

\begin{tabular}{|c|c|c|c|c|c|c|c|c|c|c|c|c|c|c|}
\hline Item & $\begin{array}{l}\text { cos } \\
\text { pot }\end{array}$ & $\begin{array}{l}\text { COS1 } \\
\text { Past }\end{array}$ & cos2 & $\begin{array}{l}\text { SOCpot- } \\
\text { SOC1 }\end{array}$ & $\begin{array}{l}\text { SOC1- } \\
\text { SOC2 }\end{array}$ & Fctrans & $\begin{array}{c}\text { COS1 } \\
\text { Cult } \\
\text { Temp }\end{array}$ & $\begin{array}{l}\text { SOCpot- } \\
\text { SOC1 }\end{array}$ & $\begin{array}{l}\text { SOC1- } \\
\text { SOC2 }\end{array}$ & Fctrans & $\begin{array}{c}\text { COS1 } \\
\text { Cult } \\
\text { Perm }\end{array}$ & $\begin{array}{l}\text { SOCpot- } \\
\text { SOC1 }\end{array}$ & $\begin{array}{l}\text { SOC1- } \\
\text { SOC2 }\end{array}$ & FCtrans \\
\hline 145 & & 53,94 & 42 & 7,99 & 12 & 13,8 & 45,36 & 16,57 & 3 & 18,1 & 45,36 & 16,57 & 3 & 18,1 \\
\hline 146 & & 53,94 & 29 & 7,99 & 25 & 20,2 & 45,36 & 16,57 & 16 & 24,5 & 45,36 & 16,57 & 16 & 24,5 \\
\hline 147 & & 53,94 & 33 & 7,99 & 21 & 18,6 & 45,36 & 16,57 & 13 & 22,9 & 45,36 & 16,57 & 13 & 22,9 \\
\hline 148 & & 53,94 & 49 & 7,99 & 5 & 10,6 & 45,36 & 16,57 & -3 & 14,9 & 45,36 & 16,57 & -3 & 14,9 \\
\hline 149 & & 53,94 & 34 & 7,99 & 20 & 18,0 & 45,36 & 16,57 & 12 & 22,3 & 45,36 & 16,57 & 12 & 22,3 \\
\hline 150 & & 53,94 & 38 & 7,99 & 16 & 16,2 & 45,36 & 16,57 & 8 & 20,5 & 45,36 & 16,57 & 8 & 20,5 \\
\hline 151 & & 53,94 & 52 & 7,99 & 2 & 9,1 & 45,36 & 16,57 & -6 & 13,4 & 45,36 & 16,57 & -6 & 13,4 \\
\hline 152 & & 53,94 & 36 & 7,99 & 18 & 17,0 & 45,36 & 16,57 & 9 & 21,3 & 45,36 & 16,57 & 9 & 21,3 \\
\hline 153 & & 53,94 & 40 & 7,99 & 14 & 15,0 & 45,36 & 16,57 & 6 & 19,3 & 45,36 & 16,57 & 6 & 19,3 \\
\hline 154 & & 53,94 & 88 & 7,99 & -34 & $-9,2$ & 45,36 & 16,57 & -43 & $-44,0$ & 45,36 & 16,57 & -43 & $-4,9$ \\
\hline 155 & & 53,94 & 61 & 7,99 & -7 & 4,3 & 45,36 & 16,57 & -16 & 77,4 & 45,36 & 16,57 & -16 & 8,6 \\
\hline 156 & 12 & 53,94 & 68 & 7,99 & -14 & 0,9 & 45,36 & 16,57 & -23 & 47,1 & 45,36 & 16,57 & -23 & 5,2 \\
\hline 157 & 1,0 & 53,94 & 102 & 7,99 & -48 & $-15,8$ & 45,36 & 16,57 & -56 & $-103,6$ & 45,36 & 16,57 & -56 & $-11,5$ \\
\hline 158 & & 53,94 & 70 & 7,99 & -17 & $-0,3$ & 45,36 & 16,57 & -25 & 36,0 & 45,36 & 16,57 & -25 & 4,0 \\
\hline 159 & & 53,94 & 78 & 7,99 & -24 & $-4,2$ & 45,36 & 16,57 & -33 & 1,1 & 45,36 & 16,57 & -33 & 0,1 \\
\hline 160 & & 53,94 & 108 & 7,99 & -54 & $-18,9$ & 45,36 & 16,57 & -62 & $-131,4$ & 45,36 & 16,57 & -62 & $-14,6$ \\
\hline 161 & & 53,94 & 75 & 7,99 & -21 & $-2,4$ & 45,36 & 16,57 & -29 & 16,7 & 45,36 & 16,57 & -29 & 1,9 \\
\hline 162 & & 53,94 & 83 & 7,99 & -29 & $-6,5$ & 45,36 & 16,57 & -38 & $-20,3$ & 45,36 & 16,57 & -38 & $-2,3$ \\
\hline 163 & & 53,94 & 72 & 7,99 & -18 & $-0,9$ & 45,36 & 16,57 & -26 & 30,5 & 45,36 & 16,57 & -26 & 3,4 \\
\hline 164 & & 53,94 & 80 & 7,99 & -26 & $-4,8$ & 45,36 & 16,57 & -34 & $-3,3$ & 45,36 & 16,57 & -34 & $-1,1$ \\
\hline 165 & & 53,94 & 59 & 7,99 & -6 & 5,2 & 45,36 & 16,57 & -14 & 57,1 & 45,36 & 16,57 & -14 & 19,0 \\
\hline 166 & & 53,94 & 43 & 7,99 & 11 & 13,5 & 45,36 & 16,57 & 2 & 106,8 & 45,36 & 16,57 & 2 & 35,6 \\
\hline 167 & & 53,94 & 39 & 7,99 & 15 & 30,7 & 45,36 & 16,57 & 6 & 39,3 & 45,36 & 16,57 & 6 & 39,3 \\
\hline 168 & & 53,94 & 49 & 7,99 & 5 & 20,9 & 45,36 & 16,57 & -4 & 29,5 & 45,36 & 16,57 & -4 & 29,5 \\
\hline
\end{tabular}




\begin{tabular}{|c|c|c|c|c|c|c|c|c|c|c|c|c|c|c|}
\hline Item & $\begin{array}{l}\text { cos } \\
\text { pot }\end{array}$ & $\begin{array}{c}\text { COS1 } \\
\text { Past }\end{array}$ & cos2 & $\begin{array}{c}\text { SOCpot- } \\
\text { SOC1 }\end{array}$ & $\begin{array}{l}\text { SOC1- } \\
\text { SOC2 }\end{array}$ & Fctrans & $\begin{array}{c}\text { COS1 } \\
\text { Cult } \\
\text { Temp }\end{array}$ & $\begin{array}{l}\text { SOCpot- } \\
\text { SOC1 }\end{array}$ & $\begin{array}{l}\text { SOC1- } \\
\text { SOC2 }\end{array}$ & Fctrans & $\begin{array}{l}\text { COS1 } \\
\text { Cult } \\
\text { Perm }\end{array}$ & $\begin{array}{l}\text { SOCpot- } \\
\text { SOC1 }\end{array}$ & $\begin{array}{l}\text { SOC1- } \\
\text { SOC2 }\end{array}$ & FCtrans \\
\hline 169 & \multirow{24}{*}{73} & 64,2 & 50 & 8,75 & 14 & 15,6 & 53,98 & 18,97 & 4 & 20,7 & 53,98 & 18,97 & 4 & 20,7 \\
\hline 170 & & 64,2 & 35 & 8,75 & 29 & 23,3 & 53,98 & 18,97 & 19 & 28,5 & 53,98 & 18,97 & 19 & 28,5 \\
\hline 171 & & 64,2 & 39 & 8,75 & 25 & 21,4 & 53,98 & 18,97 & 15 & 26,5 & 53,98 & 18,97 & 15 & 26,5 \\
\hline 172 & & 64,2 & 58 & 8,75 & 6 & 11,9 & 53,98 & 18,97 & -4 & 17,0 & 53,98 & 18,97 & -4 & 17,0 \\
\hline 173 & & 64,2 & 40 & 8,75 & 24 & 20,7 & 53,98 & 18,97 & 14 & 25,8 & 53,98 & 18,97 & 14 & 25,8 \\
\hline 174 & & 64,2 & 45 & 8,75 & 20 & 18,5 & 53,98 & 18,97 & 9 & 23,6 & 53,98 & 18,97 & 9 & 23,6 \\
\hline 175 & & 64,2 & 62 & 8,75 & 3 & 10,1 & 53,98 & 18,97 & -8 & 15,2 & 53,98 & 18,97 & -8 & 15,2 \\
\hline 176 & & 64,2 & 43 & 8,75 & 21 & 19,5 & 53,98 & 18,97 & 11 & 24,6 & 53,98 & 18,97 & 11 & 24,6 \\
\hline 177 & & 64,2 & 47 & 8,75 & 17 & 17,1 & 53,98 & 18,97 & 7 & 22,3 & 53,98 & 18,97 & 7 & 22,3 \\
\hline 178 & & 64,2 & 105 & 8,75 & -41 & $-11,7$ & 53,98 & 18,97 & -51 & $-59,1$ & 53,98 & 18,97 & -51 & $-6,6$ \\
\hline 179 & & 64,2 & 73 & 8,75 & -9 & 4,4 & 53,98 & 18,97 & -19 & 85,4 & 53,98 & 18,97 & -19 & 9,5 \\
\hline 180 & & 64,2 & 81 & 8,75 & -17 & 0,4 & 53,98 & 18,97 & -27 & 49,3 & 53,98 & 18,97 & -27 & 5,5 \\
\hline 181 & & 64,2 & 121 & 8,75 & -57 & $-19,6$ & 53,98 & 18,97 & -67 & $-130,0$ & 53,98 & 18,97 & -67 & $-14,4$ \\
\hline 182 & & 64,2 & 84 & 8,75 & -20 & $-1,1$ & 53,98 & 18,97 & -30 & 36,1 & 53,98 & 18,97 & -30 & 4,0 \\
\hline 183 & & 64,2 & 93 & 8,75 & -29 & $-5,7$ & 53,98 & 18,97 & -39 & $-5,4$ & 53,98 & 18,97 & -39 & $-0,6$ \\
\hline 184 & & 64,2 & 128 & 8,75 & -64 & $-23,2$ & 53,98 & 18,97 & -74 & $-163,1$ & 53,98 & 18,97 & -74 & $-18,1$ \\
\hline 185 & & 64,2 & 89 & 8,75 & -25 & $-3,6$ & 53,98 & 18,97 & -35 & 13,1 & 53,98 & 18,97 & -35 & 1,5 \\
\hline 186 & & 64,2 & 99 & 8,75 & -35 & $-8,5$ & 53,98 & 18,97 & -45 & $-30,9$ & 53,98 & 18,97 & -45 & $-3,4$ \\
\hline 187 & & 64,2 & 85 & 8,75 & -21 & $-1,8$ & 53,98 & 18,97 & -31 & 29,6 & 53,98 & 18,97 & -31 & 3,3 \\
\hline 188 & & 64,2 & 95 & 8,75 & -31 & $-6,5$ & 53,98 & 18,97 & -41 & $-8,5$ & 53,98 & 18,97 & -41 & $-2,8$ \\
\hline 189 & & 64,2 & 71 & 8,75 & -7 & 5,5 & 53,98 & 18,97 & -17 & 63,5 & 53,98 & 18,97 & -17 & 21,2 \\
\hline 190 & & 64,2 & 51 & 8,75 & 13 & 15,3 & 53,98 & 18,97 & 3 & 122,6 & 53,98 & 18,97 & 3 & 40,9 \\
\hline 191 & & 64,2 & 47 & 8,75 & 18 & 35,0 & 53,98 & 18,97 & 7 & 45,2 & 53,98 & 18,97 & 7 & 45,2 \\
\hline 192 & & 64,2 & 58 & 8,75 & 6 & 23,3 & 53,98 & 18,97 & -4 & 33,6 & 53,98 & 18,97 & -4 & 33,6 \\
\hline
\end{tabular}


Continuação da Tabela Y.1

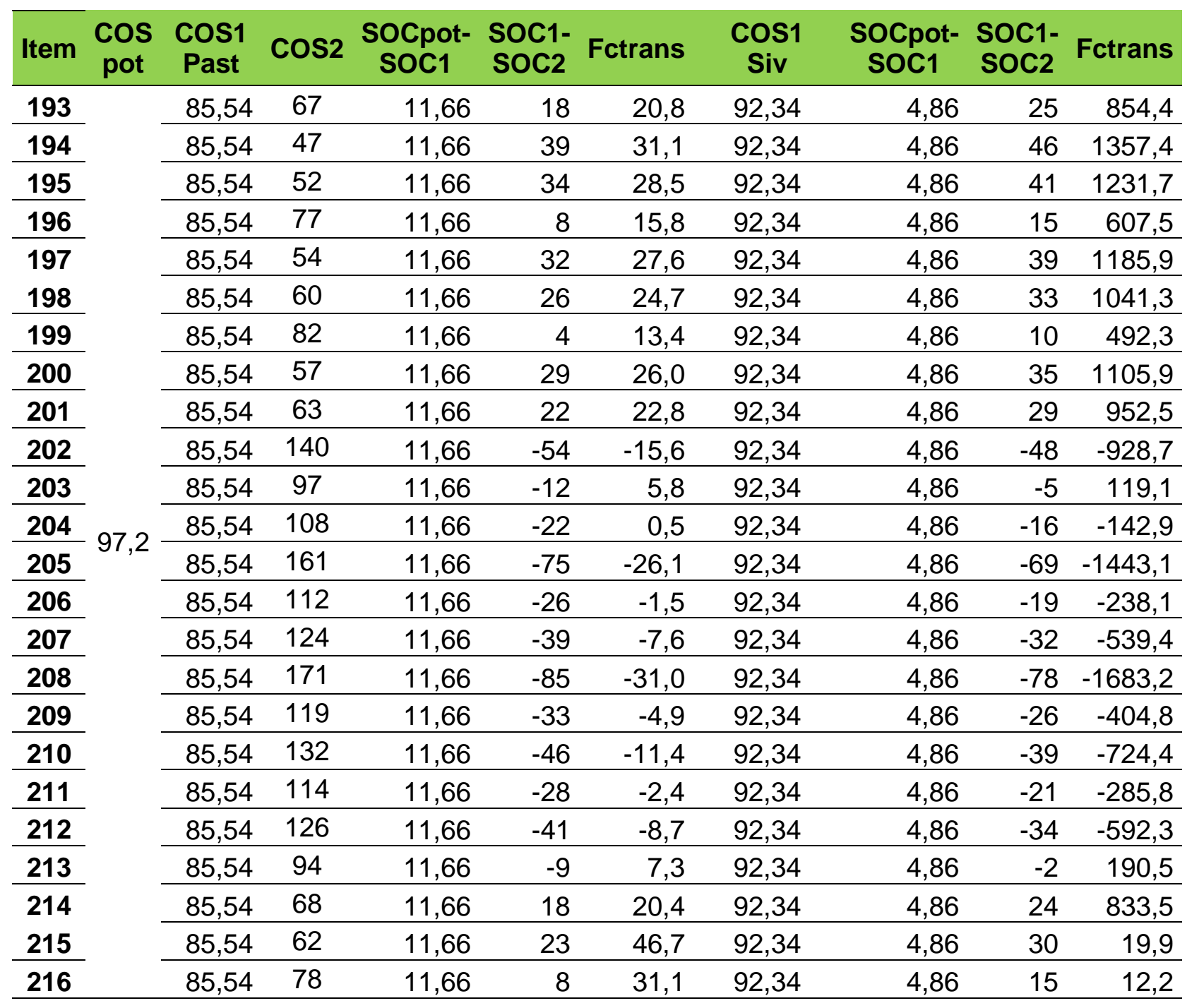


Continuação da Tabela Y.1

\begin{tabular}{|c|c|c|c|c|c|c|c|c|c|}
\hline Item & $\begin{array}{c}\text { CO } \\
\text { S } \\
\text { pot }\end{array}$ & $\begin{array}{c}\text { COS1 } \\
\text { Cult } \\
\text { Temp } \\
\end{array}$ & $\begin{array}{c}\text { SOCpot } \\
- \\
\text { soc1 }\end{array}$ & $\begin{array}{c}\text { SOC1 } \\
- \\
\text { SOC2 }\end{array}$ & $\begin{array}{c}\text { Fctran } \\
\mathrm{s}\end{array}$ & $\begin{array}{c}\text { COS1 } \\
\text { Cult } \\
\text { Perm } \\
\end{array}$ & $\begin{array}{c}\text { SOCpot } \\
- \\
\text { soc1 }\end{array}$ & $\begin{array}{c}\text { SOC1 } \\
- \\
\text { soc2 } \\
\end{array}$ & $\begin{array}{c}\text { Fctran } \\
s\end{array}$ \\
\hline 193 & \multirow{24}{*}{97,2} & 71,93 & 25,27 & 30 & 40,3 & 71,93 & 25,27 & 30 & 40,3 \\
\hline 194 & & 71,93 & 25,27 & 51 & 50,5 & 71,93 & 25,27 & 51 & 50,5 \\
\hline 195 & & 71,93 & 25,27 & 45 & 48,0 & 71,93 & 25,27 & 45 & 48,0 \\
\hline 196 & & 71,93 & 25,27 & 20 & 35,2 & 71,93 & 25,27 & 20 & 35,2 \\
\hline 197 & & 71,93 & 25,27 & 44 & 47,0 & 71,93 & 25,27 & 44 & 47,0 \\
\hline 198 & & 71,93 & 25,27 & 38 & 44,1 & 71,93 & 25,27 & 38 & 44,1 \\
\hline 199 & & 71,93 & 25,27 & 15 & 32,9 & 71,93 & 25,27 & 15 & 32,9 \\
\hline 200 & & 71,93 & 25,27 & 40 & 45,4 & 71,93 & 25,27 & 40 & 45,4 \\
\hline 201 & & 71,93 & 25,27 & 34 & 42,3 & 71,93 & 25,27 & 34 & 42,3 \\
\hline 202 & & 71,93 & 25,27 & -43 & 35,0 & 71,93 & 25,27 & -43 & 3,9 \\
\hline 203 & & 71,93 & 25,27 & 0 & 227,4 & 71,93 & 25,27 & 0 & 25,3 \\
\hline 204 & & 71,93 & 25,27 & -11 & 179,3 & 71,93 & 25,27 & -11 & 19,9 \\
\hline 205 & & 71,93 & 25,27 & -64 & $-59,5$ & 71,93 & 25,27 & -64 & $-6,6$ \\
\hline 206 & & 71,93 & 25,27 & -15 & 161,8 & 71,93 & 25,27 & -15 & 18,0 \\
\hline 207 & & 71,93 & 25,27 & -27 & 106,5 & 71,93 & 25,27 & -27 & 11,8 \\
\hline 208 & & 71,93 & 25,27 & -74 & $-103,6$ & 71,93 & 25,27 & -74 & $-11,5$ \\
\hline 209 & & 71,93 & 25,27 & -21 & 131,2 & 71,93 & 25,27 & -21 & 14,6 \\
\hline 210 & & 71,93 & 25,27 & -34 & 72,5 & 71,93 & 25,27 & -34 & 8,1 \\
\hline 211 & & 71,93 & 25,27 & -17 & 153,1 & 71,93 & 25,27 & -17 & 17,0 \\
\hline 212 & & 71,93 & 25,27 & -29 & 64,5 & 71,93 & 25,27 & -29 & 21,5 \\
\hline 213 & & 71,93 & 25,27 & 3 & 160,4 & 71,93 & 25,27 & 3 & 53,5 \\
\hline 214 & & 71,93 & 25,27 & 29 & 239,1 & 71,93 & 25,27 & 29 & 79,7 \\
\hline 215 & & 71,93 & 25,27 & 35 & 85,5 & 71,93 & 25,27 & 35 & 85,5 \\
\hline 216 & & 71,93 & 25,27 & 19 & 70,0 & 71,93 & 25,27 & 19 & 70,0 \\
\hline
\end{tabular}


APÊNDICE W - Fator de caracterização para a ocupação do solo

Tabela W. 1 - Fatores de Caracterização para a Ocupação (tC ha-1 ano- ${ }^{1}$ ano)

\begin{tabular}{|c|c|c|c|c|c|c|c|c|}
\hline Item & $\begin{array}{l}\text { COS } \\
\text { pot }\end{array}$ & $\begin{array}{l}\text { COS }_{1} \\
\text { Past }\end{array}$ & $\mathrm{COS}_{2}$ & FCoc & $\begin{array}{c}\operatorname{COS}_{1} \\
\text { Siv }\end{array}$ & FCoc & $\begin{array}{l}\text { COS }_{1} \\
\text { Cult Temp- } \\
\text { Perm }\end{array}$ & FCoc \\
\hline 1 & \multirow{21}{*}{84,9} & 74,71 & 59 & 16 & 80,66 & 22 & 62,83 & 4 \\
\hline 3 & & 74,71 & 45 & 29 & 80,66 & 35 & 62,83 & 18 \\
\hline 4 & & 74,71 & 67 & 7 & 80,66 & 13 & 62,83 & -5 \\
\hline 5 & & 74,71 & 47 & 28 & 80,66 & 34 & 62,83 & 16 \\
\hline 7 & & 74,71 & 72 & 3 & 80,66 & 9 & 62,83 & -9 \\
\hline 8 & & 74,71 & 50 & 25 & 80,66 & 31 & 62,83 & 13 \\
\hline 9 & & 74,71 & 55 & 20 & 80,66 & 25 & 62,83 & 8 \\
\hline 10 & & 74,71 & 122 & -48 & 80,66 & -42 & 62,83 & -59 \\
\hline 11 & & 74,71 & 85 & -10 & 80,66 & -4 & 62,83 & -22 \\
\hline 12 & & 74,71 & 94 & -20 & 80,66 & -14 & 62,83 & -31 \\
\hline 13 & & 74,71 & 141 & -66 & 80,66 & -60 & 62,83 & -78 \\
\hline 14 & & 74,71 & 98 & -23 & 80,66 & -17 & 62,83 & -35 \\
\hline 16 & & 74,71 & 149 & -74 & 80,66 & -68 & 62,83 & -86 \\
\hline 17 & & 74,71 & 104 & -29 & 80,66 & -23 & 62,83 & -41 \\
\hline 18 & & 74,71 & 115 & -40 & 80,66 & -34 & 62,83 & -52 \\
\hline 19 & & 74,71 & 99 & -25 & 80,66 & -19 & 62,83 & -37 \\
\hline 20 & & 74,71 & 110 & -36 & 80,66 & -30 & 62,83 & -47 \\
\hline 21 & & 74,71 & 82 & -8 & 80,66 & -2 & 62,83 & -20 \\
\hline 22 & & 74,71 & 59 & 15 & 80,66 & 21 & 62,83 & 3 \\
\hline 23 & & 74,71 & 54 & 20 & 80,66 & 26 & 62,83 & 8 \\
\hline 24 & & 74,71 & 68 & 7 & 80,66 & 13 & 62,83 & -5 \\
\hline
\end{tabular}


Continuação da Tabela W.1

\begin{tabular}{|c|c|c|c|c|c|c|}
\hline Item & $\begin{array}{c}\text { Cos } \\
\text { pot }\end{array}$ & $\begin{array}{l}\operatorname{COS}_{1} \\
\text { Past }\end{array}$ & $\mathrm{COS}_{2}$ & FCoc & $\begin{array}{c}\text { COS }_{1} \\
\text { Cult } \\
\text { Temp- } \\
\text { Perm } \\
\end{array}$ & FCoc \\
\hline 25 & \multirow{24}{*}{93} & 81,84 & 64 & 18 & 68,82 & 5 \\
\hline 26 & & 81,84 & 45 & 37 & 68,82 & 24 \\
\hline 27 & & 81,84 & 50 & 32 & 68,82 & 19 \\
\hline 28 & & 81,84 & 74 & 8 & 68,82 & -5 \\
\hline 29 & & 81,84 & 51 & 31 & 68,82 & 17 \\
\hline 30 & & 81,84 & 57 & 25 & 68,82 & 12 \\
\hline 31 & & 81,84 & 78 & 3 & 68,82 & -10 \\
\hline 32 & & 81,84 & 54 & 27 & 68,82 & 14 \\
\hline 33 & & 81,84 & 60 & 21 & 68,82 & 8 \\
\hline 34 & & 81,84 & 134 & -52 & 68,82 & -65 \\
\hline 35 & & 81,84 & 93 & -11 & 68,82 & -24 \\
\hline 36 & & 81,84 & 103 & -21 & 68,82 & -34 \\
\hline 37 & & 81,84 & 154 & -72 & 68,82 & -85 \\
\hline 38 & & 81,84 & 107 & -25 & 68,82 & -38 \\
\hline 39 & & 81,84 & 119 & -37 & 68,82 & -50 \\
\hline 40 & & 81,84 & 163 & -82 & 68,82 & -95 \\
\hline 41 & & 81,84 & 113 & -32 & 68,82 & -45 \\
\hline 42 & & 81,84 & 126 & -44 & 68,82 & -57 \\
\hline 43 & & 81,84 & 109 & -27 & 68,82 & -40 \\
\hline 44 & & 81,84 & 121 & -39 & 68,82 & -52 \\
\hline 45 & & 81,84 & 90 & -8 & 68,82 & -21 \\
\hline 46 & & 81,84 & 65 & 17 & 68,82 & 4 \\
\hline 47 & & 81,84 & 60 & 22 & 68,82 & 9 \\
\hline 48 & & 81,84 & 74 & 7 & 68,82 & -6 \\
\hline
\end{tabular}


Continuação da Tabela W.1

\begin{tabular}{|c|c|c|c|c|c|c|}
\hline Item & $\begin{array}{l}\text { COS } \\
\text { pot }\end{array}$ & $\begin{array}{l}\cos _{1} \\
\text { Past }\end{array}$ & $\cos _{2}$ & FCoc & $\begin{array}{c}\text { COS }_{1} \\
\text { Cult } \\
\text { Temp- } \\
\text { Perm }\end{array}$ & FCoc \\
\hline 49 & \multirow{24}{*}{216,5} & 190,52 & 150 & 41 & 160,21 & 11 \\
\hline 50 & & 190,52 & 104 & 87 & 160,21 & 56 \\
\hline 51 & & 190,52 & 115 & 75 & 160,21 & 45 \\
\hline 52 & & 190,52 & 172 & 18 & 160,21 & -12 \\
\hline 53 & & 190,52 & 120 & 71 & 160,21 & 41 \\
\hline 54 & & 190,52 & 133 & 58 & 160,21 & 28 \\
\hline 55 & & 190,52 & 183 & 8 & 160,21 & -22 \\
\hline 56 & & 190,52 & 127 & 64 & 160,21 & 33 \\
\hline 57 & & 190,52 & 141 & 50 & 160,21 & 19 \\
\hline 58 & & 190,52 & 312 & -121 & 160,21 & -152 \\
\hline 59 & & 190,52 & 217 & -26 & 160,21 & -56 \\
\hline 60 & & 190,52 & 240 & -50 & 160,21 & -80 \\
\hline 61 & & 190,52 & 359 & -168 & 160,21 & -198 \\
\hline 62 & & 190,52 & 249 & -58 & 160,21 & -89 \\
\hline 63 & & 190,52 & 276 & -86 & 160,21 & -116 \\
\hline 64 & & 190,52 & 380 & -190 & 160,21 & -220 \\
\hline 65 & & 190,52 & 264 & -74 & 160,21 & -104 \\
\hline 66 & & 190,52 & 293 & -103 & 160,21 & -133 \\
\hline 67 & & 190,52 & 253 & -63 & 160,21 & -93 \\
\hline 68 & & 190,52 & 281 & -91 & 160,21 & -121 \\
\hline 69 & & 190,52 & 210 & -19 & 160,21 & -50 \\
\hline 70 & & 190,52 & 152 & 39 & 160,21 & 9 \\
\hline 71 & & 190,52 & 139 & 52 & 160,21 & 22 \\
\hline 72 & & 190,52 & 173 & 17 & 160,21 & -13 \\
\hline
\end{tabular}


Continuação da Tabela W.1

\begin{tabular}{|c|c|c|c|c|c|c|c|c|}
\hline Item & $\begin{array}{c}\text { COS } \\
\text { pot }\end{array}$ & $\begin{array}{l}\operatorname{CoS}_{1} \\
\text { Past }\end{array}$ & $\mathrm{COS}_{2}$ & FCoc & $\begin{array}{c}\operatorname{Cos}_{1} \\
\text { Siv }\end{array}$ & FCoc & $\begin{array}{c}\text { COS }_{1} \\
\text { Cult Temp- } \\
\text { Perm }\end{array}$ & FCoc \\
\hline 73 & \multirow{24}{*}{105,1} & 92,49 & 73 & 20 & 99,85 & 27 & 77,77 & 5 \\
\hline 74 & & 92,49 & 50 & 42 & 99,85 & 49 & 77,77 & 27 \\
\hline 75 & & 92,49 & 56 & 36 & 99,85 & 44 & 77,77 & 22 \\
\hline 76 & & 92,49 & 84 & 9 & 99,85 & 16 & 77,77 & -6 \\
\hline 77 & & 92,49 & 58 & 34 & 99,85 & 42 & 77,77 & 20 \\
\hline 78 & & 92,49 & 64 & 28 & 99,85 & 35 & 77,77 & 13 \\
\hline 79 & & 92,49 & 89 & 4 & 99,85 & 11 & 77,77 & -11 \\
\hline 80 & & 92,49 & 62 & 31 & 99,85 & 38 & 77,77 & 16 \\
\hline 81 & & 92,49 & 68 & 24 & 99,85 & 32 & 77,77 & 9 \\
\hline 82 & & 92,49 & 151 & -59 & 99,85 & -51 & 77,77 & -74 \\
\hline 83 & & 92,49 & 105 & -13 & 99,85 & -5 & 77,77 & -27 \\
\hline 84 & & 92,49 & 117 & -24 & 99,85 & -17 & 77,77 & -39 \\
\hline 85 & & 92,49 & 174 & -82 & 99,85 & -74 & 77,77 & -96 \\
\hline 86 & & 92,49 & 121 & -28 & 99,85 & -21 & 77,77 & -43 \\
\hline 87 & & 92,49 & 134 & -42 & 99,85 & -34 & 77,77 & -56 \\
\hline 88 & & 92,49 & 185 & -92 & 99,85 & -85 & 77,77 & -107 \\
\hline 89 & & 92,49 & 128 & -36 & 99,85 & -28 & 77,77 & -50 \\
\hline 90 & & 92,49 & 142 & -50 & 99,85 & -42 & 77,77 & -65 \\
\hline 91 & & 92,49 & 123 & -30 & 99,85 & -23 & 77,77 & -45 \\
\hline 92 & & 92,49 & 136 & -44 & 99,85 & -37 & 77,77 & -59 \\
\hline 93 & & 92,49 & 102 & -9 & 99,85 & -2 & 77,77 & -24 \\
\hline 94 & & 92,49 & 74 & 19 & 99,85 & 26 & 77,77 & 4 \\
\hline 95 & & 92,49 & 67 & 25 & 99,85 & 33 & 77,77 & 11 \\
\hline 96 & & 92,49 & 84 & 8 & 99,85 & 16 & 77,77 & -6 \\
\hline
\end{tabular}


Continuação da Tabela W.1

\begin{tabular}{|c|c|c|c|c|c|c|}
\hline Item & $\begin{array}{c}\text { COS } \\
\text { pot }\end{array}$ & $\begin{array}{l}\operatorname{COS}_{1} \\
\text { Past }\end{array}$ & $\cos _{2}$ & FCoc & $\begin{array}{l}\text { COS }_{1} \\
\text { Cult } \\
\text { Temp- } \\
\text { Perm }\end{array}$ & FCoc \\
\hline 97 & \multirow{24}{*}{57,5} & 57,5 & 40 & 18 & 36,51 & -3 \\
\hline 98 & & 57,5 & 28 & 30 & 36,51 & 9 \\
\hline 99 & & 57,5 & 31 & 27 & 36,51 & 6 \\
\hline 100 & & 57,5 & 46 & 12 & 36,51 & -9 \\
\hline 101 & & 57,5 & 32 & 26 & 36,51 & 5 \\
\hline 102 & & 57,5 & 35 & 22 & 36,51 & 1 \\
\hline 103 & & 57,5 & 48 & 9 & 36,51 & -12 \\
\hline 104 & & 57,5 & 34 & 24 & 36,51 & 3 \\
\hline 105 & & 57,5 & 37 & 20 & 36,51 & -1 \\
\hline 106 & & 57,5 & 83 & -25 & 36,51 & -46 \\
\hline 107 & & 57,5 & 58 & 0 & 36,51 & -21 \\
\hline 108 & & 57,5 & 64 & -6 & 36,51 & -27 \\
\hline 109 & & 57,5 & 95 & -38 & 36,51 & -59 \\
\hline 110 & & 57,5 & 66 & -9 & 36,51 & -30 \\
\hline 111 & & 57,5 & 73 & -16 & 36,51 & -37 \\
\hline 112 & & 57,5 & 101 & -44 & 36,51 & -65 \\
\hline 113 & & 57,5 & 70 & -13 & 36,51 & -34 \\
\hline 114 & & 57,5 & 78 & -20 & 36,51 & -41 \\
\hline 115 & & 57,5 & 67 & -10 & 36,51 & -31 \\
\hline 116 & & 57,5 & 75 & -17 & 36,51 & -38 \\
\hline 117 & & 57,5 & 56 & 2 & 36,51 & -19 \\
\hline 118 & & 57,5 & 40 & 17 & 36,51 & -4 \\
\hline 119 & & 57,5 & 37 & 21 & 36,51 & 0 \\
\hline 120 & & 57,5 & 46 & 12 & 36,51 & -9 \\
\hline
\end{tabular}


Continuação da Tabela W.1

\begin{tabular}{|c|c|c|c|c|c|c|}
\hline Item & $\begin{array}{l}\text { cos } \\
\text { pot }\end{array}$ & $\begin{array}{l}\cos _{1} \\
\text { Past }\end{array}$ & $\cos _{2}$ & FCoc & $\begin{array}{c}\text { COS }_{1} \\
\text { Cult } \\
\text { Temp- } \\
\text { Perm }\end{array}$ & FCoc \\
\hline 121 & \multirow{24}{*}{65} & 65 & 45 & 20 & 41,28 & -4 \\
\hline 122 & & 65 & 31 & 34 & 41,28 & 10 \\
\hline 123 & & 65 & 35 & 30 & 41,28 & 7 \\
\hline 124 & & 65 & 52 & 13 & 41,28 & -10 \\
\hline 125 & & 65 & 36 & 29 & 41,28 & 5 \\
\hline 126 & & 65 & 40 & 25 & 41,28 & 1 \\
\hline 127 & & 65 & 55 & 10 & 41,28 & -14 \\
\hline 128 & & 65 & 38 & 27 & 41,28 & 3 \\
\hline 129 & & 65 & 42 & 23 & 41,28 & -1 \\
\hline 130 & & 65 & 94 & -29 & 41,28 & -52 \\
\hline 131 & & 65 & 65 & 0 & 41,28 & -24 \\
\hline 132 & & 65 & 72 & -7 & 41,28 & -31 \\
\hline 133 & & 65 & 108 & -43 & 41,28 & -66 \\
\hline 134 & & 65 & 75 & -10 & 41,28 & -33 \\
\hline 135 & & 65 & 83 & -18 & 41,28 & -42 \\
\hline 136 & & 65 & 114 & -49 & 41,28 & -73 \\
\hline 137 & & 65 & 79 & -14 & 41,28 & -38 \\
\hline 138 & & 65 & 88 & -23 & 41,28 & -47 \\
\hline 139 & & 65 & 76 & -11 & 41,28 & -35 \\
\hline 140 & & 65 & 84 & -19 & 41,28 & -43 \\
\hline 141 & & 65 & 63 & 2 & 41,28 & -22 \\
\hline 142 & & 65 & 46 & 20 & 41,28 & -4 \\
\hline 143 & & 65 & 42 & 23 & 41,28 & 0 \\
\hline 144 & & 65 & 52 & 13 & 41,28 & -11 \\
\hline
\end{tabular}


Continuação da Tabela W.1

\begin{tabular}{|c|c|c|c|c|c|c|}
\hline Item & $\begin{array}{l}\text { COS } \\
\text { pot }\end{array}$ & $\begin{array}{l}\cos _{1} \\
\text { Past }\end{array}$ & $\cos _{2}$ & FCoc & $\begin{array}{c}\text { COS }_{1} \\
\text { Cult } \\
\text { Temp- } \\
\text { Perm }\end{array}$ & FCoc \\
\hline 145 & \multirow{24}{*}{61,3} & 53,94 & 42 & 12 & 45,36 & 3 \\
\hline 146 & & 53,94 & 29 & 25 & 45,36 & 16 \\
\hline 147 & & 53,94 & 33 & 21 & 45,36 & 13 \\
\hline 148 & & 53,94 & 49 & 5 & 45,36 & -3 \\
\hline 149 & & 53,94 & 34 & 20 & 45,36 & 12 \\
\hline 150 & & 53,94 & 38 & 16 & 45,36 & 8 \\
\hline 151 & & 53,94 & 52 & 2 & 45,36 & -6 \\
\hline 152 & & 53,94 & 36 & 18 & 45,36 & 9 \\
\hline 153 & & 53,94 & 40 & 14 & 45,36 & 6 \\
\hline 154 & & 53,94 & 88 & -34 & 45,36 & -43 \\
\hline 155 & & 53,94 & 61 & -7 & 45,36 & -16 \\
\hline 156 & & 53,94 & 68 & -14 & 45,36 & -23 \\
\hline 157 & & 53,94 & 102 & -48 & 45,36 & -56 \\
\hline 158 & & 53,94 & 70 & -17 & 45,36 & -25 \\
\hline 159 & & 53,94 & 78 & -24 & 45,36 & -33 \\
\hline 160 & & 53,94 & 108 & -54 & 45,36 & -62 \\
\hline 161 & & 53,94 & 75 & -21 & 45,36 & -29 \\
\hline 162 & & 53,94 & 83 & -29 & 45,36 & -38 \\
\hline 163 & & 53,94 & 72 & -18 & 45,36 & -26 \\
\hline 164 & & 53,94 & 80 & -26 & 45,36 & -34 \\
\hline 165 & & 53,94 & 59 & -6 & 45,36 & -14 \\
\hline 166 & & 53,94 & 43 & 11 & 45,36 & 2 \\
\hline 167 & & 53,94 & 39 & 15 & 45,36 & 6 \\
\hline 168 & & 53,94 & 49 & 5 & 45,36 & -4 \\
\hline
\end{tabular}


Continuação da Tabela W.1

\begin{tabular}{|c|c|c|c|c|c|c|}
\hline Item & $\begin{array}{l}\text { cos } \\
\text { pot }\end{array}$ & $\begin{array}{l}\cos _{1} \\
\text { Past }\end{array}$ & $\cos _{2}$ & FCoc & $\begin{array}{c}\text { COS }_{1} \\
\text { Cult } \\
\text { Temp- } \\
\text { Perm }\end{array}$ & FCoc \\
\hline 169 & \multirow{24}{*}{72,95} & 64,2 & 50 & 14 & 53,98 & 4 \\
\hline 170 & & 64,2 & 35 & 29 & 53,98 & 19 \\
\hline 171 & & 64,2 & 39 & 25 & 53,98 & 15 \\
\hline 172 & & 64,2 & 58 & 6 & 53,98 & -4 \\
\hline 173 & & 64,2 & 40 & 24 & 53,98 & 14 \\
\hline 174 & & 64,2 & 45 & 20 & 53,98 & 9 \\
\hline 175 & & 64,2 & 62 & 3 & 53,98 & -8 \\
\hline 176 & & 64,2 & 43 & 21 & 53,98 & 11 \\
\hline 177 & & 64,2 & 47 & 17 & 53,98 & 7 \\
\hline 178 & & 64,2 & 105 & -41 & 53,98 & -51 \\
\hline 179 & & 64,2 & 73 & -9 & 53,98 & -19 \\
\hline 180 & & 64,2 & 81 & -17 & 53,98 & -27 \\
\hline 181 & & 64,2 & 121 & -57 & 53,98 & -67 \\
\hline 182 & & 64,2 & 84 & -20 & 53,98 & -30 \\
\hline 183 & & 64,2 & 93 & -29 & 53,98 & -39 \\
\hline 184 & & 64,2 & 128 & -64 & 53,98 & -74 \\
\hline 185 & & 64,2 & 89 & -25 & 53,98 & -35 \\
\hline 186 & & 64,2 & 99 & -35 & 53,98 & -45 \\
\hline 187 & & 64,2 & 85 & -21 & 53,98 & -31 \\
\hline 188 & & 64,2 & 95 & -31 & 53,98 & -41 \\
\hline 189 & & 64,2 & 71 & -7 & 53,98 & -17 \\
\hline 190 & & 64,2 & 51 & 13 & 53,98 & 3 \\
\hline 191 & & 64,2 & 47 & 18 & 53,98 & 7 \\
\hline 192 & & 64,2 & 58 & 6 & 53,98 & -4 \\
\hline
\end{tabular}


Continuação da Tabela W.1

\begin{tabular}{|c|c|c|c|c|c|c|c|c|}
\hline Item & $\begin{array}{l}\text { cos } \\
\text { pot }\end{array}$ & $\begin{array}{c}\text { COS }_{1} \\
\text { Past }\end{array}$ & $\mathrm{COS}_{2}$ & Fcoc & $\begin{array}{c}\text { COS }_{1} \\
\text { Siv }\end{array}$ & FCoc & $\begin{array}{c}\text { COS }_{1} \\
\text { Cult Temp- } \\
\text { Perm }\end{array}$ & FCoc \\
\hline 193 & \multirow{24}{*}{97,2} & 85,54 & 67 & 18 & 92,34 & 25 & 71,93 & 30 \\
\hline 194 & & 85,54 & 47 & 39 & 92,34 & 46 & 71,93 & 51 \\
\hline 195 & & 85,54 & 52 & 34 & 92,34 & 41 & 71,93 & 45 \\
\hline 196 & & 85,54 & 77 & 8 & 92,34 & 15 & 71,93 & 20 \\
\hline 197 & & 85,54 & 54 & 32 & 92,34 & 39 & 71,93 & 44 \\
\hline 198 & & 85,54 & 60 & 26 & 92,34 & 33 & 71,93 & 38 \\
\hline 199 & & 85,54 & 82 & 4 & 92,34 & 10 & 71,93 & 15 \\
\hline 200 & & 85,54 & 57 & 29 & 92,34 & 35 & 71,93 & 40 \\
\hline 201 & & 85,54 & 63 & 22 & 92,34 & 29 & 71,93 & 34 \\
\hline 202 & & 85,54 & 140 & -54 & 92,34 & -48 & 71,93 & -43 \\
\hline 203 & & 85,54 & 97 & -12 & 92,34 & -5 & 71,93 & 0 \\
\hline 204 & & 85,54 & 108 & -22 & 92,34 & -16 & 71,93 & -11 \\
\hline 205 & & 85,54 & 161 & -75 & 92,34 & -69 & 71,93 & -64 \\
\hline 206 & & 85,54 & 112 & -26 & 92,34 & -19 & 71,93 & -15 \\
\hline 207 & & 85,54 & 124 & -39 & 92,34 & -32 & 71,93 & -27 \\
\hline 208 & & 85,54 & 171 & -85 & 92,34 & -78 & 71,93 & -74 \\
\hline 209 & & 85,54 & 119 & -33 & 92,34 & -26 & 71,93 & -21 \\
\hline 210 & & 85,54 & 132 & -46 & 92,34 & -39 & 71,93 & -34 \\
\hline 211 & & 85,54 & 114 & -28 & 92,34 & -21 & 71,93 & -17 \\
\hline 212 & & 85,54 & 126 & -41 & 92,34 & -34 & 71,93 & -29 \\
\hline 213 & & 85,54 & 94 & -9 & 92,34 & -2 & 71,93 & 3 \\
\hline 214 & & 85,54 & 68 & 18 & 92,34 & 24 & 71,93 & 29 \\
\hline 215 & & 85,54 & 62 & 23 & 92,34 & 30 & 71,93 & 35 \\
\hline 216 & & 85,54 & 78 & 8 & 92,34 & 15 & 71,93 & 19 \\
\hline
\end{tabular}

